\title{
Performance of Mixed Matrix Membranes Containing Porous Two-Dimensional (2D) and Three-Dimensional (3D) Fillers for $\mathrm{CO}_{2}$ Separation: A Review
}

\author{
Mahdi Ahmadi (D), Saravanan Janakiram, Zhongde Dai, Luca Ansaloni * (1) and Liyuan Deng * \\ Department of Chemical Engineering, Norwegian University of Science and Technology (NTNU), \\ NO-7491 Trondheim, Norway; mahdi.ahmadi@ntnu.no (M.A.); saravanan.janakiram@ntnu.no (S.J.); \\ zhongde.dai@ntnu.no (Z.D.) \\ * Correspondence: luca.ansaloni@ntnu.no (L.A.); liyuan.deng@ntnu.no (L.D.); Tel.: +47-7359-4112 (L.D.)
}

Received: 26 June 2018; Accepted: 22 July 2018; Published: 28 July 2018

\begin{abstract}
Application of conventional polymeric membranes in $\mathrm{CO}_{2}$ separation processes are limited by the existing trade-off between permeability and selectivity represented by the renowned upper bound. Addition of porous nanofillers in polymeric membranes is a promising approach to transcend the upper bound, owing to their superior separation capabilities. Porous nanofillers entice increased attention over nonporous counterparts due to their inherent $\mathrm{CO}_{2}$ uptake capacities and secondary transport pathways when added to polymer matrices. Infinite possibilities of tuning the porous architecture of these nanofillers also facilitate simultaneous enhancement of permeability, selectivity and stability features of the membrane conveniently heading in the direction towards industrial realization. This review focuses on presenting a complete synopsis of inherent capacities of several porous nanofillers, like metal organic frameworks (MOFs), Zeolites, and porous organic frameworks (POFs) and the effects on their addition to polymeric membranes. Gas permeation performances of select hybrids with these three-dimensional (3D) fillers and porous nanosheets have been summarized and discussed with respect to each type. Consequently, the benefits and shortcomings of each class of materials have been outlined and future research directions concerning the hybrids with 3D fillers have been suggested.
\end{abstract}

Keywords: mixed matrix membranes; $\mathrm{CO}_{2}$ separation; porous nanoparticles

\section{Introduction}

An wide scientific consensus is nowadays established in the international community over the anthropogenic climate change and global warming due to a drastic increase of atmospheric level of $\mathrm{CO}_{2}$ [1]. Anthropogenic activities within transportation, energy supply from fossil fuels [2], and raw materials (e.g., cement, steel) production [3] have significantly contributed to increase in levels of $\mathrm{CO}_{2}$ emissions over the last century, raising the $\mathrm{CO}_{2}$ concentration in the atmosphere [4]. The primary strategy to mitigate $\mathrm{CO}_{2}$ emission in the short term is carbon capture and sequestration (CCS), which mainly includes post-combustion (capture downstream to the combustion), oxy-fuel (purified $\mathrm{O}_{2}$ used for the combustion), and pre-combustion (capture upstream to the combustion) processes [2]. Furthermore, $\mathrm{CO}_{2}$ separation is relevant also for other applications, such as Natural Gas sweetening, where acid components in the presence of water can corrode pipelines and equipment, thus lowering the value of the natural gas [3,5]. Therefore, the development of efficient technologies to separate and capture $\mathrm{CO}_{2}$ is of primary interest. 
Physical and chemical adsorption/absorption technologies have been widely applied to industrial plants to separate $\mathrm{CO}_{2}$ from gaseous streams. These conventional methods exploit pressure and temperature swing absorption/adsorption, which are typically energy-intensive and are not preferred from an environmental and economic standpoint [6]. The most mature technology for post combustion application is absorption using amine-base solvents, but, despite the efforts that are made, the increase in the cost of electricity would be still above the limit of $35 \%$, which is identified as viable solution from a market perspective [7]. When compared to traditional technologies, membrane-based gas separation technology offers several advantages: lower energy consumption (no need for regeneration), no use of harmful chemicals, modularity and easier scalability. Additionally, membrane gas separation offers lower capital and operating costs. Depending on their base material, membranes used for $\mathrm{CO}_{2}$ separation can be separated in inorganic or polymeric. Even though inorganic membranes offer good separation abilities, polymeric materials are preferred for the application that requires large separation area, due to the lower production costs and easier processability. However, constant research is ongoing in order to improve the state-of-the-art separation for polymeric membranes, aiming at improving their competitiveness to traditional technologies.

Gas transport through a nonporous polymeric membrane is typically based on the "solution-diffusion" mechanism. Conceptually, the gas molecules is absorbed on the upstream side of the membrane layer, it diffuses across the thickness, and is finally desorbed on the downstream side. The permeation is therefore described as contribution of a thermodynamic parameter (solubility) and a kinetic factor (diffusivity), which affect the transport of gas molecules across the membrane matrix. The two most important features characterizing gas permeation membranes are permeability and selectivity [8]. Permeability of a given gaseous species (A) is as an intrinsic property of the material and is defined as the specific flux $\left(J_{A}\right)$ normalized on the membrane thickness $(\ell)$ and partial pressure difference between the upstream and downstream side of the membrane $\left(\Delta p_{A}\right)$, as showed in Equation (1):

$$
P_{A}=\frac{J_{A} \cdot \ell}{\Delta p_{A}}
$$

Permeability is frequently reported in Barrer $\left(1\right.$ Barrer $=10^{-10} \mathrm{~cm}^{3}(\mathrm{STP}) \mathrm{cm}^{-1} \mathrm{~s}^{-1} \mathrm{cmHg}^{-1}=$ $\left.3.346 \times 10^{-16} \mathrm{~mol} \mathrm{~m}^{-1} \mathrm{~Pa}^{-1} \mathrm{~s}^{-1}\right)$. For the implementation of membranes in real process operations, membranenologists have to focus on the fabrication of thin composite membranes, aiming at maximizing the transmembrane flux of permeants [9]. In this perspective, the capacity of a membrane to allow for a specific gas to permeate through the selective layer is described by means of permeance, often reported in GPU (gas permeation unit, $1 \mathrm{GPU}=10^{-6} \mathrm{~cm}^{3}$ (STP) $\mathrm{cm}^{-2} \mathrm{~s}^{-1} \mathrm{cmHg}^{-1}=3.346 \times$ $10^{-10} \mathrm{~mol} \mathrm{~m}^{-2} \mathrm{~Pa}^{-1} \mathrm{~s}^{-1}$ ). Unlike permeability, permeance is not an intrinsic property of the polymeric material, but it directly quantifies the actual transmembrane flux achievable for a given driving force. For this reason, the gas permeance is described as the ratio of the flux $\left(J_{A}\right)$ and the driving force $\left(\Delta p_{A}\right)$. The other key membrane feature is the separation factor (or selectivity), which is defined as the molar ratio of gases $A$ and $B$ in the permeate $(y)$ and in the feed side $(x)$, with $A$ being the most permeable gaseous species:

$$
\alpha=\frac{y_{A} / y_{B}}{x_{A} / x_{B}}
$$

When single gas tests are performed, the membrane "ideal" selectivity can be estimated as the ratio between the permeability of the two penetrants [10].

The analysis of the performance of a larger amount of polymers for gas permeation allowed for Robeson [11,12] to highlight the existence of a trade-off between permeability and selectivity for materials governed by the solution-diffusion mechanism. This relation between permeability and selectivity reveals that for polymer membranes, an increase in permeability happens typically at the expense of selectivity, and vice versa. In the attempt to provide a more fundamental explanation, of an empirical relationship between permeability and selectivity was established $[13,14]$, and it was shown 
that in the determination of the upper bound slope, the diffusion coefficient plays a dominant role as compared to the solubility coefficient.

Among the different strategies to overcome the upper bound (fabrication of highly permeable polymers, such as thermally rearranged polymers [15], high free volume glassy polymers [16]; facilitated transport membranes [17]), a promising approach is the embedment of different phases (inorganic or liquid) within the membrane matrix, fabricating so-called hybrid membranes. Inorganic membranes that are made of non-polymeric materials, such as carbon molecular sieves, zeolites, or metal organic frameworks (MOFs) are typically characterized by performance exceeding the upper bound [18], but their cost and poor mechanical stability limit their applicability at large scale. Nevertheless, the dispersion of high performance nano-phases within a polymer matrix can significantly improve the neat polymer separation properties. In recent years, extensive efforts have been made in order to fabricated hybrid materials containing dispersed inorganic phases within polymeric matrices [8,19-21].

Based on the type of the embedded phase, hybrid membranes are classified in two main groups, known as mixed matrix membranes and nanocomposite membranes [10]. Nanocomposite membranes contain nano-sized impermeable nanoparticles that can contribute to the overall transport via surface adsorption or due to the presence of moieties with a specific affinity towards a specific penetrant. In our previous review, a broad overview of the performance of nanocomposite membranes has been presented [22]. On the opposite side, in mixed matrix membranes, the embedded phase contributes to a secondary transport mechanism. The fillers are typically porous and the pore architecture confers a larger $\mathrm{CO}_{2}$ solubility and/or diffusivity selectivity to the hybrid when compared to the neat polymer. Based on the nature of the embedded phase, the secondary transport mechanism can be described by molecular sieving, surface diffusion, or Knudsen diffusion. Nevertheless, the effect of the fillers on the overall transport through the hybrid membrane is inherently related to the type of polymer-particle interface that is achieved [10]. Ideal adhesion between the two phases would allow for achieving the largest enhancement, whereas poor interface morphology would result in the formation of unselective voids, frequently reflected by deteriorated separation performances.

We previously categorized [22] inorganic fillers in different categories based on their morphology (zero- to three-dimensional morphology), specifying which type constitutes the class of nanocomposite (zero-dimensional (0D) to two-dimensional (2D) nanofillers) or mixed matrix membranes (three-dimensional (3D) nanoparticles). Silica, metal oxide, nanotubes, nanofibers, and graphene derivate are categorized within the nanoparticles used for the fabrication of nanocomposite membranes, whereas zeolites, metal organic frameworks (MOFs), and porous organic frameworks (POFs) are listed as nano-phases that are used for the fabrication of mixed matrix membranes.

The current report mainly focuses on the latest advances in hybrid membranes containing phases that are able to add secondary transport mechanisms of gas permeation in the polymer matrix, such as 3D nanofillers and porous nanosheets. Differently from other reviews recently reported [23-27], a systematical assessment of the impact of different porous nanomaterials on the $\mathrm{CO}_{2}$ separation performance of polymeric matrices is proposed, limiting the analysis mainly to the results reported in the last five years. The benefits that are related to the addition of the different porous nanofillers are discussed, categorizing the hybrid membranes according to the nature of the dispersed phases. The performances that are achieved by each dispersed phase are analyzed and compared among different polymeric matrices and loadings. This systematical analysis allows to identify the benefits and issues of each nanofiller type, offering an interesting tool to shape the direction of future research. The $\mathrm{CO}_{2}$ separation performance are analyzed for the gas pairs of interest for carbon capture $\left(\mathrm{CO}_{2}\right.$ vs. $\mathrm{N}_{2}$ and $\mathrm{CO}_{2}$ vs. $\left.\mathrm{H}_{2}\right)$ and for natural gas and biogas purification $\left(\mathrm{CO}_{2}\right.$ vs. $\left.\mathrm{CH}_{4}\right)$. If no numerical values were reported in the original manuscript to describe the performance, relevant information were carefully extracted via plots' digitalization (WebPlotDigitizer, Version 4.1). 


\section{Metal Organic Frameworks (MOFs)}

MOFs represent a heterogeneous class of hybrid materials constructed from organic bridging ligands and inorganic metal nods [28]. When compared to traditional porous materials, such as zeolites, MOFs have drawn considerable attention thanks to their porous structure, large pore volume, fine tunable chemistry, and high surface area. MOFs are used in a large variety of applications, such as catalysis, sensing and electronic devices, drug delivery, energy storage, and gas separation [29-31]. In gas separation applications, recently, several efforts have been dedicated to the incorporation of MOFs in polymeric matrixes to produce hybrid membranes [20]. When compared to fully inorganic materials, such as Zeolites, the presence of organic ligands in the MOFs' structure leads to better affinity and adhesion with polymers and organic materials [6], making MOFs extremely promising for the achievement of proper interface morphology, and thus, improved separation performance. Hydrothermal, solvothermal or sonication-assisted methods, microwave-assisted, and room temperature reaction are the synthesis procedures that are frequently reported for MOFs [32]. Surface porosity, pore volume, and particle size of MOFs can be finely tuned by controlling the effective synthesis parameters, such as temperature, concentration, time, and $\mathrm{pH}$. Theoretically, the unlimited number of ligands and metal ions provide infinite MOFs combinations.

MOFs frameworks can be either rigid or flexible. Rigid MOFs with tuned pore diameter could be a promising alternative to molecular sieves. The sieving behavior in rigid MOFs gives rise to considerably enhanced diffusion selectivity of gas pairs with different kinetic diameters, such as $\mathrm{CO}_{2} / \mathrm{N}_{2}$ or $\mathrm{CO}_{2} / \mathrm{CH}_{4}$. On the other hand, flexible structures undergo a considerable framework relaxation in the presence of external stimuli, such as host-gas interaction, pressure, temperature, or light [33-35]. Typically, this temporary structural transformability is a non-desirable effect, as it alters the initial sieving ability of the MOF structure [36]. The main structural rearrangements are typically referred as "gate opening" and "breathing" [33]. The former phenomenon is described as a transition from a closed and nonporous to a porous with open gates configuration upon the effect of external stimuli. As an example, ZIF-8 shows the swing in the imidazole linker and opening the narrow window at low to high pressure [37]. On the other side, the breathing effect is described as the abrupt expansion or compression of the unit cell. This is typically observed in MILs, where the structural transformation is referred as open pore, closed pore (cp), narrow pore (np), and large pore (lp) [34]. Linker rotation is another possible structural change, which is typically observed for UiO-66, where the benzene ring present on the organic ligand shows a rotational barrier that can be overcome at higher temperature [38,39]. Other important parameters that affect the transport properties of MOF nanoparticles are the pore volume and the surface area, as they mainly affect the gas sorption capacity of the MOF nanoparticles. In the case of $\mathrm{CO}_{2}$, for example, it has been reported that the presence of unsaturated open metal sites can greatly enhance the $\mathrm{CO}_{2}$ sorption capacity due to considerable polarizability and quadrupole moment. Open metal cations play as Lewis acidic nodes that strongly favors $\mathrm{CO}_{2}[40,41]$. The occurrence of breathing is reported to significantly affect the pore volume, and, therefore, the gas sorption ability. For example, in the case of MIL-53, an expansion of the unit cell volume from $1012.8 \AA^{3}$ to $1522.5 \AA^{3}$ when the $\mathrm{CO}_{2}$ pressure is increased from 5 bar to 15 bar has been observed [36].

In the following sections, common MOFs that are used in fabricating mixed matrix membranes (MMMs) for $\mathrm{CO}_{2}$ separation have been grouped according to their type of metal ion constituting the MOFs' architecture. Individual analyses of gas permeation have been dedicated to the MMMs containing Zeolitic Imidazolate Frameworks (translational metal ions), UiO-66 (Zr-based), $\mathrm{CO}_{2}$-philic MOFs (Cu-based) and Materials Institute Lavoisier MOFs (trivalent metal ions). Other new and emerging MOFs have also been listed together in a separate section.

\subsection{Zeolitic Imidazolate Frameworks (ZIFs)}

Zeolitic imidazolate frameworks, known as ZIFs, have received great attention due to their exceptional transport properties [42]. Generally, ZIFs are a subclass of metal organic frameworks 
with a zeolite, like topology, consisting of large cavities linked by narrow apertures [1]. ZIFs are composed of M-Im-M, where M stands for transitional metal ions (such as $\mathrm{Zn}, \mathrm{Cr}$ ) and Im is the organic linker (imidazolate and its derivatives), respectively. M-Im-M forms a $145^{\circ}$ angle, which is similar to $\mathrm{Si}-\mathrm{O}-\mathrm{Si}$ angle in conventional aluminosilicate zeolites and makes structures analogous to zeolites with topologies of sod, rho, gme, lta, and ana [30,43]. Among the different ZIFs that are available [42], ZIF-7, ZIF-8, ZIF-11, ZIF-71, and ZIF-90 (Figure 1) are the most common MOFs incorporated in polymer matrix to produce hybrid membranes for carbon capture applications.
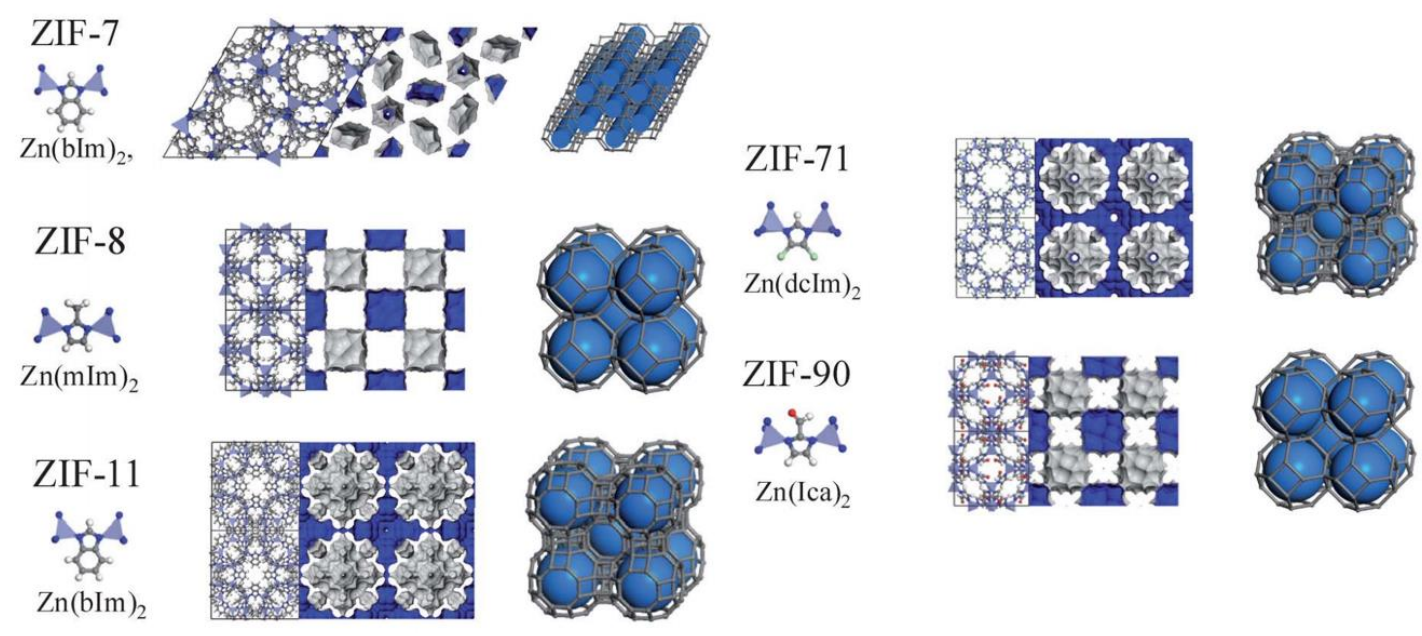

Figure 1. Zeolitic Imidazolate Frameworks (ZIF) structures with building blocks, topology, and accessible surface area for a probe diameter of $2 \AA$. Adapted from [42], with copyright permission from (C) 2012, Royal Society of Chemistry.

\subsubsection{ZIF-8}

ZIF-8 with sod-type topology and tetrahedral structure is the most frequently investigated MOF among the ZIFs family, which exhibits good thermal and exceptional chemical stability [44,45]. ZIF-8 has large pores of $11.8 \AA$ and the pore limiting diameter of $3.4 \AA$, which represents a perfect sieving range for gas separation, such as $\mathrm{CO}_{2} / \mathrm{N}_{2}$ and $\mathrm{CO}_{2} / \mathrm{CH}_{4}$ [43]. However, the ZIF-8 framework is rather flexible, owing to the swing effect of organic linker that significantly affects the sieving ability [37,46]. This swing effect, which is supported experimentally and theoretically, was described by the rotation of imidazolate linker oscillating between two configurations of open window and close window [47]. The separation properties of ZIFs have been examined and researchers have explored their potential in the use of composite membranes for gas separation.

Matrimid $^{\circledR}$ is a commercial glassy polyimide, which is widely used as polymer basis for comparison of MOFs' separation performance. Ordonez et al. [48] fabricated ZIF-8/Matrimid ${ }^{\circledR}$ mixed matrix membranes with nanoparticles loading up to $80 \mathrm{wt} \%$ and investigated their transport properties for $\mathrm{CO}_{2} / \mathrm{N}_{2}$ and $\mathrm{CO}_{2} / \mathrm{CH}_{4}$ separation at 2.6 bar and $35^{\circ} \mathrm{C}$. ZIF-8 with a size range within 50-150 $\mathrm{nm}$ were dispersed in chloroform together with the polymer and self-standing membranes were obtained via solvent casting and dried at $240{ }^{\circ} \mathrm{C}$ under vacuum. While increasing the ZIF-8 loading, the tensile strength of the hybrid matrix dropped significantly and samples with $80 \mathrm{wt} . \%$ loading were found too brittle to be tested. Interestingly, the analysis of the transport properties showed a double behavior of the hybrids. Up to $40 \mathrm{wt} . \%$, the disruption of the chain packing that is produced by the presence of the nanoparticles resulted in an increase in free volume, and consequently, in gas permeability. A $158 \%$ increase in $\mathrm{CO}_{2}$ permeability (Table 1) was observed, even though the variation took place independent from the gas nature. On the contrary, at 50 and 60 wt.\% loading the gas permeability dropped significantly, showing a considerable increase in the selective feature $\left(\mathrm{CO}_{2} / \mathrm{CH}_{4}\right)$. The authors suggested a transition from a polymer-based to a ZIF-8-regulated transport, 
with the sieving effect of the fillers becoming dominant above a certain inorganic content. Interestingly, despite the $\mathrm{CO}_{2}$-philic nature of ZIF-8, the hybrid samples maintained the $\mathrm{H}_{2}$-selective features of the neat polymer (Table 1$)$, but the low selectivity values $\left(\mathrm{H}_{2} / \mathrm{CO}_{2}<5\right)$ are not of interest for the industrial applications. The $\mathrm{CO}_{2}$ separation performances of ZIF-8/Matrimid hybrid membranes have also been investigated by Basu et al. [49], limiting the loading up to $30 \mathrm{wt} \%$. SEM imaging showed the formation of a proper interface morphology between the particles and the polymer phase. Similar to the previous case, the $\mathrm{CO}_{2}$ permeability increased proportionally to the loading, reaching a $209 \%$ enhancement when compared to the neat polymer at the maximum loading. Possibly, the larger enhancement compared to the previous case may be attributed to the larger ZIF-8 size (250-500 nm). However, the separation factor appeared to be hardly affected by the presence of nanoparticles, with a maximum enhancement of $15 \%$. Interestingly, the authors also compared the performance of other two MOFs (MIL-53 and $\mathrm{Cu}_{3}(\mathrm{BTC})_{2}$ ), observing that the enhancement in $\mathrm{CO}_{2}$ permeability is mainly dependent on the loading, whereas the nanoparticles nature and size play a minor role in affecting the transport properties. Song et al. [50] synthesized ZIF-8 with particle size of about $60 \mathrm{~nm}$, and fabricated mixed matrix membranes by embedding them into Matrimid. Morphological analysis showed a proper polymer/particle interface up to the maximum loading investigated (30 wt.\%). Notably, the smaller ZIF-8 size determined a $250 \%$ enhancement in $\mathrm{CO}_{2}$ permeability at the highest loading, even though a negative effect on selectivity was observed (25\% decrease at $30 \mathrm{wt}$. \% loading) for both $\mathrm{CO}_{2} / \mathrm{N}_{2}$ and $\mathrm{CO}_{2} / \mathrm{CH}_{4}$.

Sonication has also been reported to be an important factor affecting the performance of ZIF-8-based mixed matrix membranes [51]. ZIF-8 nanoparticles were dispersed into Matrimid, exposing the casting solution to direct (sonication horn) or indirect (sonication bath) ultrasound wave (Figure 2). The study showed that different sonication intensities produced a significant change in the morphology of the nanoparticles, with limited influence on crystallinity and microporosity. When higher sonication intensity was applied to the casting solution, a proper interfacial morphology was achieved, with a simultaneous increase of permeability and selectivity (Table 1) and full consistency with the Maxwell model. When indirect sonication was employed, nanoparticles agglomeration was observed, affecting the efficiency of the hybrid membranes. ZIF-8 modification using mixed organic ligand (2-aminobenzimidazole as a substitution linker) has also been reported [52], leading to differences in pore size distribution and porosity when compared to pristine ZIF-8. When hybrid membranes were prepared while using Matrimid as polymer phase, no gate opening effect or structural flexibility was observed, and the ideal selectivity improved (Table 1). An interesting approach to improve the interface morphology has been proposed by Casado Coterillo et al. [53], who fabricated a ternary system, embedding ZIF-8 in a polymer matrix composed of Chitosan and [Emim][Ac]. At low ZIF-8 loading ( $5 \mathrm{wt} . \%$ ), they achieved the best $\mathrm{CO}_{2} / \mathrm{N}_{2}$ separation performance and attributed the effect to a better adhesion between the Chitosan and the ZIF-8 phase that is offered by the presence of the ionic liquid at the interface.

Carter et al. [54] loaded 10\% ZIF-8 with particle size of $95 \mathrm{~nm}$ in Matrimid and prepared two different dense membrane films with aggregated ZIF-8 nanoparticles and with a homogeneous dispersion. As expected, the single gas permeation tests showed improved selectivity and permeability for the well-dispersed membrane and the lower drop observed for the $\mathrm{N}_{2}$ permeability, with respect to $\mathrm{CH}_{4}$ permeability, was explained in terms of surface diffusion mechanism and framework flexibility of ZIF-8. Again, the addition of ZIF-8 nanoparticles enhanced the $\mathrm{H}_{2}$-selective properties of the hybrids, with the aggregated samples showing even better performance (68\% increase in $\mathrm{H}_{2}$ permeability) when compared to the one with homogeneous dispersion (Table 1). However, the selectivity remained too low $\left(\mathrm{H}_{2} / \mathrm{CO}_{2}<5\right)$ to become valuable for real $\mathrm{H}_{2}$ purification. Interestingly, the reported analysis of hybrid membranes based on Matrimid and ZIF-8 clearly showed that synthesis protocol, particle size, and possible modification play a major role in the determination of the membrane performance. Guo et al. [55] recently investigated the effect of ZIF-8 nanoparticles on another commercial polyimide, P84. As reported for Matrimid, the $\mathrm{CO}_{2}$ permeability increased proportionally to the MOF content. 
Also, the $\mathrm{CO}_{2} / \mathrm{CH}_{4}$ selectivity increased remarkably, but at the highest loading (31 wt.\%), a drop (Table 1) was observed. A drop in the diffusion selectivity was measured (Figure 3), clearly suggesting that the formation of interfacial voids that are associated to MOFs aggregation is responsible for the observed phenomenon.
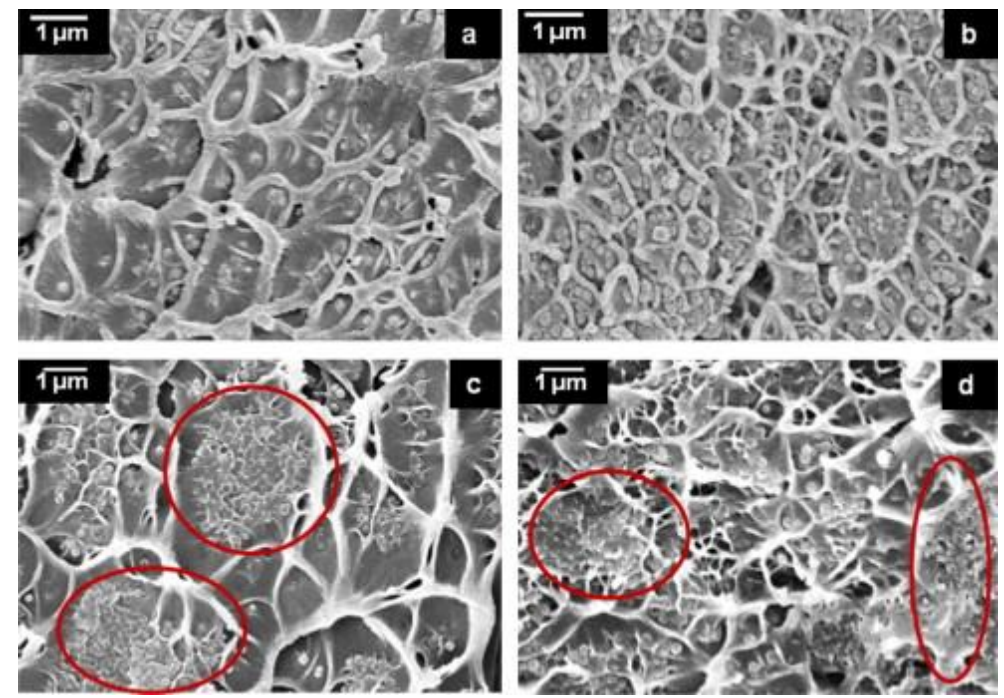

Figure 2. Dispersion of ZIF-8 by direct $(\mathbf{a}, \mathbf{b})$ and indirect $(\mathbf{c}, \mathbf{d})$ sonication of $10 \mathrm{wt}$. $\%(\mathbf{a}, \mathbf{c})$ and $25 \mathrm{wt}$. $\%$ (b,d) loading in Matrimid [51], with copyright permission from (C) 2012 Elsevier.

(a)

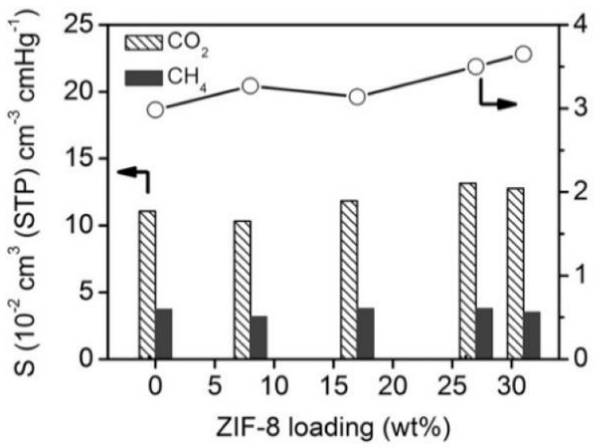

(b)

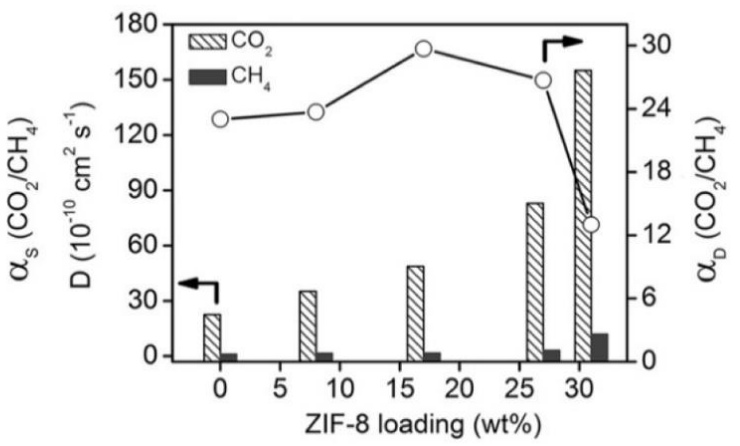

Figure 3. Effect of ZIF-8 loading on the solubility and the diffusivity selectivity when embedded in P84 polyimide [55], with copyright permission from (c) 2018 Elsevier.

6FDA is another glassy polyimide that has been largely investigated for the fabrication of ZIF-based mixed matrix membranes. The higher free volume when compared to Matrimid allows for the 6FDA polymer family to achieve larger gas permeation, offering a more suitable option for industrial applications. Jusoh et al. [56] reported significant improvement in $\mathrm{CO}_{2}$ permeability of 6FDA-durene by embedding up to $20 \mathrm{wt} . \%$ ZIF-8 in the polymer matrix. An optimum loading of $10 \mathrm{wt} . \%$ was identified (Table 1), as a further increase of the inorganic content led to negligible enhancement of $\mathrm{CO}_{2}$ permeability, but a significant decrease of $\mathrm{CO}_{2} / \mathrm{CH}_{4}$ selectivity. Furthermore, the gas separation enhancement of ZIF-8/6FDA-durene was attributed to the influence of pore limiting diameter and quadrupole interaction of $\mathrm{CO}_{2}$ with the ligand in $\mathrm{ZIF}-8$ framework. Wijenayake et al. [57] proposed surface crosslinking as possible approach to improve the performance of 6FDA-based hybrid membranes containing ZIF-8 nanoparticles. The addition of $33 \mathrm{wt} . \%$ ZIF-8 in the polymer matrix enhanced significantly the $\mathrm{CO}_{2}$ permeability $(\sim 400 \%$, Table 1$)$, reaching up to $\sim 1500$ Barrer, similar 
to the one that was observed in the previous study. The effect on the selectivity was limited. Even though post-synthetic modification of ZIF-8 using ethylenediamine showed enhanced $\mathrm{CO}_{2}$ adsorption capacity [58], the use of ethylenediamine vapors to crosslink the surface of the hybrid membrane led to a limited improvement on the $\mathrm{CO}_{2}$ selectivity along with a drastic drop in $\mathrm{CO}_{2}$ permeability. As in the case of Matrimid, the addition of ZIF-8 to 6FDA polyimide improved the $\mathrm{H}_{2}$-selective feature, and a $\mathrm{H}_{2} / \mathrm{CO}_{2}$ selectivity of 12 has been achieved upon surface modification. Askari and Chung [59] studied the effect of annealing temperature on the performance of $20 \mathrm{wt}$ \% ZIF-8 containing 6FDA-durene mixed matrix membrane by heating to different temperature $\left(200,350\right.$, and $\left.400{ }^{\circ} \mathrm{C}\right)$ below glass transition temperature $\left(\mathrm{T}_{\mathrm{g}}>400^{\circ} \mathrm{C}\right)$. The highest gas permeability was obtained for $20 \mathrm{wt} . \%$ loaded membrane annealed at $400{ }^{\circ} \mathrm{C}$ (from 487 Barrer at $200{ }^{\circ} \mathrm{C}$ to 1090 Barrer at $400{ }^{\circ} \mathrm{C}$ ) and the contribution of the inorganic phase was enhanced at higher annealing temperatures. When the cross-linkable co-polyimide (6FDA-durene/DABA) was used in the place of the homopolymer, higher selectivity values could be achieved, but the improvement took place to the detriment of $\mathrm{CO}_{2}$ permeability. Nafisi and Hägg investigated the gas separation performance of ZIF-8 containing membrane prepared using 6FDA-durene [60] and PEBAX 2533 [61] (a commercial polyether-block-amide) as polymer phase. In both cases, the $\mathrm{CO}_{2}$ permeability increased along with the inorganic content, but the influence of ZIF-8 nanoparticles appeared to be more effective for PEBAX 2533. At $30 \mathrm{wt} \%$ loading, a 50\% enhancement of $\mathrm{CO}_{2}$ permeability (2186 Barrer) was observed for 6FDA-durene whereas a ZIF-8 loading of $35 \mathrm{wt}$ \% in PEBAX 2533 corresponded to a 3.6-fold improvement of the $\mathrm{CO}_{2}$ permeability (1287 Barrer). Furthermore, at high inorganic loading, the polyimide showed reduced $\mathrm{CO}_{2}$ selectivity, whereas negligible effect on the separation performance was observed for PEBAX.

Recently, Sanchez-Lainez et al. [62] reported the fabrication of mixed matrix membranes based on polybenzimidazole (PBI), obtained via phase inversion method for $\mathrm{H}_{2} / \mathrm{CO}_{2}$ separation. At $180{ }^{\circ} \mathrm{C}$, the presence of the ZIF- 8 nanoparticles improved the $\mathrm{H}_{2} / \mathrm{CO}_{2}$ selectivity as well as the $\mathrm{H}_{2}$ permeance. At higher temperature $\left(250^{\circ} \mathrm{C}\right)$, the presence of defects resulted in a drop in the selective characteristic, but higher feed pressure ( 3 bar vs 6 bar) restored the $\mathrm{H}_{2} / \mathrm{CO}_{2}$ selectivity to a value close to 20 .

Recent publications showed an increasing research also on the fabrication of thin composite membranes containing ZIF-8 nanoparticles. Dai et al. [63] fabricated asymmetric hollow fiber mixed matrix membranes using dry jet-wet quench method. In particular, they dispersed $13 \mathrm{wt} \%$ ZIF-8 nanoparticles (size $200 \mathrm{~nm}$ ) into a polyetherimide (Ultem 1000) matrix. $\mathrm{CO}_{2} / \mathrm{N}_{2}$ separation performance for the $\mathrm{HF}$ membranes were tested at $35^{\circ} \mathrm{C}$ and 100 psi. For both pure and mixed gas, the separation performance was improved. The permeance and selectivity of the ZIF- 8 containing hollow fibers improved by $85 \%$ and $20 \%$, respectively, when compared to the unloaded hollow fibers. Higher selective feature were observed for mixed gas conditions using 20 vol. $\% \mathrm{CO}_{2}$ in the feed. A comprehensive review on progresses and trends on hollow fiber mixed matrix membranes has been recently reported by Mubashir et al. [64]. The review includes a comparison between the results obtained for flat sheet and hollow fiber mixed matrix membranes at similar filler loading and operating conditions. It was concluded that hollow fiber mixed matrix membranes that are loaded with ZIF-8, ZIF-93, and amine functionalized MILs show higher separation performance for $\mathrm{CO}_{2} / \mathrm{N}_{2}$ and $\mathrm{CO}_{2} / \mathrm{CH}_{4}$.

Thin film can be obtained also by coating on porous support. Thin film composite membranes and thin film nanocomposite membrane containing MOFs have been developed for nanofiltration and organic solvent separation [65-68]. However, only few studies can be found in literature investigating the gas transport properties of thin hybrid selective layers. Sánchez-Laínez et al. [69] reported a novel ultra-permeable thin film nanocomposite (TFN) containing ZIF-8 for $\mathrm{H}_{2} / \mathrm{CO}_{2}$ separation. The selective layer (50-100 nm) was formed on a polyimide P84 asymmetric support. The nanoparticles were dispersed in different loadings $(0.2,0.4$, and $0.8 \% w / v)$ in a polyamide matrix. The incorporation of ZIF-8 nanoparticles enhanced the gas separation performance. At $35^{\circ} \mathrm{C}$ and $0.4 \% w / v$ ZIF content, a 3-fold increase in selectivity was observed compared to the pristine polymer. An increase in the temperature had a positive impact on the performance, especially in terms of $\mathrm{H}_{2}$ permeance (up to 
$988 \mathrm{GPU}$ at $250{ }^{\circ} \mathrm{C}$ for the pristine polymer). At $180{ }^{\circ} \mathrm{C}$, TFN membranes containing 0.2 and $0.4 \%$ $(w / v)$ of ZIF-8 exhibited a marked selectivity increase of $42 \%$ and $64 \%$, respectively. At higher loading $(0.8 \% w / v)$, the presence of micro voids and defects determined a significant drop in both permeance and selectivity. A further increase in temperature led to higher $\mathrm{H}_{2}$ permeance of TFN membranes with negligible influence on the selective features.

\subsubsection{ZIF-7}

ZIF-7 is another promising candidate of the ZIFs family for gas separation applications. $1 \mathrm{H}$-benzimidazole is the bridging ligand, which is connected to the $\mathrm{Zn}$ metal clusters and creates a 3D sodalite topological framework (Figure 2). Its pore diameter ranges between 3 and $4.3 \AA$ [44,70]. The narrow pore size makes ZIF-7 suitable for $\mathrm{H}_{2}$ purification from $\mathrm{CO}_{2}$. Nevertheless, due to the flexibility of the benzimidazole linker, ZIF-7 also shows the "gate opening effect", undergoing a reversible transition of the pores (from narrow to large framework flexibility of ZIF-7 that allows for gas molecules with a molecular diameter as large as $5.2 \AA$ to access the pores and cavities). This gate opening effect of ZIF-7 was observed in adsorption isotherms $\left(\mathrm{CO}_{2}\right.$, ethane, and ethylene) [71].

Li et al. [72] evaluated the separation performance of ultrathin hybrid membrane composed by a poly(amide-b-ethylene oxide) (Pebax 1657) and ZIF-7 nanoparticles. ZIF-7 particles with a size between 40 and $50 \mathrm{~nm}$ were synthesized and embedded up to $34 \mathrm{wt}$ \% within the polymer matrix. Subsequently, thin composite membranes were prepared by coating the casting solution on a porous PAN support (PTMSP gutter layer was used to prevent pore penetration of the selective layer). Increasing the ZIF-7 loading up to $22 \mathrm{wt}$ \% showed a remarkable increase (Table 1) in both $\mathrm{CO}_{2}$ permeability and $\mathrm{CO}_{2} / \mathrm{CH}_{4}$ and $\mathrm{CO}_{2} / \mathrm{N}_{2}$ ideal selectivity. However, at higher loading (34 wt.\%) polymer rigidification around the nanoparticles took place, positively affecting the selectivity (214\% and 208\% enhancement for $\mathrm{CO}_{2} / \mathrm{CH}_{4}$ and $\mathrm{CO}_{2} / \mathrm{N}_{2}$, respectively), while the $\mathrm{CO}_{2}$ permeability was considerably lower when compared to that of the neat polymer. Post synthesis modification of nanosized (40-70 nm) ZIF-7 was implemented by Al-Maythalony et al. [73], aiming at tuning the pore size by exchanging the organic ligand, benzimidazolate with benzotriazolate. The synthesized nZIF-7 and PSM-nZIF-7 were embedded in a polyetherimide (PEI) matrix. The post synthesis modification resulted in an increase of $\mathrm{CO}_{2}$ permeability of all the examined gases $\left(\mathrm{N}_{2}, \mathrm{CH}_{4}\right.$, and $\mathrm{CO}_{2}$ by $737 \%, 470 \%$, and $198 \%$, respectively). Nevertheless, the bigger enhancement of gases with larger kinetic diameters reduced the $\mathrm{CO}_{2}$-selective feature of the hybrids when compared to the pristine PEI.

\subsubsection{ZIF-11, ZIF-71, and ZIF-90}

ZIF-11, ZIF-71, and ZIF-90 are the other three structures from the ZIFs library that are of interest for gas separation applications and are characterized by rho (for both ZIF-11 and ZIF-71), and sod type topology with apertures of $3 \AA, 4.2 \AA$, and $3.5 \AA$, respectively [45,74]. ZIF-90 is an attractive MOF for $\mathrm{CO}_{2}$ capture owing to its covalent carbonyl bond in the imidazole linker favoring $\mathrm{CO}_{2}$ and the $0.35 \mathrm{~nm}$ of pore size, which is suitable for $\mathrm{CO}_{2} / \mathrm{CH}_{4}$ separation. Alternatively, $\mathrm{ZIF}-71$ is selected due to its large cavity pore diameter $(16.5 \AA$ ) when compared to that of ZIF-8, ZIF-90, and ZIF-11 (cavity pore diameter $11.6,11.2$, and $14.6 \AA$, respectively) that has the potential to enhance the gas separation performance of hybrid membranes $[75,76]$.

Ehsani and Pakizeh [77] examined the performance of hybrid membranes with a ZIF-11 loading range of 10-70 wt.\% incorporated into PEBAX 2533. Morphological characterization of MMMs revealed an excellent adhesion between the polymer matrix and the nanoparticles. Even at 50 to $70 \mathrm{wt}$ \% ZIF-11 loading, no significant agglomeration could be observed, even though poorer interfacial morphology appeared. At lower MOF loading, the presence of polymer chain rigidification and pore blockage resulted in a gas permeability reduction ( $20 \%$ ). At higher loading ( $>50$ wt. $\%)$, the $\mathrm{CO}_{2}$ permeability increased when compared to pristine polymeric membrane, reaching a value of 403 Barrer at $70 \mathrm{wt} . \%$ (Table 1). Different effects were observed for selectivity: the $\mathrm{CO}_{2} / \mathrm{CH}_{4}$ selectivity increased from 8 to 12.5 at increasing the MOF content, but a negative trend was observed in the case of $\mathrm{CO}_{2} / \mathrm{N}_{2}$ 
selectivity. ZIF-11 has also been embedded in 6FDA-DAM polyimide [78]. SEM micrographs showed no apparent agglomeration for loading up to $30 \mathrm{wt} . \%$. An optimum was observed incorporating $20 \mathrm{wt} . \%$ ZIF-11, leading to a 12 -fold enhancement of $\mathrm{CO}_{2}$ permeability (Table 1), with limited effect on the ideal selectivity. The $\mathrm{CO}_{2}$ permeability improvement was associated to the achievement of particles alignment, and subsequently, an increase in fractional free volume of the hybrid matrix, which is confirmed by d-spacing analysis. The lack of selectivity improvement for $20 \mathrm{wt} . \%$ loading was related to the much higher gas permeability of ZIF-11 as compared to 6FDA-DAM, as predicted by the Maxwell model. Further increase in ZIF-11 loading did not show any improvement of the separation performance, owing to polymer chain rigidification and pore blockage.

Hybrid membranes based on PIM-1 and ZIF-71 with various loading were fabricated by Hao et al. [79]. The addition of ZIF-71 into PIM-1 considerably improved the gas transport, and in the case of $\mathrm{CO}_{2}$, the permeability value increased from 3295 to 8377 Barrer (Table 1). Photo oxidation obtained via UV treatment of the neat polymeric matrix increased the ideal selectivity to the detriment of gas permeability. As expected, the presence of the nanofillers helped in minimizing the gas permeability drop, showing impressive membrane performance $\left(\mathrm{CO}_{2}\right.$ permeability of 3459 Barrer, $\mathrm{CO}_{2} / \mathrm{CH}_{4}$ and $\mathrm{CO}_{2} / \mathrm{N}_{2}$ selectivity of 35.6 and 26.9 , respectively) [79]. The effect of particle size (30, 200, and $600 \mathrm{~nm}$, as seen in Figure 4) has also been investigated, using a fixed amount of nanoparticles in 6FDA-durene (Table 1) [76]. The permeability enhancement associated to the presence of the nanoparticles did not scale with the particle size, but it showed an optimum when the $200 \mathrm{~nm}$ particles size were used. In addition, the negligible effect on the ideal gas selectivity suggested the existence of a trade-off between the particle size and the gas separation performance, giving an important indication for the further development of nano-hybrid membranes.

(a)

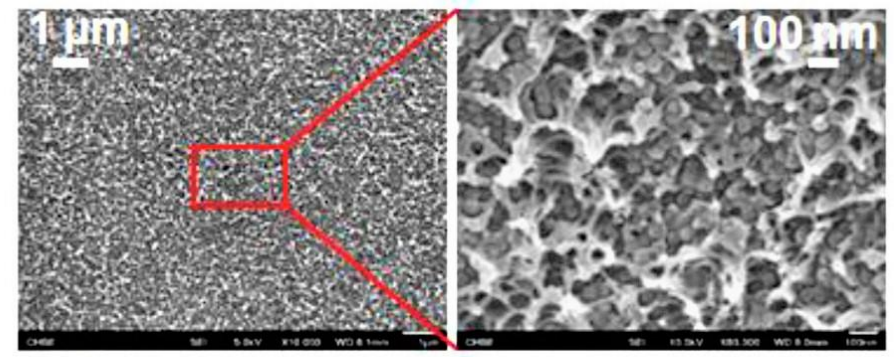

(b)

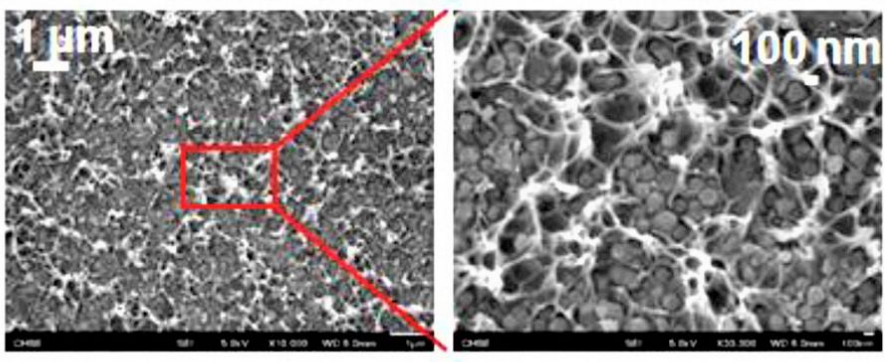

(c)

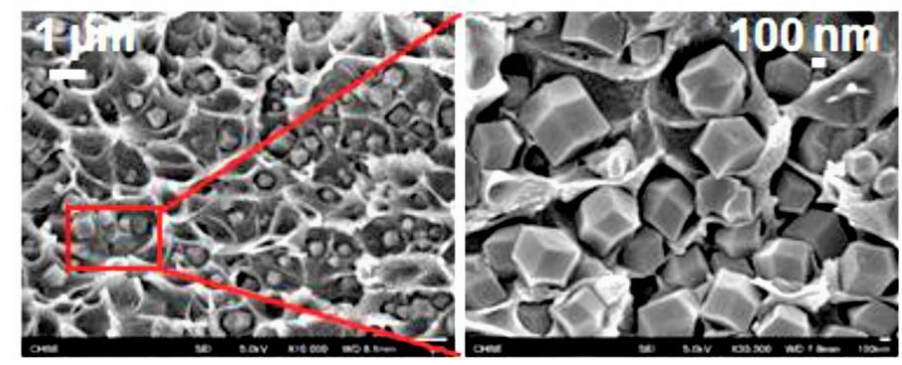

Figure 4. Cross-sectional morphology of 6FDA-Durene containing ZIF71 particles with average size of $30 \mathrm{~nm}(\mathbf{a}) ; 200 \mathrm{~nm}(\mathbf{b})$; and $600 \mathrm{~nm}(\mathbf{c})$ [76], with copyright permission from @ 2016, American Chemical Society. 
Bae et al. [80] studied the $\mathrm{CO}_{2}$ separation performance of MMMs containing a fixed amount of ZIF-90 (15 wt.\%), coupled with three different polyimides (6FDA-DAM, Matrimid and Ultem), aiming at determining the effect of the nanofillers on different polymer phases. In the case of Matrimid and Ultem, the $\mathrm{CO}_{2}$ permeability increased ( 100\%, Table 1). As previously reported, the negligible selectivity variation observed is related to the higher gas permeability of the nanoparticles, as predicted by the Maxwell model. When a more permeable matrix was used (6FDA-DAM), the $\mathrm{CO}_{2}$ permeability improvement was followed by an increase of the $\mathrm{CO}_{2}$-selective features of the hybrid matrix. Mixed gas permeation tests showed separation performances well above the $\mathrm{CO}_{2} / \mathrm{CH}_{4}$ and $\mathrm{CO}_{2} / \mathrm{N}_{2}$ upper bounds. Zhang et al. [81] utilized ZIF-90 as the filler in triptycene-based polymer and prepared hybrid membranes for $\mathrm{CO}_{2} / \mathrm{N}_{2}$ and $\mathrm{CO}_{2} / \mathrm{CH}_{4}$ separation. Cross-sectional SEM images revealed homogenous dispersion of the nanofillers and membranes with defect-free interfacial morphology, even at high loadings. The membrane containing $50 \mathrm{wt} \%$ ZIF-90 showed a $215 \%$ increase of the $\mathrm{CO}_{2}$ permeability value (Table 1), without sacrificing the gas selectivity. The ability of ZIF-90 to disrupt the polymer chain packing, and consequently, increase in free volume, was also suggested as source of additional permeability enhancement.

Table 1. Gas separation performance of ZIFs-b ased mixed matrix membranes (operating conditions ranging within $1-5$ bar, $20-35^{\circ} \mathrm{C}$, unless differently specified).

\begin{tabular}{|c|c|c|c|c|c|c|c|}
\hline Filler & Polymer & $\begin{array}{c}\text { Loading } \\
\text { (wt. \%) }\end{array}$ & $\begin{array}{c}P_{\mathrm{CO} 2} \\
\text { (Barrer) }\end{array}$ & $\alpha_{\mathrm{CO} 2 / \mathrm{N} 2}$ & $\alpha_{\mathrm{CO} 2 / \mathrm{CH} 4}$ & $\alpha_{\mathrm{CO} 2 / \mathrm{H} 2}$ & Ref. \\
\hline \multicolumn{8}{|c|}{ ZIF-8 } \\
\hline \multirow{6}{*}{$\begin{array}{c}\text { ZIF-8 } \\
\text { 50-150 nm }\end{array}$} & \multirow{6}{*}{ Matrimid 5218} & 0 & 9.5 & 30.7 & 39.8 & 0.34 & \multirow[t]{6}{*}{ [48] } \\
\hline & & 20 & 9.0 & 30.1 & 51.1 & 0.29 & \\
\hline & & 30 & 14.2 & 24.1 & 38.2 & 0.31 & \\
\hline & & 40 & 24.5 & 23.4 & 27.8 & 0.35 & \\
\hline & & 50 & 4.7 & 26.2 & 124.9 & 0.35 & \\
\hline & & 60 & 8.1 & 18.4 & 80.7 & 0.26 & \\
\hline \multirow{4}{*}{$\begin{array}{c}\text { ZIF-8 } \\
250-500 \mathrm{~nm}\end{array}$} & \multirow[t]{4}{*}{ Matrimid 9725} & 0 & $0.21^{\mathrm{a}}$ & & 28.0 & & \multirow[t]{4}{*}{ [49] } \\
\hline & & 10 & $0.31^{\mathrm{a}}$ & & 29.5 & & \\
\hline & & 20 & $0.42^{\mathrm{a}}$ & & 31.0 & & \\
\hline & & 30 & $0.7^{\mathrm{a}}$ & & 31.5 & & \\
\hline \multirow{5}{*}{$\begin{array}{l}\text { ZIF-8 } \\
60 \mathrm{~nm}\end{array}$} & \multirow[t]{5}{*}{ Matrimid 5218} & 0 & 8.1 & 22.4 & 35.2 & & \multirow[t]{5}{*}[50]{} \\
\hline & & 5 & 10.1 & 21.2 & 39.1 & & \\
\hline & & 10 & 13.7 & 21.6 & 30.6 & & \\
\hline & & 20 & 16.6 & 19.0 & 35.8 & & \\
\hline & & 30 & 28.7 & 17.1 & 24.9 & & \\
\hline ZIF-8 & \multirow[t]{5}{*}{ Matrimid } & 0 & 10.7 & & 33.9 & & \multirow[t]{5}{*}{ [51] } \\
\hline \multirow[t]{2}{*}{ Dir. Son. } & & 10 & 21.9 & & 36.0 & & \\
\hline & & 25 & 47.0 & & 39.0 & & \\
\hline \multirow[t]{2}{*}{ Indir. Son. } & & 10 & 13.2 & & 31.0 & & \\
\hline & & 25 & 23.2 & & 31.9 & & \\
\hline \multirow{4}{*}{$\begin{array}{c}\text { ZIF-8 } \\
\text { ZIF-8-ambz }\end{array}$} & \multirow[t]{4}{*}{ Matrimid 5218} & 0 & 9.0 & & 35.0 & & \multirow[t]{4}{*}{ [52] } \\
\hline & & 15 & 11.3 & & 35.0 & & \\
\hline & & 15 & 10.4 & & 36.5 & & \\
\hline & & 30 & 10.2 & & 38.0 & & \\
\hline & \multirow[t]{3}{*}{ Matrimid 5218} & 0 & 9.5 & 13.6 & 29.8 & 0.31 & \multirow[t]{3}{*}{ [54] } \\
\hline ZIF-8 & & 10 & 13.1 & 20.5 & & 0.26 & \\
\hline \multirow[t]{2}{*}{$95 \mathrm{~nm}$} & & $10^{b}$ & 15.5 & 26.7 & 34.4 & 0.34 & \\
\hline & P84 & 0 & $2.7^{\mathrm{c}}$ & & 54.1 & & \multirow[t]{5}{*}{ [55] } \\
\hline ZIF-8 & & 8 & $3.2^{\mathrm{c}}$ & & 63.5 & & \\
\hline \multirow[t]{3}{*}{$30 \mathrm{~nm}$} & & 17 & $6.3^{c}$ & & 93.6 & & \\
\hline & & 27 & $11.0^{\mathrm{C}}$ & & 92.3 & & \\
\hline & & 31 & $20.0^{c}$ & & 45.8 & & \\
\hline
\end{tabular}


Table 1. Cont.

\begin{tabular}{|c|c|c|c|c|c|c|c|}
\hline Filler & Polymer & $\begin{array}{l}\text { Loading } \\
\text { (wt. \%) }\end{array}$ & $\begin{array}{c}\mathrm{P}_{\mathrm{CO} 2} \\
\text { (Barrer) }\end{array}$ & $\alpha_{\mathrm{CO} 2 / \mathrm{N} 2}$ & $\alpha_{\mathrm{CO} 2 / \mathrm{CH} 4}$ & $\alpha_{\mathrm{CO} 2 / \mathrm{H} 2}$ & Ref. \\
\hline & 6FDA-durene & 0 & 468 & & 7 & & [56] \\
\hline ZIF-8 & & 5 & 694 & & 16.5 & & \\
\hline \multirow{3}{*}{$50 \mathrm{~nm}$} & & 10 & 1427 & & 28.7 & & \\
\hline & & 15 & 1466 & & 11.3 & & \\
\hline & & 20 & 1463 & & 8.97 & & \\
\hline \multirow{3}{*}{ ZIF-8 } & 6FDA-durene & 0 & 469 & 13.4 & 15.6 & 0.91 & [57] \\
\hline & & 33 & 1553 & 11.3 & 11.1 & 0.71 & \\
\hline & & $33^{d}$ & 23.7 & 11.8 & 16.9 & 0.08 & \\
\hline \multirow{6}{*}{$\begin{array}{l}\text { ZIF-8 } \\
80 \mathrm{~nm}\end{array}$} & 6FDA-durene & 0 & 352 & & 16.6 & & [59] \\
\hline & $\mathrm{T}=200^{\circ} \mathrm{C}$ & 20 & 487 & & 17.9 & & \\
\hline & $\mathrm{T}=350{ }^{\circ} \mathrm{C}$ & 0 & 432 & & 13.8 & & \\
\hline & & 20 & 857 & & 13.1 & & \\
\hline & $\mathrm{T}=400{ }^{\circ} \mathrm{C}$ & 0 & 541 & & 13.1 & & \\
\hline & & 20 & 1090 & & 13.0 & & \\
\hline \multirow{8}{*}{$\begin{array}{c}\text { ZIF-8 } \\
100-200 \mathrm{~nm}\end{array}$} & 6FDA-durene & 0 & 1468 & 25.4 & 22.6 & & [60] \\
\hline & & 3 & 1593 & 25.7 & 21.9 & & \\
\hline & & 5 & 1695 & 22.7 & 20.1 & & \\
\hline & & 7 & 1774 & 22.1 & 19.4 & & \\
\hline & & 10 & 1882 & 20.5 & 19 & & \\
\hline & & 15 & 1940 & 18.6 & 18.1 & & \\
\hline & & 20 & 2027 & 17.5 & 16.9 & & \\
\hline & & 30 & 2186 & 17 & 17.1 & & \\
\hline \multirow{8}{*}{ ZIF-8 } & PEBAX 2533 & 0 & 351 & 35.1 & 8.3 & & [61] \\
\hline & & 5 & 305 & 25.4 & 6.8 & & \\
\hline & & 10 & 427 & 30.5 & 8.5 & & \\
\hline & & 15 & 574 & 30.2 & 10.4 & & \\
\hline & & 20 & 854 & 28.5 & 9.2 & & \\
\hline & & 25 & 1082 & 30.9 & 8.5 & & \\
\hline & & 30 & 1176 & 31.8 & 8.7 & & \\
\hline & & 35 & 1287 & 32.2 & 9 & & \\
\hline \multirow{3}{*}{ ZIF-8 } & Ultem 1000 & 0 & $14^{\mathrm{e}}$ & 30 & & & [63] \\
\hline & & 13 & $26^{\mathrm{e}}$ & 36 & & & \\
\hline & & & ZIF-7 & & & & \\
\hline \multirow{4}{*}{$\begin{array}{c}\text { ZIF-7 } \\
40-50 \mathrm{~nm}\end{array}$} & PEBAX 1657 & 0 & 72 & 34 & 14 & & [72] \\
\hline & & 8 & 145 & 68 & 23 & & \\
\hline & & 22 & 111 & 97 & 30 & & \\
\hline & & 34 & 41 & 105 & 44 & & \\
\hline & PEI & 0 & 82.5 & 3.8 & 4.4 & & [73] \\
\hline ZIF-7 & & 5 & 64.7 & 17 & 12.9 & & \\
\hline PSM-ZIF-7 g & & 5 & 246 & 1.3 & 2.3 & & \\
\hline \multicolumn{8}{|c|}{ ZIF-11 } \\
\hline \multirow{5}{*}{$\begin{array}{c}\text { ZIF-11 } \\
500-5000 \mathrm{~nm}\end{array}$} & PEBAX 2533 & 0 & 232 & 41.3 & 8 & & [77] \\
\hline & & 10 & 212 & 53 & 9.7 & & \\
\hline & & 30 & 186 & 47.9 & 11.4 & & \\
\hline & & 50 & 233 & 46.9 & 11.2 & & \\
\hline & & 70 & 402 & 29 & 12.4 & & \\
\hline \multirow{4}{*}{$\begin{array}{c}\text { ZIF-11 } \\
\text { 200-2000 nm }\end{array}$} & 6FDA-DAM & 0 & 21.4 & & 32.7 & & [78] \\
\hline & & 10 & 107 & & 31.3 & & \\
\hline & & 20 & 273 & & 31 & & \\
\hline & & 30 & 76.7 & & 30.4 & & \\
\hline
\end{tabular}


Table 1. Cont

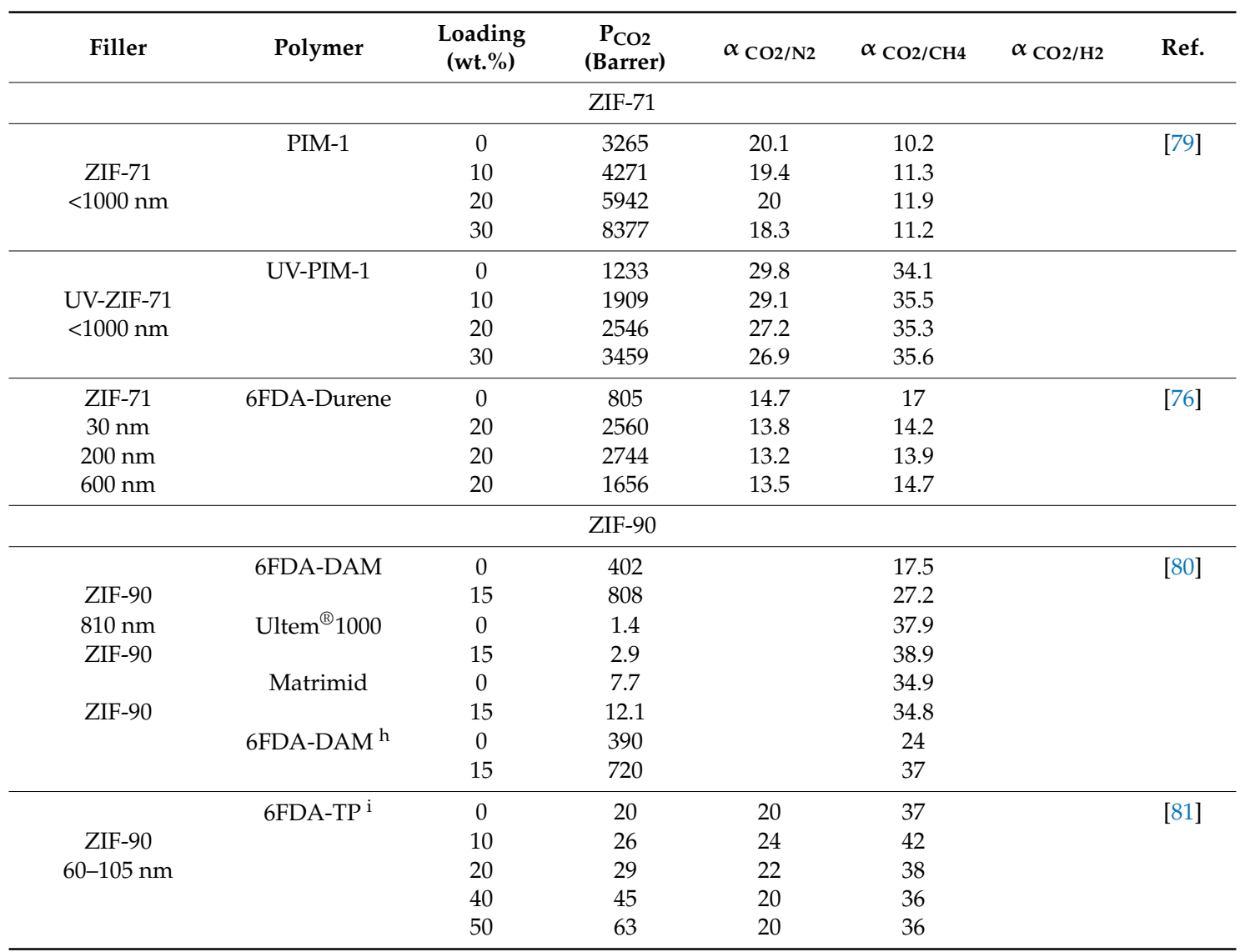

a Permeance (GPU), membrane thickness $40-65 \mu \mathrm{m}$; ${ }^{\text {b }}$ ZIF-8 synthesized using the solution collected from freshly-synthesized ZIF-8 dope after centrifugation; ${ }^{c}$ equimolar $\mathrm{CO}_{2} / \mathrm{CH}_{4}$ mixture; ${ }^{\mathrm{d}}$ membrane surface cross-linked using ethylenediamine vapour; ${ }^{\mathrm{e}}$ Permeance (GPU), membrane thickness $\sim 60 \mu \mathrm{m}$; ${ }^{\mathrm{f}}$ Permeance (GPU), membrane thickness $50-100 \mathrm{~nm}$; ${ }^{\mathrm{g}}$ PSM: post-synthetic modification; ${ }^{\mathrm{h}}$ gaseous mixture as feed gas; ${ }^{\mathrm{i}} \mathrm{TP}$ : triptycene, $10 \mathrm{~atm}$ feed pressure.

According to the analysis of different ZIFs in different polymeric materials, it appears that it is possible to achieve relatively high loading of isotropic ZIFs particles in the polymer matrix (up to $60 \mathrm{wt} . \%$ ). However, the optimum concentration of inorganic nanofillers appeared to be in the range of 30 to $40 \mathrm{wt} . \%$; at higher loading, no significant benefits for $\mathrm{CO}_{2}$ permeability can be obtained, but a decrease in selectivity can be expected. The use of ZIFs has been demonstrated to also be successful for highly permeable polymer (6FDA-based polymides, PIM-1, PEBAX), and typically the introduction of nanoparticles has the main function of disrupting the polymer chain packing and increasing the free volume in the hybrid matrix. However, despite the achievement of suitable interface morphology, the addition of ZIFs to polymer matrix seldom is reported to have a significant impact on the selective feature of the mixed matrix membrane. Among the investigated ZIFs, it is not possible to identify one type that is able to stand out, but the efficiency of each type also depends on the chosen polymeric phase and the synthetic procedures. Furthermore, ZIF nanoparticles with smaller size appears to be more effective when compared to inorganic phases with bigger average size. Finally, despite the $\mathrm{CO}_{2}$-philic nature of the nanofillers, the incorporation of ZIFs in polymeric matrix typically enhances the $\mathrm{H}_{2}$-selective feature of the pristine polymeric matrix. 


\subsection{Zirconium 1,4-Dicarboxybenzene (UiO-66)}

$\mathrm{UiO}-66$ is a zirconium-based metal-organic framework that is built from zirconium oxide $\left(\mathrm{Zr}_{6} \mathrm{O}_{4}(\mathrm{OH})_{4}\right)$ nodes linked together by 1,4-benzendicarboxylate as a bridging ligand [82]. UiO-66 is the first member of zirconium based MOFs family with $f c u$-topology introduced by Cavka et al. [83]. It owns a Langmuir surface area of $1187 \mathrm{~m}^{2} / \mathrm{g}$ and the narrow triangular windows that are present in the UiO-66 framework have different sizes (Figure 5): $6 \AA$ is the window connected to the two octahedral cages, with the size of $11 \AA$, and the tetrahedral cage, which has an opening of $8 \AA$ (Figure 5). UiO-66 showed exceptional mechanical and chemical stability on exposure to high temperature, up to $500{ }^{\circ} \mathrm{C}$, and chemicals, making this MOF a promising candidate for many applications [82,84]. The benzene ring has been found to be characterized by the rotational barrier as compared to other MOFs, leading to changes in the pore opening size (Figure $5 \mathrm{C}$ ), and this effect showed a temperature dependency behavior [85].

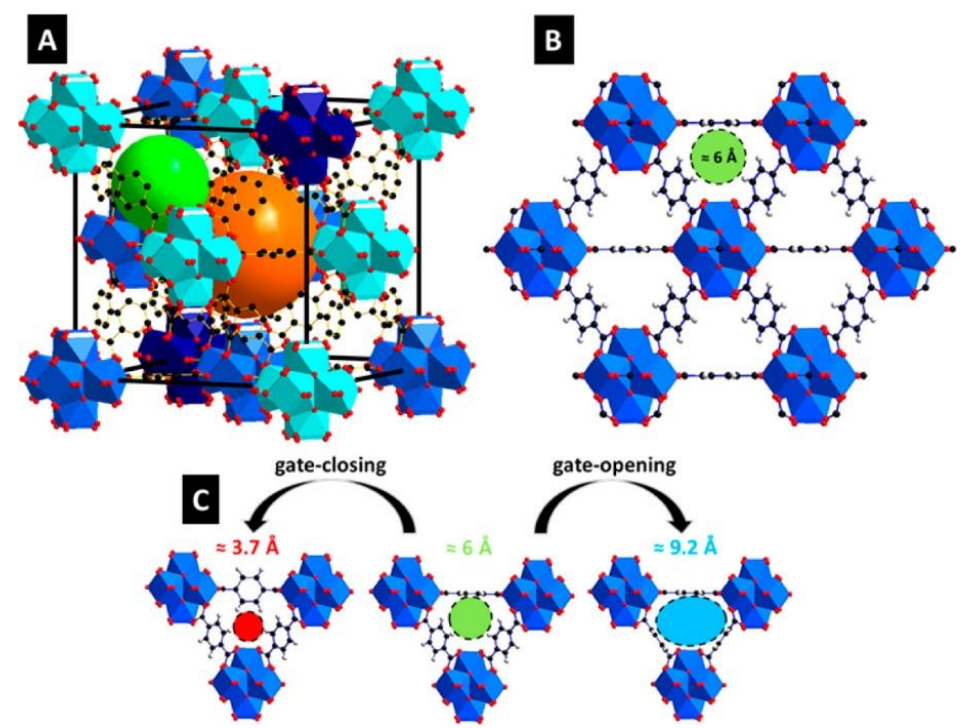

Figure 5. Three-dimensional (3D) structure of UiO-66 (A) visualizing the octahedral cage (orange) and the tetrahedral cage (green). Triangular windows (B) between the octahedral and tetrahedral cages. Pore opening changes upon rotation of the benzene ligands (C) [84], with copyright permission from (C) 2017, American Chemical Society.

Hybrid membranes embedding 5 to $20 \mathrm{wt} \%$ pristine UiO-66 and amine functionalized UiO-66- $\mathrm{NH}_{2}$ (average size 60-80 nm) in PEBAX 1657 have been prepared [86]. For both types of nanoparticles, the $\mathrm{CO}_{2}$ permeability increased proportionally to the amount of inorganic phase, reaching a $\sim 2.5$-fold enhancement of the pristine polymer value (Table 2 ). These results suggested that UiO-66 showed a strong affinity towards $\mathrm{CO}_{2}$ due to the presence of $\mathrm{OH}$ coordinated bond connected to $\mathrm{Zr}$ cluster. Different trends were observed for the $\mathrm{CO}_{2} / \mathrm{N}_{2}$ selectivity, which showed an optimum between 7.5 and $10 \mathrm{wt}$ \% loading. The better affinity of the UiO-66- $\mathrm{NH}_{2}$ with the polymer phase allowed for reaching better selectivity improvement $(88 \%)$ as compared to the pristine MOF (42\%). Interestingly, the mixed matrix membranes prepared with $\mathrm{UiO}-66-\mathrm{NH}_{2}$, retained stable performances even in the presence of humidity. Similar nanoparticles (UiO-66 and UiO-66- $\mathrm{NH}_{2}$ ) have been embedded also into Matrimid 9725 [87]. The use of two modulators (benzoic acid, BA, and 4-aminobenzoic acid, ABA) was reported to allow for the linkage of the amine groups in different positions in the UiO-66 structure. The presence of the ABA modulator increased the $\mathrm{CO}_{2} / \mathrm{CH}_{4}$ selectivity up to $55 \%$ (from 31.2 to 47.4 ), together with a six-folds improvement of the $\mathrm{CO}_{2}$ permeability for the amine-modified UiO-66 (Table 2). Surface modification of the UiO-66 has also been proposed as a possible approach to improve the nanoscale morphology at the organic/inorganic interface [88]. 
The surface modification was performed using phenyl acetyl (PA), decanoyl acetyl (DA), and succinic acid (SA) in order to enhance the interaction between nanoparticles and Matrimid 5218 was used as polymer phase. A good adhesion and interaction between surface functionalized UiO-66- $\mathrm{NH}_{2}$ and polymer matrix was observed, leading to improved mechanical and chemical properties of and the hybrid membranes. 23 wt. \% loading of PA-modified UiO-66- $\mathrm{NH}_{2}$ enhanced the $\mathrm{CO}_{2}$ permeability by $229 \%$ (from 8.5 Barrer to 28 Barrer), with a simultaneous improvement of $\mathrm{CO}_{2} / \mathrm{N}_{2}$ selectivity by $25 \%$. The permeability and selectivity increased due to the strong interactions between the $\mathrm{CO}_{2}$ and the $\mathrm{NH}_{2}$ groups that are present in the MOF, together with interaction of imide group in Matrimid and aromatic ring in PA through $\pi-\pi$ bonds. The poor interaction between fillers and Matrimid in DA and SA-modified UiO-66- $\mathrm{NH}_{2}$ resulted in a reduction in permeability and selectivity when compared to PA-modified UiO-66- $\mathrm{NH}_{2}$ particles.

The influence of amino and carboxylic group functionalization of UiO-66 have been investigated using PIM-1 as polymer phase [89]. The investigation considered "as-cast" and "solvent exchanged" PIM-1 membrane: the latter showed higher $\mathrm{CO}_{2}$ permeability (8210 Barrer) compared to the pristine membrane (4770 Barrer), and the difference is attributed to the excess free volume that is generated by the solvent removal. The addition of pristine UiO-66 to the matrix generated an enhancement in $\mathrm{CO}_{2}$ permeability (up to $59 \%$ for the "as cast" membrane and $32 \%$ for the "solvent exchanged sample, Table 2) when compared to the pristine polymeric sample. In the case of UiO-66- $\mathrm{NH}_{2}$ and UiO-66- $(\mathrm{COOH})_{2}$, the $\mathrm{CO}_{2}$ permeability also showed an increase, but with a lower extent as compared to the pristine nanoparticles. In the case of the selectivity, the parameter showed a limited variation for both $\mathrm{CO}_{2} / \mathrm{N}_{2}$ (decrease up to $10 \%$ ) and $\mathrm{CO}_{2} / \mathrm{CH}_{4}$ (decrease up to $20 \%$ ) upon the addition of the nanoparticles, both pristine and functionalized. Performance for $\mathrm{CO}_{2} / \mathrm{H}_{2}$ separation were also reported. The pristine polymer showed a $\mathrm{CO}_{2}$-philic behavior, which was slightly enhanced in presence of the nanoparticles (particularly in the case of UiO-66-(COOH $\left.)_{2}\right)$. However, the selectivity value remains too low to be attractive for industrial separations.

In another study [90], water modulation was employed to reduce the particle size of UiO-66 (from 100-200 to around 20-30 nm) and the water modulated nanoparticles (UiO-66-H) were further surface-modified using amine $\left(\mathrm{UiO}-66-\mathrm{NH}_{2}\right)$ and bromide $(\mathrm{UiO}-66-\mathrm{Br})$ functional groups. The reduction in particle size improved the dispersion of UiO-66 into polymer matrix by minimizing the formation of non-selective microvoids. The decrease in the $\mathrm{CO}_{2}$ selective feature of the hybrids observed with increasing the content of unmodified UiO-66 was therefore prevented (Figure 6), and a selectivity enhancement was observed for all of the modified nanoparticles (up to $71 \%$ and $95 \%$ in the case of $\mathrm{CO}_{2} / \mathrm{N}_{2}$ and $\mathrm{CO}_{2} / \mathrm{CH}_{4}$ selectivity for $10 \mathrm{wt}$.\% UiO-66- $\mathrm{NH}_{2}$ loading). This effect was mainly associated to the increased rigidity of interphase. However, the improved interactions between the functionalized nanoparticles and the polymer chains led to a negligible effect on $\mathrm{CO}_{2}$ permeability, which instead was significantly enhanced $(\sim 100 \%)$ in the case of unmodified UiO-66. Despite the differences that were observed with respect to the previous study in terms of pristine PIM-1 transport properties, the performance achieved by embedding $\mathrm{UiO}-66$ and $\mathrm{UiO}-66-\mathrm{NH}_{2}$ are similar, supporting the consistency of the results. 

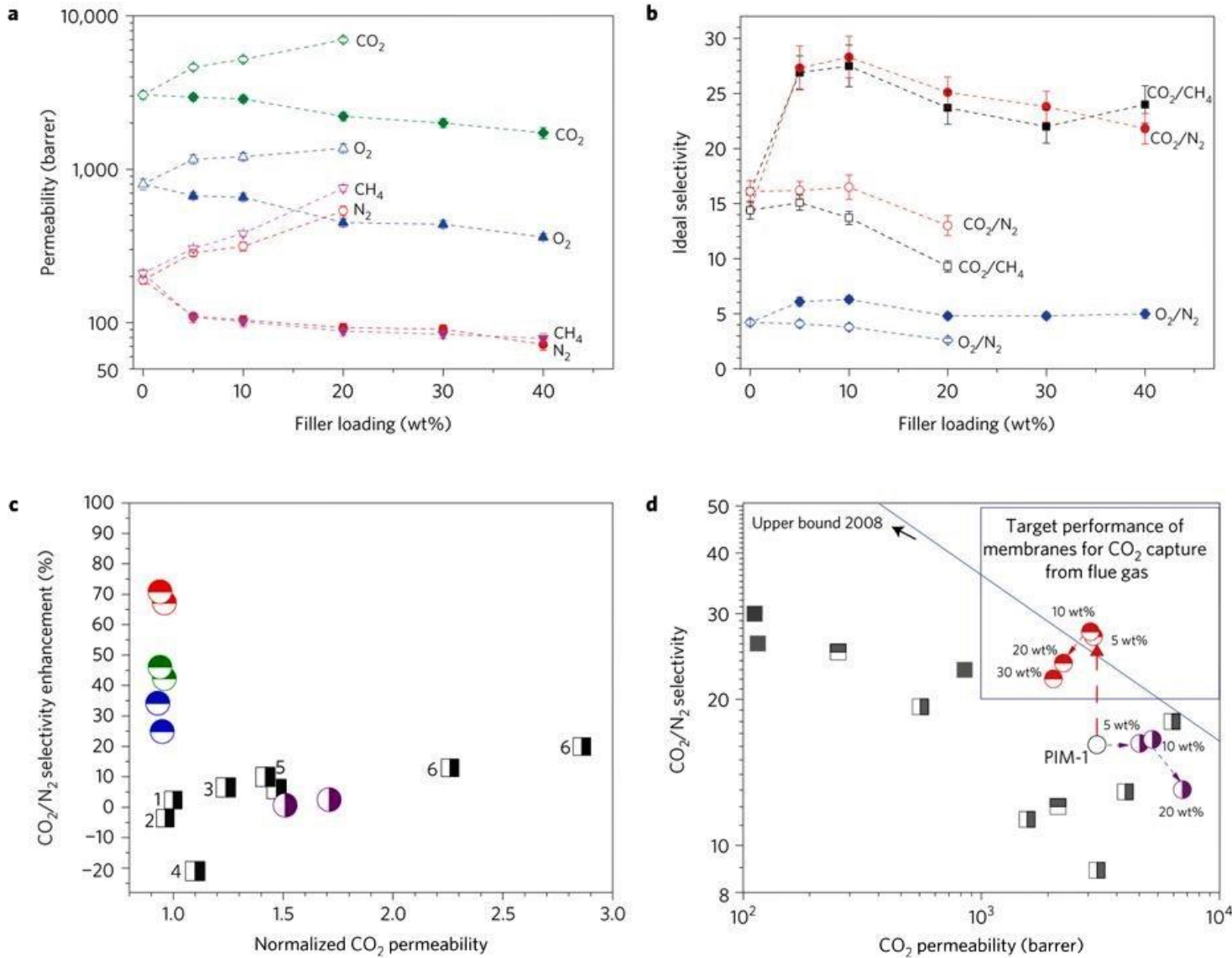

Figure 6. Gas permeability (a) and gas selectivity (b) of $\mathrm{UiO}-66-\mathrm{NH}_{2}$ (filled symbols) and pristine UiO-66 (open symbols) embedded in PIM-1. Comparison with literature results (c) and Robeson plot (d) for $\mathrm{CO}_{2} / \mathrm{N}_{2}$ separation [90], with copyright permission from (C) 2017, Springer Nature.

The influence of UiO-66 on the gas separation performance of 6FDA-based polyimides were also evaluated for mixed gas feed $\mathrm{CO}_{2} / \mathrm{CH}_{4}(50 / 50 \mathrm{v} / \mathrm{v})$ [91]. Different $6 \mathrm{FDA}$-based polymers were investigated (6FDA-BisP, 6FDA-ODA, and 6FDA-DAM). $\mathrm{CO}_{2}$ permeability was found to increase proportionally to the inorganic content for all of the different polymer phases, even though a larger enhancement was observed for the low permeable ones. In the case of 6FDA-Bisp and 6FDA-ODA, $\mathrm{CO}_{2}$ permeability improved by $357 \%$ and $178 \%$, whereas for $6 \mathrm{FDA}-\mathrm{DAM}$, the enhancement was limited to $136 \%$. The permeability improvement was associated to a FFV increase upon the incorporation of the inorganic phase, and the benefits was more pronounced for the polymer phase with an initially lower FFV. Improvement in terms of selectivity was observed for 6FDA-BisP and 6FDA-ODA up to $17 \mathrm{wt} . \%$ loading, but at higher loadings, poor nanoparticles dispersion determined a drop in the selective feature of the hybrids. Interestingly, a negligible effect was observed for the more permeable 6FDA-DAM. The authors also investigated the effect of surface functionalization of UiO-66 when embedded in 6FDA-DAM [92]. The amino-functionalized UiO-66- $\mathrm{NH}_{2}$ was prepared via the direct synthesis method, and $\mathrm{UiO}-66-\mathrm{NH}-\mathrm{COCH}_{3}$ was synthesized via post-synthetic modification of UiO-66- $\mathrm{NH}_{2}$ using acetamide-ligand. When compared to the results that were obtained with the pristine UiO-66, the surface modification helped in achieving a better polymer-MOF interface, reducing the free volume of the hybrid matrix at a given loading. At low pressure, negligible effects were observed on the transport properties when the modified MOFs were used, but at higher feed pressure, the post-synthetic modification showed better results in terms of $\mathrm{CO}_{2} / \mathrm{CH}_{4}$ selectivity. 
Table 2. Gas separation performance of UiO-66-based mixed matrix membranes (operating conditions ranging within $1-5$ bar, $20-35{ }^{\circ} \mathrm{C}$, unless differently specified).

\begin{tabular}{|c|c|c|c|c|c|c|c|}
\hline Filler & Polymer & $\begin{array}{l}\text { Loading } \\
\text { (wt.\%) }\end{array}$ & $\begin{array}{c}\mathrm{P}_{\mathrm{CO} 2} \\
\text { (Barrer) }\end{array}$ & $\alpha_{\mathrm{CO} 2 / \mathrm{N} 2}$ & $\alpha_{\mathrm{CO} 2 / \mathrm{CH} 4}$ & $\alpha_{\mathrm{CO} 2 / \mathrm{H} 2}$ & Ref. \\
\hline & PEBAX 1657 & 0 & 51.5 & 42.1 & & & [86] \\
\hline $\mathrm{UiO}-66$ & & 5 & 75.0 & 56.0 & & & \\
\hline \multirow{5}{*}{$60-80 \mathrm{~nm}$} & & 7.5 & 90.0 & 60.0 & & & \\
\hline & & 10 & 96.3 & 56.6 & & & \\
\hline & & 12.5 & 110.5 & 40.0 & & & \\
\hline & & 15 & 115.0 & 27.0 & & & \\
\hline & & 20 & 134.0 & 21.0 & & & \\
\hline UiO-66--NH ${ }_{2}$ & & 5 & 71.0 & 68.0 & & & \\
\hline \multirow[t]{5}{*}{$60-80 \mathrm{~nm}$} & & 7.5 & 78.0 & 76.0 & & & \\
\hline & & 10 & 87.0 & 79.2 & & & \\
\hline & & 12.5 & 96.0 & 45.0 & & & \\
\hline & & 15 & 100.0 & 37.5 & & & \\
\hline & & 20 & 122 & 26 & & & \\
\hline & Matrimid $9725^{\text {a }}$ & 0 & 5.9 & & 31.2 & & [87] \\
\hline UiO-66 & & 30 & 15.0 & & 35.8 & & \\
\hline UiO-66-BA & & 30 & 17.8 & & 42.9 & & \\
\hline UiO-66-ABA & & 30 & 13.6 & & 45.1 & & \\
\hline $\mathrm{UiO}-66-\mathrm{NH}_{2}$ & & 30 & 17.8 & & 37.3 & & \\
\hline UiO-66-NH $-\mathrm{NH}_{2}$ & & 30 & 17.4 & & 39.3 & & \\
\hline \multirow[t]{2}{*}{$\mathrm{UiO}-66-\mathrm{NH}_{2}-\mathrm{ABA}$} & & 30 & 38.0 & & 47.4 & & \\
\hline & Matrimid $5218^{\mathrm{b}}$ & 0 & 8.5 & 29 & & & [88] \\
\hline $\mathrm{UiO}-66-\mathrm{NH}_{2}$ & & 12 & 18.5 & 33 & & & \\
\hline \multirow[t]{2}{*}{$200 \mathrm{~nm}$} & & 23 & 24 & 36 & & & \\
\hline & & 40 & 28 & 27.5 & & & \\
\hline \multirow[t]{3}{*}{$\mathrm{UiO}-66-\mathrm{NH}_{2}-\mathrm{PA}$} & & 12 & 20.5 & 32.5 & & & \\
\hline & & 23 & 28 & 36.5 & & & \\
\hline & & 40 & 31 & 28 & & & \\
\hline UiO-66--NH $\mathrm{N}_{2}-\mathrm{C} 10$ & & 23 & 22.5 & 28 & & & \\
\hline \multirow[t]{2}{*}{$\mathrm{UiO}-66-\mathrm{NH}_{2}-\mathrm{SA}$} & & 23 & 20 & 30.5 & & & \\
\hline & PIM-1 & 0 & 4770 & 21.8 & 16.7 & 1.76 & [89] \\
\hline UiO-66 & as cast & 9.1 & 5940 & 23.2 & 16. & 1.93 & \\
\hline \multirow{3}{*}{$200 \mathrm{~nm}$} & & 16.6 & 7610 & 20.7 & 14.4 & 1.67 & \\
\hline & & 23.1 & 7610 & 20.7 & 14.4 & 1.67 & \\
\hline & & 28.6 & 4940 & 13.6 & 11.2 & 0.66 & \\
\hline UiO-66-(COOH $)_{2}$ & & 9.1 & 4600 & 20.9 & 14.1 & 2.22 & \\
\hline \multirow[t]{3}{*}{$200 \mathrm{~nm}$} & & 16.6 & 5190 & 20.4 & 13.2 & 2.19 & \\
\hline & & 23.1 & 5300 & 19.9 & 12.9 & 2.22 & \\
\hline & & 28.6 & 6090 & 20.6 & 15.2 & 1.63 & \\
\hline UiO-66-- $\mathrm{NH}_{2}$ & & 9.1 & 4810 & 22.2 & 16.5 & 1.62 & \\
\hline \multirow{4}{*}{$200 \mathrm{~nm}$} & & 16.6 & 6340 & 20.9 & 14.9 & 2.03 & \\
\hline & & 23.1 & 5070 & 20.1 & 14.7 & 1.58 & \\
\hline & & 28.6 & 6310 & 21.5 & 13.3 & 2.10 & \\
\hline & PIM-1 & 0 & 8210 & 21.2 & 15.7 & 1.63 & \\
\hline UiO-66 & exchanged solvent & 16.6 & 9980 & 21.6 & 17 & 1.23 & \\
\hline \multirow[t]{2}{*}{$200 \mathrm{~nm}$} & & 23.1 & 9980 & 21.6 & 17 & 1.23 & \\
\hline & & 28.6 & 10,900 & 15.2 & 13.2 & 1.74 & \\
\hline $\mathrm{UiO}-66-(\mathrm{COOH})_{2}$ & & 16.6 & 9720 & 18.9 & 11.7 & 2.28 & \\
\hline \multirow[t]{2}{*}{$200 \mathrm{~nm}$} & & 23.1 & 8770 & 18.1 & 11 & 2.05 & \\
\hline & & 28.6 & 9020 & 22.1 & 13.5 & 1.02 & \\
\hline UiO-66-NH $\mathrm{NH}_{2}$ & & 9.1 & 8740 & 22 & 14.7 & 1.84 & \\
\hline \multirow[t]{3}{*}{$200 \mathrm{~nm}$} & & 16.6 & 10,700 & 21.4 & 13.7 & 1.88 & \\
\hline & & 23.1 & 9570 & 23.4 & 13.8 & 1.43 & \\
\hline & & 28.6 & 9030 & 19.5 & 13 & 1.70 & \\
\hline
\end{tabular}


Table 2. Cont

\begin{tabular}{|c|c|c|c|c|c|c|c|}
\hline Filler & Polymer & $\begin{array}{c}\text { Loading } \\
\text { (wt. } \% \text { ) }\end{array}$ & $\begin{array}{c}P_{\mathrm{CO} 2} \\
\text { (Barrer) }\end{array}$ & $\alpha_{\mathrm{CO} 2 / \mathrm{N} 2}$ & $\alpha_{\mathrm{CO} 2 / \mathrm{CH} 4}$ & $\alpha_{\mathrm{CO} 2 / \mathrm{H} 2}$ & Ref. \\
\hline & PIM-1 & 0 & 3054 & 16.1 & 14.5 & 1.67 & [90] \\
\hline UiO-66 & & 5 & 4620 & 16.2 & 15.1 & 1.90 & \\
\hline \multirow[t]{2}{*}{$100-200 \mathrm{~nm}$} & & 10 & 5210 & 16.5 & 13.7 & 2.04 & \\
\hline & & 20 & 6981 & 13 & 9.3 & 2.60 & \\
\hline UiO-66-H & & 5 & 2765 & 22.9 & 18.2 & 0.88 & \\
\hline \multirow[t]{4}{*}{$20-30 \mathrm{~nm}$} & & 10 & 2631 & 23.5 & 18.8 & 0.88 & \\
\hline & & 20 & 2606 & 24.6 & 20.1 & 0.89 & \\
\hline & & 30 & 1880 & 18.3 & 16.1 & 1.55 & \\
\hline & & 40 & 1023 & 21.4 & 15.8 & 1.67 & \\
\hline $\mathrm{UiO}-66-\mathrm{NH}_{2}$ & & 5 & 2952 & 26.9 & 27.3 & 1.11 & \\
\hline \multirow[t]{4}{*}{$20-30 \mathrm{~nm}$} & & 10 & 2869 & 27.5 & 28.3 & 1.09 & \\
\hline & & 20 & 2210 & 23.7 & 25.1 & 0.99 & \\
\hline & & 30 & 2005 & 22 & 23.8 & 0.99 & \\
\hline & & 40 & 1727 & 24 & 21.8 & 0.86 & \\
\hline UiO-66-Br & & 5 & 2890 & 20.1 & 18.1 & 1.49 & \\
\hline \multirow[t]{4}{*}{$20-30 \mathrm{~nm}$} & & 10 & 2846 & 21.6 & 17.1 & 1.25 & \\
\hline & & 20 & 2416 & 19.3 & 16.3 & 1.53 & \\
\hline & & 30 & 2294 & 19 & 17.1 & 1.57 & \\
\hline & & 40 & 1441 & 23.6 & 20.8 & 1.03 & \\
\hline & 6FDA-BisP & 0 & 33.9 & & 27.5 & & [91] \\
\hline UiO-66 & & 6 & 56.7 & & 33.6 & & \\
\hline \multirow[t]{4}{*}{$50-100 \mathrm{~nm}$} & & 14 & 83.9 & & 36.2 & & \\
\hline & & 17 & 108 & & 41.9 & & \\
\hline & & 21 & 155 & & 24.6 & & \\
\hline & 6FDA-ODA & 0 & 25.9 & & 20.6 & & \\
\hline UiO-66 & & 4 & 30.1 & & 38 & & \\
\hline \multirow[t]{4}{*}{$50-100 \mathrm{~nm}$} & & 8 & 37.4 & & 51.5 & & \\
\hline & & 17 & 43.3 & & 57 & & \\
\hline & & 23 & 72 & & 21.5 & & \\
\hline & 6FDA-DAM & 0 & 997 & & 29.2 & & \\
\hline UiO-66 & & 4 & 1283 & & 29.6 & & \\
\hline \multirow[t]{3}{*}{$50-100 \mathrm{~nm}$} & & 8 & 1728 & & 32 & & \\
\hline & & 14 & 1912 & & 30.9 & & \\
\hline & & 21 & 2358 & & 12.7 & & \\
\hline \multirow{5}{*}{$\mathrm{UiO}-66$} & 6FDA-DAM & 0 & $1010^{c}$ & & 29.2 & & [92] \\
\hline & & 4 & $1290^{c}$ & & 29.6 & & \\
\hline & & 8 & $1730^{c}$ & & 32.1 & & \\
\hline & & 14 & $1915^{c}$ & & 31.2 & & \\
\hline & & 21 & $2365^{c}$ & & 12.6 & & \\
\hline \multirow[t]{4}{*}{$\mathrm{UiO}-66-\mathrm{NH}_{2}$} & & 4 & $1295^{c}$ & & 29.2 & & \\
\hline & & 8 & $1300^{c}$ & & 30.3 & & \\
\hline & & 14 & $1345^{c}$ & & 29.9 & & \\
\hline & & 21 & $1585^{c}$ & & 20.7 & & \\
\hline \multirow[t]{4}{*}{$\mathrm{UiO}-66-\mathrm{NH}-\mathrm{COCH}_{3}$} & & 4 & $1081^{\mathrm{c}}$ & & 30.3 & & \\
\hline & & 8 & $1171^{\mathrm{c}}$ & & 32.5 & & \\
\hline & & 14 & $1266^{c}$ & & 33.1 & & \\
\hline & & 21 & $1417^{c}$ & & 24.1 & & \\
\hline
\end{tabular}

${ }^{\mathrm{a}}$ feed pressure $=9 \mathrm{bar} ;{ }^{\mathrm{b}}$ feed pressure $=10 \mathrm{bar} ;{ }^{\mathrm{c}}$ equimolar $\mathrm{CO}_{2} / \mathrm{CH}_{4}$ gas mixture.

In view of the reported data, UiO-66 appeared to be a promising inorganic phase to fabricate $\mathrm{CO}_{2}$-selective hybrid membranes. Unlike the case of ZIF, the loading for UiO-66-based mixed matrix membranes has been limited to $40 \mathrm{wt} . \%$, as agglomeration and poor polymer-fillers interface was observed at high loadings. In the case of unmodified particles, the $\mathrm{CO}_{2}$ permeability was found to increase proportionally to the inorganic content for all of the investigated studies, but when considering the selective feature, an optimum is observed for a loading range between 10 and $20 \mathrm{wt} . \%$. Amine modified UiO-66 (UiO-66- $\left.\mathrm{NH}_{2}\right)$ showed typically better performance as compared to the pristine nanoparticles, which is mainly due to the enhanced $\mathrm{CO}_{2}$-philicity. In general, surface modification led to improved polymer-particle interface, but for highly permeable polymers, this led to limited effect in terms of both selectivity and permeability. 


\subsection{Copper-Based MOFs}

When compared to other metal organic frameworks, $\mathrm{Cu}$-based MOFs offer an exceptional $\mathrm{CO}_{2}$ uptake due to their high affinity with polar molecules. The presence of unsaturated open metal sites in $\mathrm{Cu}$-based MOFs after activation is reported as an assisted mechanism in $\mathrm{CO}_{2}$ sorption [93]. Comparison of the $\mathrm{CO}_{2}$ adsorption capacity of two well-known MOFs containing the same ligand in their framework (Cu-BTC and Fe-BTC) showed that the Cu-BTC is characterized by a much larger $\mathrm{CO}_{2}$ uptake $\left(73.2 \mathrm{~cm}^{3} \mathrm{~g}^{-1}\right.$, at room temperature and atmospheric pressure) when compared to the Fe-BTC $\left(15.9 \mathrm{~cm}^{3} \mathrm{~g}^{-1}\right)$ [94]. The results clearly pointed out the higher $\mathrm{CO}_{2}$ affinity and interaction of $\mathrm{Cu}$ ions together with open metal sites, making $\mathrm{Cu}$-based MOFs interesting for the fabrication of mixed matrix membranes for $\mathrm{CO}_{2}$ separation.

Basu et al. [49] investigated the effect of $\mathrm{Cu}_{3}(\mathrm{BTC})_{2}$ when embedded in Matrimid 9725 polymer phase. Upon the incorporation of the nanofiller, both $\mathrm{CO}_{2}$ permeability $(196 \%)$ and $\mathrm{CO}_{2} / \mathrm{CH}_{4}$ separation factor increased along with the inorganic content (Table 3). The overall increase of the separation performance was ascribed to the interactions between polymer and MOF and electrostatic interaction between the MOF and gas molecules, which leads to the existence of a competitive behavior. $\mathrm{Cu}_{3}(\mathrm{BTC})_{2}$ was dispersed also in poly(2,6-dimethyl-1,4-phenylene oxide) (PPO), reducing the particles size via sonication from 50 to $6 \mu \mathrm{m}$ [95]. Sonication was also reported to be able to improve the micropore volume of the nanoparticles and their dispersability within the polymeric matrix. By embedding $10 \mathrm{wt} . \%$ of $\mathrm{Cu}_{3}(\mathrm{BTC})_{2}$ filler, the $\mathrm{CO}_{2}$ permeability increased proportionally to the filler content, and the maximum enhancement was achieved for the smallest particles $(26 \%$, Table 3). The reduction of particles size showed a positive impact on the membrane selectivity: the improved compatibility with the polymer matrix prevented the selectivity drop observed as in the case of bigger particles. Abedini et al. [96] embedded $\mathrm{Cu}_{3}(\mathrm{BTC})_{2}$ with a particle size of $100 \mathrm{~nm}$ in poly(4-methyl-1-pentyne) (PMP). By increasing the loading to $20 \mathrm{wt} . \%$, they observed a simultaneous increase in $\mathrm{CO}_{2}$ permeability (90\%, Table 3) and selectivity (between 40 and $60 \%$ for the investigated gas pairs, Table 3). The observed variation was mainly attributed to a free volume increase. Interestingly, they also observed a reduction of the physical aging influence. Amine modification of $\mathrm{Cu}_{3}(\mathrm{BTC})_{2}$ has also been reported as a possible approach to improve the $\mathrm{CO}_{2}$ separation performance of a PEBAX 1657 [97]. In view of the $\mathrm{H}$-bonding between the $-\mathrm{NH}_{2}$ group and the polymeric chain, the modified nanoparticles showed better compatibility with the polymer phase. The $\mathrm{CO}_{2}$ permeability increased proportionally to the loading (up to $100 \%$ increment, Table 3) similarly for both of the fillers, but better improvement of the $\mathrm{CO}_{2} / \mathrm{CH}_{4}$ selectivity was achieved upon amine-modification of the fillers. Interactions between the amine groups and the $\mathrm{CO}_{2}$ have also been suggested to be responsible for the improved $\mathrm{CO}_{2}$-philicity of the hybrid matrices.

Metal-organic polyhedral 18 (MOP-18) was also used to fabricate the hybrid membrane using Matrimid as polymer phase [98]. The inorganic content was increased up to $80 \mathrm{wt} . \%$, but above $44 \mathrm{wt} . \%$ the samples' brittleness did not allow for the investigation of the transport properties via permeability testing. The $\mathrm{CO}_{2}$ permeability increased along with MOP-18 content, even though a reduction in ideal selectivity was observed for both $\mathrm{CO}_{2} / \mathrm{N}_{2}$ and $\mathrm{CO}_{2} / \mathrm{CH}_{4}$. The permeability enhancement was attributed to increasing the number of alkyl chains, which improved the $\mathrm{CO}_{2}$ solubility within the hybrid matrix. $\mathrm{H}_{2}$ permeability was also measured and the addition of the nanoparticles increased the $\mathrm{CO}_{2}$-philicity of the mixed matrix (Table 3).

Ahmadi et al. [6] synthesized a new class of $\mathrm{Cu}$-based microporous metal-imidazolate framework (MMIF) and explored the separation performance of the mixed matrix membranes with $10 \mathrm{wt} . \%$ and $20 \mathrm{wt} . \%$ loading in Matrimid 5218 polymer matrix. The gas permeability showed a moderate increase (26\%) along with the MOF content with limited effect on $\mathrm{CO}_{2} / \mathrm{CH}_{4}$ and $\mathrm{CO}_{2} / \mathrm{N}_{2}$ selectivity. The single gas permeation results revealed a flexible structure of MMIF, with the consequent formation of interfacial defects and voids. Interestingly, a significant enhancement of the separation factor was measured for mixed gas experiments (Table 3), which was mainly attributed to $\mathrm{CO}_{2}$ competitive sorption within the hybrid matrix. Molecular simulation revealed that gas sorption was the dominant 
mechanism in the hybrid membrane, and the preferential $\mathrm{CO}_{2}$ uptake into the MMIF pores limited the transport of other gases $\left(\mathrm{CH}_{4}\right.$ and $\left.\mathrm{N}_{2}\right)$ through the MMIF's framework.

Zhang et al. [99] fabricated a Cu-based microporous metal-organic framework (Cu-BPY-HFS) and dispersed it in Matrimid 5218 up to $40 \mathrm{wt}$ \% loading. The SEM images proved the good adhesion between MOF and Matrimid for loading up to $30 \%$, but a higher amount of MOFs generated the formation of a poor particle-polymer interface. The $\mathrm{CO}_{2}$ permeability increased along with the $\mathrm{Cu}$-BPY-HFS content, and the variation was attributed to the $0.8 \AA$ pore diameter and the presence of interfacial voids. Interestingly, the MOF was shown to have better affinity with $\mathrm{CH}_{4}$ than $\mathrm{CO}_{2}$, and enhanced $\mathrm{CH}_{4}$ transport was observed in both pure and mixed gas tests. On the other hand, the $\mathrm{CO}_{2} / \mathrm{N}_{2}$ selectivity was negligibly affected by the presence of the MOF. As for the previous case, the addition of $\mathrm{Cu}$-based MOF nanoparticles increased the $\mathrm{CO}_{2}$-philicity, thus reducing the ability of the hybrid membranes to separate $\mathrm{H}_{2}$ from $\mathrm{CO}_{2}$.

Table 3. Gas separation performance of $\mathrm{Cu}$-based $\mathrm{MOF}$ used to prepared mixed matrix membranes (operating conditions ranging within $1-5$ bar, $20-35{ }^{\circ} \mathrm{C}$, unless differently specified).

\begin{tabular}{|c|c|c|c|c|c|c|c|}
\hline Filler & Polymer & $\begin{array}{c}\text { Loading } \\
\text { (wt.\%) }\end{array}$ & $\begin{array}{c}\mathrm{P}_{\mathrm{CO} 2} \\
\text { (Barrer) }\end{array}$ & $\alpha_{\mathrm{CO} 2 / \mathrm{N} 2}$ & $\alpha_{\mathrm{CO} 2 / \mathrm{CH} 4}$ & $\alpha_{\mathrm{CO} 2 / \mathrm{H} 2}$ & Ref. \\
\hline \multirow{4}{*}{$\begin{array}{c}\mathrm{Cu}_{3}(\mathrm{BTC})_{2} \\
10 \mu \mathrm{m}\end{array}$} & Matrimid 9725 & 0 & $0.21^{\mathrm{a}}$ & & 28.0 & & [49] \\
\hline & & 10 & $0.3^{\mathrm{a}}$ & & 30.0 & & \\
\hline & & 20 & $0.41^{\mathrm{a}}$ & & 31.0 & & \\
\hline & & 30 & $0.64^{\mathrm{a}}$ & & 32.5 & & \\
\hline \multirow{2}{*}{$\begin{array}{c}\mathrm{Cu}_{3}(\mathrm{BTC})_{2} \\
6 \mu \mathrm{m}\end{array}$} & $\mathrm{PPO}$ & 0 & 68.9 & 16.1 & 16.2 & 0.92 & [95] \\
\hline & & 10 & 87.2 & 23.8 & 28.2 & 0.94 & \\
\hline \multirow{5}{*}{$\begin{array}{c}\mathrm{Cu}_{3}(\mathrm{BTC})_{2} \\
100 \mathrm{~nm}\end{array}$} & PMP & 0 & 76.1 & 20.5 & 15.2 & 7.5 & [96] \\
\hline & & 5 & 88.3 & 22.2 & 17.1 & 8.1 & \\
\hline & & 10 & 103 & 23.7 & 19.2 & 9.2 & \\
\hline & & 15 & 124 & 25.4 & 22.7 & 10.7 & \\
\hline & & 20 & 144 & 28.6 & 24.3 & 12.2 & \\
\hline \multirow{5}{*}{$\mathrm{Cu}_{3}(\mathrm{BTC})_{2}$} & PEBAX 1657 & 0 & 84.2 & & 16.4 & & [97] \\
\hline & & 5 & 91.4 & & 17.7 & & \\
\hline & & 10 & 102.7 & & 19 & & \\
\hline & & 15 & 128.8 & & 20.5 & & \\
\hline & & 20 & 167.3 & & 19.5 & & \\
\hline \multirow[t]{4}{*}{$\mathrm{NH}_{2}-\mathrm{Cu}_{3}(\mathrm{BTC})_{2}$} & & 5 & 93 & & 18.4 & & \\
\hline & & 10 & 108.8 & & 21 & & \\
\hline & & 15 & 135.2 & & 23.6 & & \\
\hline & & 20 & 170.1 & & 26.2 & & \\
\hline \multirow{4}{*}{ MOP-18 } & Matrimid 5218 & 0 & 7.3 & 30.5 & 32.8 & 0.43 & [98] \\
\hline & & 23 & 9.4 & 27.6 & 23.2 & 0.53 & \\
\hline & & 33 & 14 & 22.9 & 21.8 & 0.63 & \\
\hline & & 44 & 15.6 & 26.0 & 16.4 & 0.70 & \\
\hline MMIF & Matrimid 5218 & 0 & 6.8 & 26.2 & 35.9 & & [6] \\
\hline $50 \mathrm{~nm}$ & & 10 & 8.1 & 27.3 & 36.9 & & \\
\hline \multirow{2}{*}{$200 \mathrm{~nm}$} & & 20 & 8.6 & 27 & 34.6 & & \\
\hline & Matrimid 5218 & 0 & $8.0^{b}$ & & 38.3 & & \\
\hline $50 \mathrm{~nm}$ & & 10 & $9.7^{b}$ & & 81 & & \\
\hline \multirow[t]{2}{*}{$200 \mathrm{~nm}$} & & 20 & $10.1^{\mathrm{b}}$ & & 88 & & \\
\hline & Matrimid 5218 & 0 & $7.1^{\mathrm{c}}$ & 32.3 & & & \\
\hline $50 \mathrm{~nm}$ & & 10 & $8.2^{c}$ & 38.9 & & & \\
\hline $200 \mathrm{~nm}$ & & 20 & $11.7^{\mathrm{c}}$ & 58 & & & \\
\hline CU-BPY-HFS ${ }^{d}$ & Matrimid 5218 & 0 & 7.3 & 33.1 & 34.7 & 0.42 & [99] \\
\hline \multirow[t]{4}{*}{$200-300 \mathrm{~nm}$} & & 10 & 7.81 & 32.5 & 31.9 & 0.46 & \\
\hline & & 20 & 9.88 & 31.9 & 27.6 & 0.59 & \\
\hline & & 30 & 10.36 & 33.4 & 27.4 & 0.51 & \\
\hline & & 40 & 15.06 & 30.7 & 25.5 & 0.56 & \\
\hline
\end{tabular}

a Permeance (GPU); membrane thickness $40-65 \mu \mathrm{m} ;{ }^{\mathrm{b}}$ Equimolar $\mathrm{CO}_{2}-\mathrm{CH}_{4}$ gas mixture; ${ }^{\mathrm{c}}$ Equimolar $\mathrm{CO}_{2}-\mathrm{N}_{2}$ gas mixture; ${ }^{\mathrm{d}} \mathrm{Cu}$-BPY-HFS: Cu-4,4'-bipyridine-hexafluorosilicate. 
According to the results that were obtained from hybrid membranes containing different $\mathrm{Cu}$-based MOFs, the high $\mathrm{CO}_{2}$ uptake capacity leads to high $\mathrm{CO}_{2}$ permeability. Although the increase in the gas transport is proportionally to the MOF content, a limited impact is observed on the selective feature of the hybrid membranes. Interestingly, this effect is more evident when the performance are evaluated through mixed gas permeation, which is presumably due to competitive sorption phenomena. In addition, amine modification appears to be a promising approach to improve the $\mathrm{CO}_{2}$-philic nature of the mixed matrix membranes.

\subsection{Materials Institute Lavoisier MOFs (MILs)}

Material Institute Lavoisier (MILs) is a sub-family of MOFs that is based on trivalent metals strongly bonded to oxygen-anion-terminated linkers. MIL-53 (chemical formula: $\mathrm{M}(\mathrm{OH})\left(\mathrm{O}_{2} \mathrm{C}-\mathrm{C}_{6} \mathrm{H}_{4}-\mathrm{CO}_{2}, \mathrm{M}=\mathrm{Al}^{3+}, \mathrm{Cr}^{3+}\right)$ is made of dicarboxylate ligand interconnected by octahedral chains of $\mathrm{MO}_{4}(\mathrm{OH})_{2}$ and has a 3D porous structure with one-dimensional (1D) diamond-shaped channels [100]. Furthermore, it is characterized by a pore limiting diameter of $\sim 8.5 \AA$ and surface area (Langmuir) of $1500 \mathrm{~m}^{2} / \mathrm{g}[100,101]$. Porous terephthalate MIL-53 showed a promising potential for $\mathrm{H}_{2}$ storage and $\mathrm{CO}_{2}$ capture [101-107]. $\mathrm{CO}_{2}$ adsorption experiments showed that MIL-53 exhibited a two-step sorption isotherm, behavior that was associated to gate opening phenomena. Notably, even though this type of phenomena is typically observed in MOFs at low pressure, in the case of MIL-53, this happened for pressure above 5 bar, determining the two-step shape of the sorption isotherm [100]. Depending on the metal coordinate, different breathing mechanisms have been observed: upon dehydration, for example, MIL-53(Cr) and MIL-53(Fe) have open-pore and closed-pore structures, respectively.

Dorosti et al. [108] incorporated MIL-53 in Matrimid 5218 up to $20 \mathrm{wt} \%$ loading. Strong interactions of $\mathrm{CO}_{2}$ molecule with the oxygen atom of hydroxyl groups present in the MIL-53 structure and the breathing effect resulted in an enhancement of $\mathrm{CO}_{2}$ permeability proportional to the $\mathrm{MOF}$ loading (Table 4). The $\mathrm{CO}_{2} / \mathrm{CH}_{4}$ selectivity showed a significant enhancement from 31 to 51.8 between the 10 and $15 \mathrm{wt}$ \% loading. However, the formation of unselective voids at higher MIL-53 content led to a significant drop of the separation performance. In view of the breathing mechanism that is affecting the MOF framework, for pressure below 3 bar MIL-53 was found to be in its close-form, whereas at higher pressure an open-framework configuration was suggested. Higher MIL-53 contents (33.3 and 37.5 wt.\%) in Matrimid were investigated by Hsieh et al. [109]. They investigated the effect of the reversible structure (closed or open form) on the transport properties. In this regard, MOF dehydrated with high temperature treatment (MIL-53-ht) and characterized by an open-pore structure was compared with as synthesized nanoparticles (MIL-53-as), which presented a closed-pore configuration. At a given loading (37.5 wt.\%) MIL-53-ht showed a higher permeability when compared to the as synthesized MIL, but the selective features were significantly compromised in the open-pore configuration. $\mathrm{CO}_{2} / \mathrm{CH}_{4}$ selectivity as high as 90.1 for $\mathrm{CO}_{2} / \mathrm{CH}_{4}$ was reported for MIL-53-as (Table 4). The significant enhancement was due to the sieving effect produced by the partial blockage of the pores by the BDC linkers, which prevents the permeation of molecules with larger kinetic diameter $\left(\mathrm{CH}_{4}\right.$ and $\left.\mathrm{N}_{2}\right)$. To further prove the effect of the pore structure, MMMs containing MIL-53-lt (activated at $50{ }^{\circ} \mathrm{C}$ ) were shown as a framework transition from close pore form to open pore.

Abedini et al. [110] loaded amine-functionalized MIL-53 (Al) (100 nm size) in Poly(4-methyl-1-pentyne) (PMP) and prepared mixed matrix membranes with loading up to 30 wt.\%. Addition of $\mathrm{NH}_{2}-\mathrm{MIL}-53$ into polymer matrix enhanced both $\mathrm{CO}_{2}$ permeability and $\mathrm{CO}_{2} / \mathrm{CH}_{4}$ selectivity (Table 4 ), which is mainly due to improved $\mathrm{CO}_{2}$ solubility in the hybrid matrix. At higher loading, the membrane performance overcame the Robeson upper bound for $\mathrm{CO}_{2} / \mathrm{CH}_{4}$ separation. In mixed gas, the same trend was observed for selectivity and permeability. However, lower separation performance (10\% lower permeability and 30\% lower selectivity) were observed when mixed gas conditions were investigated, which is possibly due to competitive sorption phenomena. Interestingly, it was observed that the addition of the porous nanoparticles increased the 
$\mathrm{CO}_{2}$-philicity of the hybrid membranes, decreasing the $\mathrm{H}_{2} / \mathrm{CO}_{2}$ selectivity that was observed for the pristine polymer. MIL-53 and amine functionalized $\mathrm{NH}_{2}$-MIL-53 (Al) have also been dispersed in Poly(vinylidene fluoride) (PVDF) [111] and modified PVDF [112]. The modification of PVDF by means of $\mathrm{KOH}$ and $\mathrm{KMNO}_{4}$ appeared to enhance the effect of the nanoparticle to a significant extent (Table 4). The $\mathrm{CO}_{2}$ permeability doubled and the $\mathrm{CO}_{2} / \mathrm{CH}_{4}$ selectivity showed a notable enhancement $(+50 \%)$ at $10 \mathrm{wt} . \%$ loading, with a minor effect being observed for modified and unmodified nanoparticles. In the case of pristine PVDF, a 50\% enhancement of the $\mathrm{CO}_{2}$ permeability was associated with small influence on the selective feature of the hybrid membranes.

Aiming at improving the interfacial interaction between MIL-53 and the polymer matrix, Tien-Binh et al. [113] introduced hydroxyl group into 6FDA-DAM polyimide backbone. 6FDA-(DAM)-(HAB) $\mathrm{x}: \mathrm{y}$ copolymer ( $\mathrm{x}$ and $\mathrm{y}$ denoted the copolymer ratio) containing hydroxyl groups facilitated the dispersion of MIL-53 (Al) and $\mathrm{NH}_{2}-\mathrm{MIL}-53(\mathrm{Al})$. Single gas and mixed gas $\left(\mathrm{CO}_{2} / \mathrm{CH}_{4}\right.$ 50:50) separation performances were investigated for the mixed matrix membranes varying the copolymer ratio. Gas permeation characterization showed that the incorporation of pristine MIL-53 resulted in an increase in $\mathrm{CO}_{2}$ permeability for both homopolymer and copolymers with increasing the MIL loading, with the effect becoming more influential for the low permeable samples (i.e., increasing the DAM/HAB ratio, Table 4). The formation of interfacial voids is suggested to be responsible for the observed variations. On the other hand, when modified MIL-53 was used a different behavior is observed: a minimum was observed for the $\mathrm{CO}_{2}$ permeability at $15 \mathrm{wt} . \%$ loading, whereas the $\mathrm{CO}_{2} / \mathrm{CH}_{4}$ selectivity was optimized at $10 \mathrm{wt} . \%$ loading. In view of the favorable interactions between the hydroxyl and the amine group, the increase in selectivity became more significant at a higher DAM/HAB ratio, also reducing the negative effect on the $\mathrm{CO}_{2}$ transport across the hybrid membranes. SEM images supported this observation. Zhu et al. [114] investigated the performance of thin film hollow fiber mixed matrix membranes filled with post-modified MIL-53 (P-MIL-53). Asymmetric hollow fibers (Ultem) coated were used as support and PDMS containing different MIL-53 content was used as selective layer. The obtained results showed that the membranes containing 15\% P-MIL-53 showed the best performance: the $\mathrm{CO}_{2}$ permeance was improved from 30 GPU to 40 GPU when compared to hollow fiber membranes coated with only pure PDMS. At $15 \%$ loading, the ideal selectivity increased from 23.3 to 28.1 for $\mathrm{CO}_{2} / \mathrm{N}_{2}$ and from 27 to 32 for $\mathrm{CO}_{2} / \mathrm{CH}_{4}$. This was mainly attributed to the strong affinity with $\mathrm{CO}_{2}$ due to dipole-quadrupole interaction of $\mathrm{CO}_{2}$ molecules with $\mathrm{NH}_{2}$ groups in the MOF. At 20 wt.\% loading, a decrease in $\mathrm{CO}_{2} / \mathrm{N}_{2}$ and $\mathrm{CO}_{2} / \mathrm{CH}_{4}$ ideal selectivity was observed, which is mainly ascribed to particle agglomeration.

MIL-101 is another MOF from the MILs' family, widely studied for gas separation application [115]. The MIL-101 framework is composed of chromium atoms making an octahedral framework with oxygen atoms and 1.4-benzene dicarboxilate (BDC) ligands. The rigid terephthalate ligand together with trimeric chromium octahedral clusters provides window aperture of $8.5 \AA$ and accessible large cages. The gas sorption analysis showed that a Langmuir surface area of $5900 \mathrm{~m}^{2} / \mathrm{g}$ [115]. Similar to MIL-53, the removal of water molecules from the structure leaves unsaturated open metal sites in the MIL-101 structure [101].

Naseri et al. [116] recently reported the gas separation performance of hybrid Matrimid membranes containing MIL-101 (Cr) up to $30 \mathrm{wt} . \%$ loading $\left(10 \mathrm{bar}\right.$ and $\left.35^{\circ} \mathrm{C}\right)$. The presence of MIL-101 in the polymer matrix enhanced the $\mathrm{CO}_{2}$ permeability (Table 4), with the main contribution coming from the increase in $\mathrm{CO}_{2}$ solubility within the hybrid matrices. The ideal $\mathrm{CO}_{2} / \mathrm{CH}_{4}$ and $\mathrm{CO}_{2} / \mathrm{N}_{2}$ selectivity showed a maximum at low loading $(10 \mathrm{wt} . \%)$ and the drop of selective features at higher loading is mainly attributed to the presence of non-selective voids at the polymer/particles interface. The effect of addition of MIL-101(Cr) on the separation performance of a blend of Matrimid and PVDF was investigated by Rajati et al. [117]. $3 \mathrm{wt} . \%$ PVDF in Matrimid was selected as the most suitable blend composition for $\mathrm{CO}_{2} / \mathrm{CH}_{4}$ separation, which showed higher $\mathrm{CO}_{2}$ permeability $(28 \%)$ and selectivity (22\%) when compared to pristine Matrimid. The embedment of $10 \mathrm{wt} \% \mathrm{MIL}-101$ showed a similar effect on both the pristine polymer matrix and the polymer blend, with about $60 \%$ 
increase in $\mathrm{CO}_{2}$ permeability and $40 \%$ higher selective features. The simultaneous enhancement of permeability and selectivity suggested the presence of a proper interface morphology. Additionally, the electrostatic interaction of functional groups in MIL-101 with $\mathrm{CO}_{2}$ resulted in better affinity and higher solubility.

MOFs-derived porous carbons (PC) based on MIL-101(Cr) and MIL-53(Al) were prepared by soaking the MOFs into $\mathrm{NH}_{4} \mathrm{OH}$ and carbamide, followed by calcination at $800^{\circ} \mathrm{C}$ [118]. The carbonized MOFs were embedded into PPO-PEG at a loading range between 5 and $25 \mathrm{wt} . \%$. For both nanoparticles, limited changes in $\mathrm{CO}_{2}$ permeability were observed up to $20 \mathrm{wt}$.\% loading, but a marked improvement was observed at $25 \mathrm{wt} . \%$ loading, achieving promising permeability values (Table 4). MIL-101(Cr)-PC showed a better performance (1896 Barrer) when compared to MIL-53(Al)-PC (1266 Barrer). The selectivity showed also an improvement, and the optimum at $20 \mathrm{wt} . \%$ MIL content clearly suggested that higher loading probably generated interfacial voids and particle agglomeration. However, unlike the effect on permeability, MIL-53(Al)-PC showed higher selective feature when compared to MIL-101(Cr)-PC.

An interesting approach to optimize the performance of mixed matrix membranes is represented by the use of mixed MOFs [119]. A mixture of MIL-101/ZIF-8 was homogenously dispersed in PSF and no agglomeration was observed. The MMMs performance showed an enhancement in $\mathrm{CO}_{2}$ permeability as a function of filler loading, and the simultaneous presence of both MIL and ZIF nanoparticles showed a synergetic effect. At $35 \mathrm{wt} . \%$ MOF loading, the $\mathrm{CO}_{2}$ permeability was significantly increased (six-fold) when compared to the pristine PSF, from 5 Barrer to 30 Barrer. This was explained as increasing free volume of polymer associated to a disruption of the polymeric chains, together with the larger pore size of MIL-101. At an intermediate loading, $16 \mathrm{wt} . \%$, the $\mathrm{CO}_{2} / \mathrm{CH}_{4}$ separation factor was increased from 23 to 40 as compared to pristine PSF. Higher loading, $35 \mathrm{wt} . \%$, led to a selectivity drop, due to poor interface morphology. The authors suggested that the coexistence of ZIF-8 and MIL-101 improved the dispersion and avoided agglomeration at low particles loading.

Finally, an interesting use of MILs as MOF scaffold (MS) has been proposed by Xie et al. [120], where the separation performance of membranes obtained from MOFs and PEG (MSP) were investigated for post combustion $\mathrm{CO}_{2}$ capture $\left(\mathrm{CO}_{2} / \mathrm{N}_{2}\right.$ 10/90). Firstly, the MS membranes were fabricated on a support; then, coatings with different PEG concentration were applied to prepare the MSP membranes. The MS membranes showed extremely high $\mathrm{CO}_{2}$ permeance (85000 GPU), but no selective feature. Upon the application of PEG coating (PEG concentration $>0.6 \mathrm{mmol} / 5 \mathrm{~mL}$ aqueous solution) suitable selectivity value $(>30)$ were achieved, maintaining high $\mathrm{CO}_{2}$ permeability $(>2700$ Barrer). It was suggested that the coated polymer provides a defect free membrane and a shorter path for $\mathrm{CO}_{2}$ transport.

Table 4. Gas separation performance of MIL-based mixed matrix membranes (operating conditions ranging within $1-5$ bar, $20-35{ }^{\circ} \mathrm{C}$, unless differently specified).

\begin{tabular}{|c|c|c|c|c|c|c|c|}
\hline Filler & Polymer & $\begin{array}{c}\text { Loading } \\
\text { (wt.\%) }\end{array}$ & $\begin{array}{c}P_{\mathrm{CO} 2} \\
\text { (Barrer) }\end{array}$ & $\alpha_{\mathrm{CO} 2 / \mathrm{N} 2}$ & $\alpha_{\mathrm{CO} 2 / \mathrm{CH} 4}$ & $\alpha_{\mathrm{CO} 2 / \mathrm{H} 2}$ & Ref. \\
\hline & Matrimid 5218 & 0 & 6.2 & & 28.2 & & [108] \\
\hline MIL-53 (Al) & & 5 & 6.8 & & 29.6 & & \\
\hline \multirow[t]{4}{*}{$123-466 \mathrm{~nm}$} & & 10 & 7.45 & & 31 & & \\
\hline & & 15 & 12.43 & & 51.8 & & \\
\hline & & 20 & 14.52 & & 15.1 & & \\
\hline & Matrimid 5218 & 0 & 8.4 & 33.6 & 39.4 & 0.33 & [109] \\
\hline MIL-53-as ${ }^{\text {a }}$ & & 37.5 & 40 & 95.2 & 90.1 & 0.55 & \\
\hline MIL-53-ht & & 33.3 & 26.6 & 42.9 & 45.7 & 0.50 & \\
\hline $50-100 \mathrm{~nm}$ & & 37.5 & 51 & 28.3 & 47.0 & 0.60 & \\
\hline
\end{tabular}


Table 4. Cont.

\begin{tabular}{|c|c|c|c|c|c|c|c|}
\hline Filler & Polymer & $\begin{array}{l}\text { Loading } \\
\text { (wt. \%) }\end{array}$ & $\begin{array}{c}P_{\mathrm{CO} 2} \\
\text { (Barrer) }\end{array}$ & $\alpha_{\mathrm{CO} 2 / \mathrm{N} 2}$ & $\alpha_{\mathrm{CO} 2 / \mathrm{CH} 4}$ & $\alpha_{\mathrm{CO} 2 / \mathrm{H} 2}$ & Ref. \\
\hline \multirow{7}{*}{$\begin{array}{c}\mathrm{NH}_{2}-\mathrm{MIL}-53(\mathrm{Al}) \\
110 \mathrm{~nm}\end{array}$} & \multirow[t]{7}{*}{ PMP } & 0 & 98.74 & & 8.72 & & \multirow[t]{7}{*}{ [110] } \\
\hline & & 5 & 107.32 & & 11.85 & & \\
\hline & & 10 & 118.74 & & 12.59 & & \\
\hline & & 15 & 139.56 & & 15.72 & & \\
\hline & & 20 & 164.78 & & 18.46 & & \\
\hline & & 25 & 203.44 & & 20.18 & & \\
\hline & & 30 & 226.37 & & 20.36 & & \\
\hline & \multirow[t]{5}{*}{ PVDF } & 0 & 0.92 & 16.3 & 21.3 & & \multirow[t]{5}{*}{ [111] } \\
\hline MIL-53 & & 5 & 1.21 & 16.3 & 21.2 & & \\
\hline $100 \mathrm{~nm}$ & & 10 & 1.55 & 16.2 & 21.0 & & \\
\hline \multirow{3}{*}{$\begin{array}{c}\mathrm{NH}_{2}-\mathrm{MIL}-53(\mathrm{Al}) \\
100 \mathrm{~nm}\end{array}$} & & 5 & 1.11 & 17.3 & 23.1 & & \\
\hline & & 10 & 1.41 & 19.5 & 26.0 & & \\
\hline & \multirow[t]{5}{*}{$\mathrm{m}-\mathrm{PVDF}{ }^{\mathrm{b}}$} & 0 & 1.2 & & 27.9 & & \multirow[t]{5}{*}{ [112] } \\
\hline MIL-53 & & 5 & 1.75 & & 35.8 & & \\
\hline $100 \mathrm{~nm}$ & & 10 & 2.45 & & 39.6 & & \\
\hline $\mathrm{NH}_{2}-\mathrm{MIL}-53$ & & 5 & 1.69 & & 37.6 & & \\
\hline $100 \mathrm{~nm}$ & & 10 & 2.24 & & 43.2 & & \\
\hline \multirow{13}{*}{$\begin{array}{l}\text { MIL-53 (Al) } \\
190-340 \mathrm{~nm}\end{array}$} & \multirow{6}{*}{$\begin{array}{c}\text { 6FDA-(DAM)-(HAB) } \\
2: 1\end{array}$} & 0 & $316.6^{c}$ & & 9.76 & & \multirow[t]{28}{*}{ [113] } \\
\hline & & 10 & $331.9^{c}$ & & 10.19 & & \\
\hline & & 15 & $354.0^{\mathrm{c}}$ & & 11.46 & & \\
\hline & & 0 & $115.7^{c}$ & & 21.65 & & \\
\hline & & 10 & $124.2^{c}$ & & 24.62 & & \\
\hline & & 15 & $134.5^{c}$ & & 26.96 & & \\
\hline & $\begin{array}{c}\text { 6FDA-(DAM)-(HAB) } \\
1: 1\end{array}$ & 0 & $46.8^{\mathrm{c}}$ & & 34.39 & & \\
\hline & & 10 & $55.3^{c}$ & & 37.15 & & \\
\hline & & 15 & $63.0^{\mathrm{c}}$ & & 40.76 & & \\
\hline & $\begin{array}{c}\text { 6FDA-(DAM)-(HAB) } \\
1: 2\end{array}$ & 0 & $19.6^{c}$ & & 43.1 & & \\
\hline & & 10 & $33.2^{\mathrm{c}}$ & & 47.13 & & \\
\hline & & 15 & $42.6^{\mathrm{c}}$ & & 48.83 & & \\
\hline & 6FDA-(DAM) & 0 & $316.2^{c}$ & & 9.77 & & \\
\hline \multirow{16}{*}{$\begin{array}{l}\mathrm{NH}_{2}-\mathrm{MIL}-53(\mathrm{Al}) \\
100-200 \mathrm{~nm}\end{array}$} & & 10 & 308.9 & & 13.63 & & \\
\hline & & 15 & $290.7^{c}$ & & 14.77 & & \\
\hline & \multirow{5}{*}{$\begin{array}{c}\text { 6FDA-(DAM)-(HAB) } \\
2: 1\end{array}$} & 20 & $299.8^{c}$ & & 8.86 & & \\
\hline & & 0 & $115.7^{c}$ & & 21.81 & & \\
\hline & & 10 & $112.1^{c}$ & & 43.63 & & \\
\hline & & 15 & $105.7^{c}$ & & 36.13 & & \\
\hline & & 20 & $122.1^{\mathrm{c}}$ & & 29.31 & & \\
\hline & \multirow{4}{*}{$\begin{array}{c}\text { 6FDA-(DAM)-(HAB) } \\
1: 1\end{array}$} & 0 & $47.4^{c}$ & & 34.54 & & \\
\hline & & 10 & $43.7^{c}$ & & 77.72 & & \\
\hline & & 15 & $44.6^{\mathrm{c}}$ & & 64.54 & & \\
\hline & & 20 & $54.7^{\mathrm{c}}$ & & 35.68 & & \\
\hline & \multirow{4}{*}{$\begin{array}{c}\text { 6FDA-(DAM)-(HAB) } \\
1: 2\end{array}$} & 0 & $24.6^{c}$ & & 53.86 & & \\
\hline & & 10 & $20.0^{c}$ & & 86.81 & & \\
\hline & & 15 & $21.9^{\mathrm{c}}$ & & 96.36 & & \\
\hline & & 20 & $31.9^{\mathrm{c}}$ & & 55.9 & & \\
\hline & PDMS & 0 & 30 & 23.3 & 27.0 & 0.22 & [114] \\
\hline P-MIL-53 & & 5 & 33.3 & 24.5 & 28.8 & & \\
\hline \multirow[t]{3}{*}{$500 \mathrm{~nm}$} & & 10 & 36.0 & 25.8 & 30.5 & \multirow[t]{3}{*}{0.24} & \\
\hline & & 15 & 40.3 & 28.1 & 32.1 & & \\
\hline & & 20 & 42.3 & 27.5 & 28.4 & & \\
\hline
\end{tabular}


Table 4. Cont.

\begin{tabular}{|c|c|c|c|c|c|c|c|}
\hline Filler & Polymer & $\begin{array}{c}\text { Loading } \\
\text { (wt.\%) }\end{array}$ & $\begin{array}{c}P_{\mathrm{CO} 2} \\
\text { (Barrer) }\end{array}$ & $\alpha_{\mathrm{CO} 2 / \mathrm{N} 2}$ & $\alpha_{\mathrm{CO} 2 / \mathrm{CH} 4}$ & $\alpha_{\mathrm{CO} 2 / \mathrm{H} 2}$ & Ref. \\
\hline & Matrimid $5218^{d}$ & 0 & 4.44 & 34 & 35 & & [116] \\
\hline MIL-101(Cr) & & 10 & 6.95 & 52 & 56 & & \\
\hline \multirow{4}{*}{$\sim 1000 \mathrm{~nm}$} & & 15 & 5.7 & 44 & 47 & & \\
\hline & & 20 & 5.85 & 42 & 37 & & \\
\hline & & 30 & 7.99 & 47 & 44 & & \\
\hline & Matrimid $5218^{\mathrm{f}}$ & 0 & 7.33 & & 34.9 & & [117] \\
\hline \multirow[t]{2}{*}{ MIL-101(Cr) } & & 10 & 12.01 & & 52.21 & & \\
\hline & Matrimid/PVDF ${ }^{\mathrm{f}}$ & 0 & 9.42 & & 42.81 & & \\
\hline \multirow[t]{2}{*}{ MIL-101(Cr) } & & 10 & 14.87 & & 62 & & \\
\hline & PPO-PEG c,e & 0 & 657 & & 18.42 & & [118] \\
\hline MIL-53(Al)-PC & & 5 & 684 & & 25.51 & & \\
\hline \multirow[t]{4}{*}{ 200-250 nm } & & 10 & 723.6 & & 29.23 & & \\
\hline & & 15 & 763 & & 35.78 & & \\
\hline & & 20 & 789 & & 40.39 & & \\
\hline & & 25 & 1266 & & 31.53 & & \\
\hline MIL-101(Cr)-PC & PPO-PEG ${ }^{c, e}$ & 0 & 657 & & 19.26 & & \\
\hline \multirow[t]{6}{*}{ 50-100 nm } & & 5 & 771 & & 22.93 & & \\
\hline & & 10 & 874 & & 26.61 & & \\
\hline & & 15 & 952 & & 30.46 & & \\
\hline & & 20 & 1056 & & 34.66 & & \\
\hline & & 25 & 1896 & & 29.24 & & \\
\hline & PSF & 0 & 5 & & 23 & & [119] \\
\hline MIL-101 & & 8 & 8 & & 21 & & \\
\hline \multirow[t]{2}{*}{$110-400 \mathrm{~nm}$} & & 16 & 8.9 & & 24 & & \\
\hline & & 24 & 18.1 & & 28 & & \\
\hline ZIF-8 & & 0 & 5 & & 23 & & \\
\hline \multirow[t]{3}{*}{$75-100 \mathrm{~nm}$} & & 8 & 10 & & 35 & & \\
\hline & & 16 & 14 & & 22 & & \\
\hline & & 24 & 24 & & 24 & & \\
\hline \multirow[t]{5}{*}{ MIL-101/ZIF-8 } & & 0 & 4.7 & & 23 & & \\
\hline & & 8 & 10.6 & & 36 & & \\
\hline & & 16 & 14.2 & & 40 & & \\
\hline & & 24 & 24 & & 26 & & \\
\hline & & 35 & 29.6 & & 24 & & \\
\hline
\end{tabular}

a as = as synthesized, "ht" = high temperature treated $\left(300{ }^{\circ} \mathrm{C}\right) ;{ }^{\mathrm{b}} \mathrm{m}-\mathrm{PVDF}=$ modified poly(vinylidene fluoride);

${ }^{c}$ mixed gas conditions; ${ }^{d}$ feed side pressure $=10$ bar; ${ }^{e}$ PPO-PEG = polyphenylene oxide-polyethylene glycol; ${ }^{f}$ feed pressure $=7$ bar; ${ }^{g}$ Permeance (GPU); ${ }^{\text {h }}$ MSxPy: MOFs Scaffold.

Similar to the previous MOFs, the MILs' family also represents a group of nanoporous particles that is suitable for the development of mixed matrix membranes for $\mathrm{CO}_{2}$ capture. The $\mathrm{CO}_{2}$ permeability is frequently found to increase along with the loading, but a loading range between 10 and $15 \mathrm{wt} . \%$ appears to be the one that is able to optimize the selective feature of the hybrid membranes. Favorable interactions with the polymeric matrix act in the direction of enhancing the $\mathrm{CO}_{2}$-philicity of the mixed matrix membranes. The closed-pore structure appears to be the most suitable one for the achievement of improved separation performance; whereas, the open-pore structure is expected to enhance the gas transport through the hybrid matrix, thus possibly compromising the selectivity.

\subsection{Other MOFs}

Fe-BTC is reported to be a low cost and water stable MOF type that exhibits a pore size between 5.5 and $8.6 \AA$ and a relatively higher surface area when compared to its $\mathrm{Cu}$ counterpart. Despite the lower uptake capacity when compared to $\mathrm{Cu}-\mathrm{BTC}$, the presence of a large number of coordinatively unsaturated sites and high water stability make the $\mathrm{MOF}$ a suitable candidate for the fabrication of mixed matrix membranes for $\mathrm{CO}_{2}$ separation. Fine Fe-BTC particles were dispersed in Matrimid 5218 matrix to prepare hybrid membranes, and the effect of the fillers on the gas transport properties and plasticization behaviour were investigated [121]. While limited effects were observed in single gas tests (Table 5), under mixed gas and high pressure ( 40 bar) conditions, the $\mathrm{CO}_{2}$ permeability increased 
by $30 \%$ and $\mathrm{CO}_{2} / \mathrm{CH}_{4}$ selectivity by $62 \%$ when compared to the neat polymer. The chain rigidity of the MOF also contributed to enhance the plasticization resistance of the hybrid membrane up to 20 bar. The effect of Fe-BTC filler on the transport properties of Matrimid has also been studied by Rita et al. [122]. The study revealed that gas diffusivity changes with increasing temperature dominated the drop in solubility, leading to an overall increase in $\mathrm{CO}_{2}$ permeability from 94.2 Barrer at $303 \mathrm{~K}$ to 217.9 Barrer at $353 \mathrm{~K}$ with a $30 \mathrm{wt} . \% \mathrm{MOF}$ loading. Interestingly, the $\mathrm{CO}_{2} / \mathrm{N}_{2}$ selectivity of the matrix increased on a similar scale with temperature increase. The effect of Fe-BTC on rubbery PEBAX 1657 for gas permeation was studied by Dorosti and Alizadehdakhel [123]. Both single gas and mixed gas $\left(\mathrm{CO}_{2} / \mathrm{CH}_{4}\right)$ tests revealed a four-time increase in $\mathrm{CO}_{2}$ permeability when compared to the neat polymer (Table 5). The gas selective feature of the hybrids showed a minor increase as compared to the pristine polymer, but a significant drop is observed at $40 \mathrm{wt} . \%$ loading due to the formation of non-selective voids. Differently from what has been observed for the glassy polyimide, the increase in feed pressure led to plasticization phenomena, and consequently to a drop in selectivity.

A new sorption selective, chemically stable, fluorinated MOF NbOFFIVE-1-Ni (KAUST-7) was developed by Cadiau et al. [124]. KAUST-7 showed an apparent pore size of $4.75 \AA$ and a $\mathrm{CO}_{2}$ sorption capacity of $2.2 \mathrm{mmol} / \mathrm{g}$ at $25^{\circ} \mathrm{C}$ and 1 bar. Recently, Chen et al. [125] synthesized nanosized KAUST-7 crystals by novel co-solvent synthesis method (Figure 7) and dispersed them in 6FDA-Durene matrix. The $\mathrm{CO}_{2}$ permeability increased along with the loading from 750 (pristine polymer) to 1038 (33 wt.\% loading) Barrer (Table 5). The selectivity marginally increased due to both increase in solubility selectivity and diffusivity selectivity. Additionally, interactions between the organic ligand and the groups of 6FDA increased compatibility, leading to enhanced plasticization resistance up to 10 bar, with a minor reduction in $\mathrm{CO}_{2} / \mathrm{CH}_{4}$ selectivity of $33 \% \mathrm{MOF}$ loaded matrix.

Bimetallic MOFs, like $\mathrm{Mg}_{2}$ (dobdc), contain many open metal sites along the pore walls facilitating a selective adsorption and transport of $\mathrm{CO}_{2}$. Bae and Long [126] developed a facile synthesis method to produce $100 \mathrm{~nm}$ primary crystals of $\mathrm{Mg}_{2}(\mathrm{dodbc})$ and successfully incorporated them in three different polymer matrices: PDMS, crosslinked-PEO, and 6FDA-TMPDA (polyimide). The study revealed that the MOF had a negative effect on the gas transport through the rubbery polymers (Table 5), possibly due to the plugging of the MOF pores by the rubbery polymer chains. On the other hand, a simultaneous enhancement of both $\mathrm{CO}_{2}$ permeability and $\mathrm{CO}_{2} / \mathrm{N}_{2}$ selectivity was observed for the glassy polyimide (Table 5). It was shown that the variation was mainly associated to the increase in $\mathrm{CO}_{2}$ solubility, with minor effects on the gas diffusion through the selective layer. A similar study by Smith et al. [127] proved that the addition of $\mathrm{Mg}_{2}$ (dobdc) to 6FDA-Durene increased the permeability of $\mathrm{CO}_{2}, \mathrm{~N}_{2}, \mathrm{H}_{2}$, and $\mathrm{CH}_{4}$ due to the increase in diffusivity of the penetrants. It was observed that the MOF particles further increased the brittleness of the films due to densification. By changing the coordination site, $\mathrm{Ni}_{2}$ (dodbc) was fabricated and it was found to improve the mechanical robustness, owing to smaller primary particle size. Both bimetallic MOFs were found to improve the performance in separations governed by diffusivity differentials, like $\mathrm{H}_{2} / \mathrm{CH}_{4}$ and $\mathrm{H}_{2} / \mathrm{N}_{2}$ when compared to $\mathrm{CO}_{2} / \mathrm{CH}_{4}$ and $\mathrm{CO}_{2} / \mathrm{N}_{2}$ separations that require both solubility and diffusivity enhancement.

Table 5. Gas separation performance of different MOFs (Fe(BTC), KAUST-7, $\mathrm{Mg}_{2}$ (dobdc)) used to prepared mixed matrix membranes (operating conditions ranging within $1-5 \mathrm{bar}, 20-35{ }^{\circ} \mathrm{C}$, unless differently specified).

\begin{tabular}{|c|c|c|c|c|c|c|c|}
\hline Filler & Polymer & $\begin{array}{l}\text { Loading } \\
\text { (wt.\%) }\end{array}$ & $\begin{array}{c}\mathrm{P}_{\mathrm{CO} 2} \\
\text { (Barrer) }\end{array}$ & $\alpha_{\mathrm{CO} 2 / \mathrm{N} 2}$ & $\alpha_{\mathrm{CO} 2 / \mathrm{CH} 4}$ & $\alpha_{\mathrm{CO} 2 / \mathrm{H} 2}$ & Ref. \\
\hline \multirow{4}{*}{$\mathrm{Fe}(\mathrm{BTC})$} & Matrimid 5218 & 0 & 9 & & 25 & & [121] \\
\hline & & 10 & 9.5 & & 27.5 & & \\
\hline & & 20 & 10.8 & & 28 & & \\
\hline & & 30 & 13.1 & & 29.5 & & \\
\hline
\end{tabular}


Table 5. Cont.

\begin{tabular}{|c|c|c|c|c|c|c|c|}
\hline Filler & Polymer & $\begin{array}{l}\text { Loading } \\
\text { (wt.\%) }\end{array}$ & $\begin{array}{c}\mathrm{P}_{\mathrm{CO} 2} \\
\text { (Barrer) }\end{array}$ & $\alpha_{\mathrm{CO} 2 / \mathrm{N} 2}$ & $\alpha_{\mathrm{CO} 2 / \mathrm{CH} 4}$ & $\alpha_{\mathrm{CO} 2 / \mathrm{H} 2}$ & Ref. \\
\hline & Matrimid $5218^{a}$ & 0 & 14.6 & 4.4 & & & [122] \\
\hline $\mathrm{Fe}(\mathrm{BTC})$ & & 10 & 84.9 & 43.5 & & & \\
\hline \multirow[t]{2}{*}{$10-20$ um } & & 20 & 91.2 & 15.4 & & & \\
\hline & & 30 & 217.9 & 23.1 & & & \\
\hline \multirow{13}{*}{$\mathrm{Fe}(\mathrm{BTC})$} & Pebax 1657 & 0 & 70.67 & & 18.4 & & [123] \\
\hline & & 5 & 80.79 & & 19.3 & & \\
\hline & & 10 & 82.32 & & 19.4 & & \\
\hline & & 15 & 89.63 & & 20.8 & & \\
\hline & & 20 & 98.32 & & 22.2 & & \\
\hline & & 25 & 148.44 & & 21.9 & & \\
\hline & & 30 & 402.69 & & 21.5 & & \\
\hline & & 40 & 425.5 & & 12.3 & & \\
\hline & & 0 & $60.35^{b}$ & & 16.9 & & \\
\hline & & 10 & $70.11^{\mathrm{b}}$ & & 17.6 & & \\
\hline & & 20 & $85.28^{b}$ & & 19.3 & & \\
\hline & & 30 & $329.7^{b}$ & & 20.5 & & \\
\hline & & 40 & $345.4^{\mathrm{b}}$ & & 13.1 & & \\
\hline \multirow{4}{*}{$\begin{array}{l}\text { KAUST-7 } \\
80 \mathrm{~nm}\end{array}$} & 6FDA Durene & 0 & $759.7^{b}$ & & 34.7 & & [125] \\
\hline & & 11 & $895.7^{\mathrm{b}}$ & & 36.2 & & \\
\hline & & 22 & $966.9^{b}$ & & 37.0 & & \\
\hline & & 33 & $1038.1^{b}$ & & 37.6 & & \\
\hline \multirow{6}{*}{$\begin{array}{c}\mathrm{Mg}_{2}(\mathrm{dobdc}) \\
100 \mathrm{~nm}\end{array}$} & PDMS & 0 & 3100.0 & 9.5 & & & [126] \\
\hline & & 20 & 2100.0 & 12 & & & \\
\hline & XLPEO & 0 & 380.0 & 22 & & & \\
\hline & & 10 & 250.0 & 25 & & & \\
\hline & 6FDA-TMPDA & 0 & 650.0 & 14 & & & \\
\hline & & 10 & 850.0 & 23 & & & \\
\hline
\end{tabular}

${ }^{\text {a }}$ Temperature $=80^{\circ} \mathrm{C}^{\text {b }}$ Mixed gas $\mathrm{CO}_{2} / \mathrm{CH}_{4} 10 / 90$.
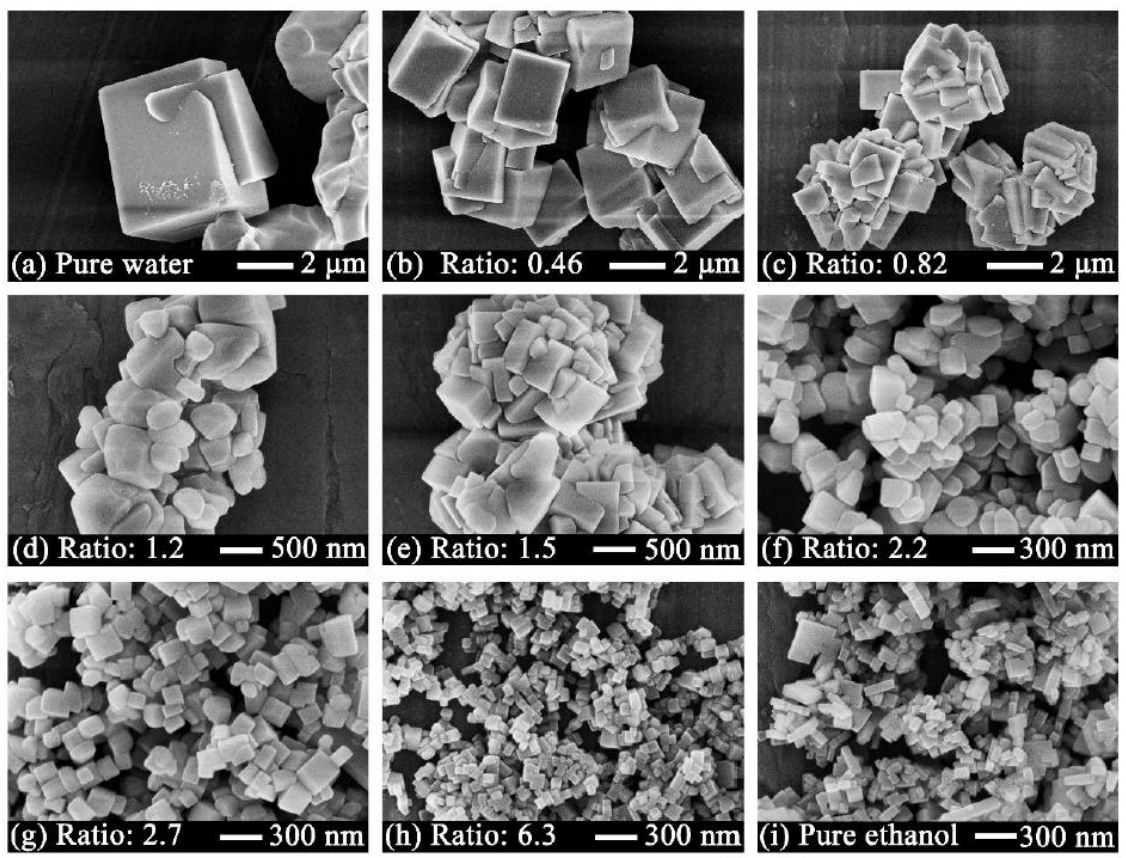

Figure 7. Fine-tuning crystal size of KAUST-7 by varying ethanol-water (solvent) ratios in synthesis solution: (a) pure water, ethanol/water ratio of (b) 0.46, (c) 0.82, (d) 1.2, (e) 1.5, (f) 2.2, (g) 2.7, (h) 6.3, and (i) pure ethanol [125], with copyright permission from (c) 2018 Elsevier. 


\section{Porous Organic Frameworks (POFs)}

Metal-organic frameworks have drawn considerable attention for their tunable chemistry and gas separation and storage performance, many MOFs suffer from the lack of chemical and physical stability. In addition, their limited sorption capacity and the presence of heavy metal ions in their framework have posed obstacles for their prospective applications [128]. Recently, a new class of porous materials known as porous organic frameworks (POFs) has attracted great attention as an alternative to MOFs. POFs can be either crystalline, such as covalent organic frameworks (COFs), or amorphous with uniform pore diameter, such as porous aromatic frameworks (PAFs) [129,130]. Due to the entirely organic structure, POFs ensure good adhesion with organic polymer phase and display better chemical compatibility [129]. PAF-1 (Figure 8) was synthesized and characterized for the first time in 2009, with the scope of exploring its potential as adsorbent [131]. PAFs have a local diamond-shape with tetrahedral bonding of tetraphenylene methane in their main building block. The exceptional surface area (Langmuir surface area of $7100 \mathrm{~m}^{2} / \mathrm{g}$ ) of PAFs has shown excellent sorption capacity for hydrogen and carbon dioxide (i.e. $1300 \mathrm{mg} / \mathrm{g} \mathrm{CO} 2$ uptake at $25^{\circ} \mathrm{C}$ and 40 bar). Furthermore, they are characterized by super hydrophobicity, enhanced adsorption enthalpies, and delocalized charged surface [128,131]. Thermal analysis of PAFs exhibited that the structural integrity remained intact up to $520{ }^{\circ} \mathrm{C}$ in air and after water boiling point for seven days [131]. The pore size distribution of PAF-1 displays a pore diameter of $1.4 \mathrm{~nm}$, which can be tuned via activated carbonization to $0.79,0.93,0.64$, and $0.6 \mathrm{~nm}$ while using $\mathrm{KOH}, \mathrm{NaOH}, \mathrm{CO}_{2}$, and $\mathrm{N}_{2}$ as an activation agent, respectively [132]. Furthermore, a Monte Carlo simulation study suggested that a nitrogen-doped PAF (NPAF-11) containing imidazolic group improves the $\mathrm{CO}_{2}$ uptake more than $130 \%$ when compared to PAF-1 [133].

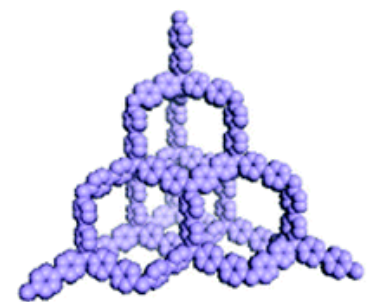

PAF-1
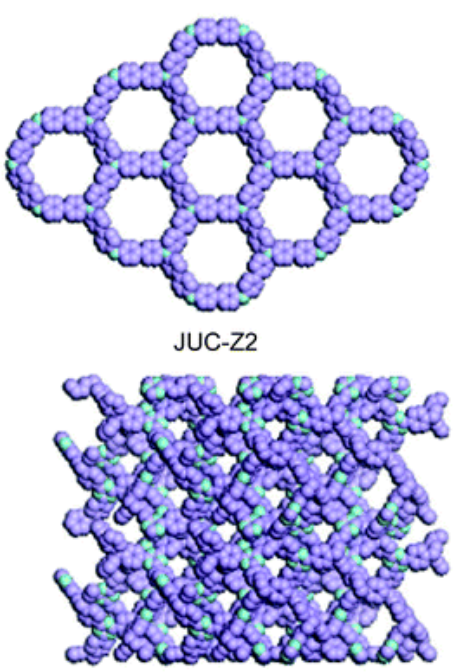

PAF-2

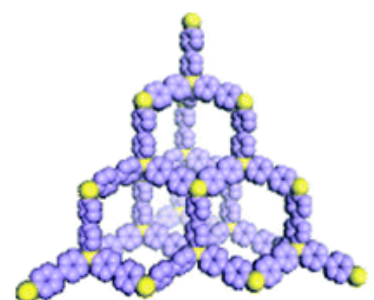

PAF-3

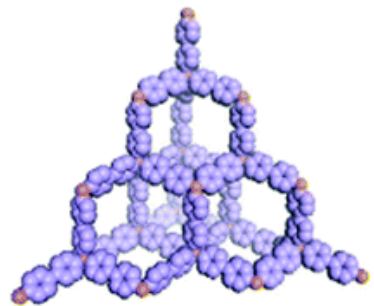

PAF-4
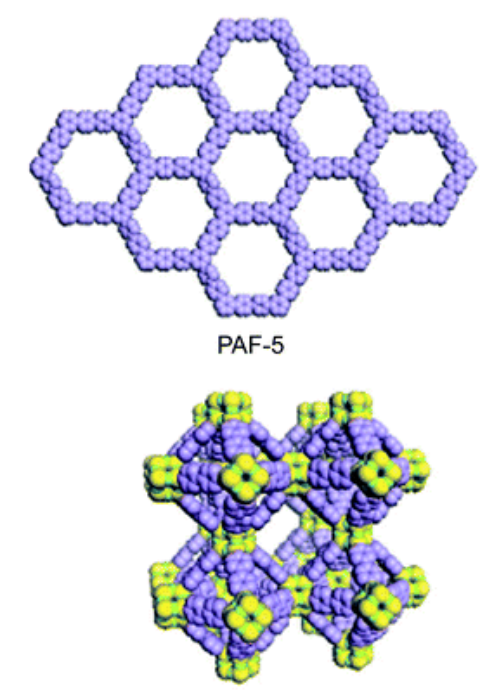

JUC-Z1

Figure 8. Structure model of synthesized and simulated porous aromatic frameworks. Atom colors: $\mathrm{C}=$ purple, $\mathrm{N}$ = blue, $\mathrm{Si}=$ yellow, $\mathrm{O}$ = green, $\mathrm{Ge}=$ brown [134], with copyright permission from (C) 2012, Royal Society of Chemistry. 
The non-equilibrium nature of glassy polymers makes them subject to physical aging, which tends to reduce their fractional free volume over time, and thus, the gas permeability coefficient. Porous organic frameworks have been reported to have the ability to play as an anti-aging filler, as they can freeze the nanostructural morphology, slowing down the aging process to a significant extent. Lau et al. [135] embedded PAF-1 (10 wt.\% loading) into three high free volume glassy polymers including PTMSP, PIM-1, and PMP in order to explore the influence of porous organic fillers on aging process of these polymers. Over a period of eight months (240 days), the $\mathrm{CO}_{2}$ permeability of pristine PTMSP dropped from 20,000 Barrer to a value of 12,500 Barrer (37\% drop). The hybrid membrane containing $10 \mathrm{wt}$ \% PAF-1 showed a higher $\mathrm{CO}_{2}$ permeability (approximately 25,000 Barrer), which dropped of only $7 \%$ over the investigated period. Similar effects were observed for PIM-1 and PMP (Table 6). Interestingly, the $\mathrm{CO}_{2} / \mathrm{N}_{2}$ selectivity improved with aging, similarly to the pristine matrix. Following a similar goal, Volkov et al. [136] embedded PAF-11 in PTMSP membrane (1-10 wt.\% loading) and monitored the variation of the transport properties over time through single gas permeation experiments. Initially, the addition of PAF-11 nanoparticles corresponded to an increase of the gas permeability of PTMSP, with a negligible effect on the selective features of the membranes. Long-term exposure to high temperature showed that the presence of the PAF nanoparticles helped in improving the mechanical stability of the PTMSP matrix: pristine PTMSP could not withstand more than $200 \mathrm{~h}$ exposure at high temperature, whereas the hybrid matrixes were tested up to $510 \mathrm{~h}$, showing good mechanical properties. Furthermore, the membrane with $10 \%$ PAF-11 loading showed a limited drop of the $\mathrm{CO}_{2}$ permeability (30\%), with stable performance over a period of more than $300 \mathrm{~h}$.

Functionalization of PAF-1 has been reported as an effective method to improve the $\mathrm{CO}_{2}$ permeability in hybrid membranes [137]. The presence of functional groups $\left(\mathrm{NH}_{2}, \mathrm{SO}_{3} \mathrm{H}, \mathrm{C}_{60}\right.$ nanoparticles, and $\mathrm{Li}_{6} \mathrm{C}_{60}$ composites) added to PAF-1 affected the $\mathrm{CO}_{2}$ sorption capacity, mainly due to the affinity of polar functional groups with $\mathrm{CO}_{2}$. Particularly promising is the introduction of $\mathrm{Li}_{6} \mathrm{C}_{60}$ functionality, which is able to provide additional $\mathrm{CO}_{2}$ sorption sites that are associated to the lithium, also increasing the PAF-1 surface area (from 3760 to $7360 \mathrm{~m}^{2} \mathrm{~g}^{-1}$ ). The $\mathrm{CO}_{2}$ permeability of PTMSP increased from 30,000 to 55,000 Barrer, and the effect of aging was limited to a $10 \%$ decrease over a period of 365 days for a $10 \mathrm{wt}$ \% of PAF-1-Li $\mathrm{C}_{60}$ loaded in PTMSP. $\mathrm{CO}_{2} / \mathrm{N}_{2}$, and $\mathrm{CO}_{2} / \mathrm{CH}_{4}$ selectivity were affected by the addition of the nanoparticles and by the physical aging to a limited extent (Table 6). Mitra et al. [138] studied the influence of a hypercrosslinked (HPC) nanofillers on the performance of PIM-1. PIM-1 membrane, prepared using dichloromethane as solvent, showed a $\mathrm{CO}_{2}$ permeability of 2258 Barrer, which dropped to a value of 1109 Barrer after 150 days. A similar trend was also observed when chloroform was used as solvent (Table 6). The addition of HCP into PIM-1 reduced the effect of physical aging for the samples prepared with different solvents, but at high loadings, the selectivity was negatively affected by the presence of the nanoparticles. Interestingly, the addition of HCP was found to prevent membrane swelling in the presence of ethanol.

Table 6. Gas separation performance of porous organic frameworks (POFs)-based mixed matrix membranes (operating conditions ranging within $1-5$ bar, $20-35^{\circ} \mathrm{C}$, unless differently specified).

\begin{tabular}{|c|c|c|c|c|c|c|c|}
\hline Filler & Polymer & $\begin{array}{l}\text { Loading } \\
\text { (wt.\%) }\end{array}$ & $\begin{array}{c}\mathrm{P}_{\mathrm{CO} 2} \\
\text { (Barrer) }\end{array}$ & $\alpha_{\mathrm{CO} 2 / \mathrm{N} 2}$ & $\alpha_{\mathrm{CO} 2 / \mathrm{CH} 4}$ & $\alpha_{\mathrm{CO} 2 / \mathrm{H} 2}$ & Ref. \\
\hline \multirow{3}{*}{ PAF-1 } & PTMSP $-0 \mathrm{~d}$ & 0 & 20,000 & 8.7 & & & [135] \\
\hline & & 10 & 25,000 & 8.1 & & & \\
\hline & PTMSP - $240 \mathrm{~d}$ & 0 & 12,400 & 9.8 & & & \\
\hline \multirow[t]{2}{*}{ PAF-1 } & & 10 & 23,200 & 9.6 & & & \\
\hline & PIM- $1-0 \mathrm{~d}$ & 0 & 4000 & 15 & & & \\
\hline \multirow[t]{2}{*}{ PAF-1 } & & 10 & 15,000 & 12 & & & \\
\hline & PIM-1 - $240 \mathrm{~d}$ & 0 & 1700 & 19 & & & \\
\hline \multirow[t]{2}{*}{ PAF-1 } & & 10 & 15,000 & 19 & & & \\
\hline & PMP- $0 \mathrm{~d}$ & 0 & 6500 & 10.5 & & & \\
\hline \multirow[t]{2}{*}{ PAF-1 } & & 10 & 11,500 & 9.4 & & & \\
\hline & PMP - $240 d$ & 0 & 3500 & 11 & & & \\
\hline PAF-1 & & 10 & 10,500 & 9.4 & & & \\
\hline
\end{tabular}


Table 6. Cont.

\begin{tabular}{|c|c|c|c|c|c|c|c|}
\hline Filler & Polymer & $\begin{array}{l}\text { Loading } \\
\text { (wt.\%) }\end{array}$ & $\begin{array}{c}\mathrm{P}_{\mathrm{CO} 2} \\
\text { (Barrer) }\end{array}$ & $\alpha_{\mathrm{CO} 2 / \mathrm{N} 2}$ & $\alpha_{\mathrm{CO} 2 / \mathrm{CH} 4}$ & $\alpha_{\mathrm{CO} 2 / \mathrm{H} 2}$ & Ref. \\
\hline \multirow{7}{*}{ PAF-11 } & PTMSP & 0 & 30,000 & 5.6 & & & [136] \\
\hline & & 1 & 38,000 & 5.9 & & & \\
\hline & & 5 & 37,000 & 5.8 & & & \\
\hline & & 10 & 34,000 & 5.6 & & & \\
\hline & 510 hours & 1 & 20,000 & 7 & & & \\
\hline & & 5 & 19,500 & 6.8 & & & \\
\hline & & 10 & 23,500 & 6.3 & & & \\
\hline & PTMSP & 0 & 30,000 & 5.9 & 2.3 & & [137] \\
\hline PAF-1 & & 10 & 35,500 & 5.7 & 2.3 & & \\
\hline PAF-1-NH ${ }_{2}$ & & 10 & 43,000 & 5.9 & 2.2 & & \\
\hline PAF-1-SO ${ }_{3} \mathrm{H}$ & & 10 & 32,500 & 5.7 & 2.3 & & \\
\hline PAF-1-C 60 & & 10 & 33,000 & 5 & 2.1 & & \\
\hline \multirow[t]{2}{*}{ PAF-1-Li ${ }_{6} \mathrm{C}_{60}$} & & 10 & 55,000 & 5.4 & 2 & & \\
\hline & Aged & 0 & 8000 & 8.8 & 5.3 & & \\
\hline PAF-1 & & 10 & 28,000 & 7.4 & 3.1 & & \\
\hline PAF-1-NH ${ }_{2}$ & & 10 & 29,000 & 7.5 & 3.6 & & \\
\hline PAF-1-SO ${ }_{3} \mathrm{H}$ & & 10 & 23,500 & 6 & 2.6 & & \\
\hline PAF-1-C 60 & & 10 & 15,000 & 8.3 & 5 & & \\
\hline PAF-1-Li ${ }_{6} \mathrm{C}_{60}$ & & 10 & 50,600 & 9 & 3.9 & & \\
\hline \multirow{4}{*}{$\mathrm{HCP}$} & PIM-1 - $\mathrm{CH}_{2} \mathrm{Cl}_{2}$ & 0 & 2258 & 24 & & & [138] \\
\hline & & 5.7 & 4690 & 17.6 & & & \\
\hline & & 16.67 & 5103 & 13.1 & & & \\
\hline & & 21.3 & 6331 & 14.1 & & & \\
\hline \multirow{3}{*}{$\mathrm{HCP}$} & $150 \mathrm{~d}$ & 0 & 1109 & 4.2 & & & \\
\hline & & 5.7 & 3616 & 19.7 & & & \\
\hline & & 21.3 & 5060 & 16 & & & \\
\hline \multirow{3}{*}{$\mathrm{HCP}$} & PIM-1 - $\mathrm{CHCl}_{3}$ & 0 & 2660 & 22.3 & & & \\
\hline & & 4.6 & 4313 & 19.8 & & & \\
\hline & & 9.1 & 4700 & 19.3 & & & \\
\hline \multirow{5}{*}{$\mathrm{HCP}$} & & 16.67 & 10,040 & 17.1 & & & \\
\hline & $150 \mathrm{~d}$ & 0 & 1225 & 21.5 & & & \\
\hline & & 4.6 & 1857 & 22.4 & & & \\
\hline & & 9.1 & 2043 & 22.2 & & & \\
\hline & & 16.67 & 4165 & 21.8 & & & \\
\hline
\end{tabular}

Despite the limited amount of investigations, POFs appeared to be promising materials for the fabrication of $\mathrm{CO}_{2}$ separation applications. The main advantage they add to polymeric materials is the significantly reduced physical aging phenomena; therefore, they are of interest for high free volume polymers. However, even though they are characterized by high $\mathrm{CO}_{2}$ uptake, their addition can increase the $\mathrm{CO}_{2}$ permeability (even in high free volume polymers), but has a limited or negligible effect on the selective feature of the hybrids. Interestingly, the young modulus has been reported to benefit from the addition of PAFs [136].

\section{Zeolites}

Zeolite molecular sieves are a class of aluminosilicate crystals that have been studied extensively and are one of the most widely reported porous materials for $\mathrm{CO}_{2}$ capture because of their physiochemical properties $[139,140]$. The pore size of zeolites varies from $4 \AA$ to $1.2 \mathrm{~nm}$ and their frameworks are formed by interconnecting channels. The molecular sieving nature coupled with the strong dipole-quadrupole interaction with carbon dioxide make zeolites promising candidates for carbon capture. $\mathrm{Si}$ and $\mathrm{Al}$ derived from silicate compounds are the main building block of zeolites nanoparticles. The morphology is controllable by varying the $\mathrm{Si}$ and $\mathrm{Al}$ content, as changes in the $\mathrm{Si} / \mathrm{Al}$ ratio lead to the electrostatic charge variation, resulting in different pore sizes distribution and adsorption capacities [139]. The thermal and chemical stability of zeolites can be improved by increasing the Si content [139], even though the zeolites do not provide the level of tenability offered by MOFs $[129,140]$. Zeolites of interest for $\mathrm{CO}_{2}$ capture applications are classified into three main 
categories: zeolites with small pore size (Linde Type A, LTA), medium pore size (Mordenite Framework Inverted, MFI), such as ZSM-5, and large pore size (Faujasite, FAU). Extensive studies have been dedicated to ensure the good adhesion between zeolites and polymer phases, as interfacial defects and voids between the organic and inorganic phases frequently resulted in the poor separation performance of the hybrids [141]. Unlike MOFs, zeolites structure is rigid and the pore dimensions are generally fixed. However, their activation by calcination may have detrimental impact on their framework integrity. The absence of accessible open metal sites (hidden by oxygen ions in the zeolite structure) is responsible for a lower $\mathrm{CO}_{2}$ uptake when compared to MOFs [141]. The mechanism typically used to describe the transport of light penetrants through zeolites is solution-diffusion [142]. Extensive studies have been dedicated to the incorporation of zeolites in hybrid membranes for $\mathrm{CO}_{2}$ separation [142] Nevertheless, the research is still extremely active, and many studies on hybrid membranes for $\mathrm{CO}_{2}$ applications employing zeolites have been reported in recent years.

Hoseinzadeh Beiragh et al. [143] investigated the effect of ZSM-5 loading on the $\mathrm{CO}_{2} / \mathrm{CH}_{4}$ separation performance of PEBAX-based membranes. The single gas permeation results revealed that an optimum for $\mathrm{CO}_{2}$ permeability is achieved at low zeolite content ( $5 \mathrm{wt} . \%$, Table 7 ), whereas the $\mathrm{CO}_{2} / \mathrm{CH}_{4}$ selectivity increased proportionally to the zeolite loading, achieving a $67 \%$ enhancement when compared to the pristine polymer. The sieving effect of zeolite (pore diameter $5.4 \AA$ ) has been suggested to be the main reason for the enhancement of the separation performance, and the decrease in fractional free volume was identified as explanation of the permeability drop at high zeolite contents. Interestingly, at higher feed pressure (up to 5 bar) the beneficial influence of zeolites on the mixed matrix performance is significantly reduced. Contrasting results were obtained when ZSM- 5 have been embedded in a glassy polyimide (Matrimid 5218) [144]. In this case, the permeance increased along with the particle loadings (from 5 to 21 GPU), whereas the selectivity showed a $75 \%$ decrease. The results have been mainly associated to poor compatibility between ZSM-5 and Matrimid, which resulted in particles agglomeration and the presence of interfacial voids already at low loadings.

Zeolite 13X have been used by Bryan et al. [145] to prepare hybrid membranes based on PEBAX 1657. When compared to ZSM-5, X zeolites are characterized by a larger pore size, between 11 and $14 \AA$ [146]. The addition of $15 \mathrm{wt}$.\% nanoparticles in the polymer matrix led to the improvement of both $\mathrm{CO}_{2}$ permeability (from 81 to 114 Barrer) and $\mathrm{CO}_{2} / \mathrm{N}_{2}$ selectivity (from 41 to 47 ), suggesting the achievement of proper interface morphology between the particles and the polymer matrix. Surya Murali et al. [147] have also prepared mixed matrix membrane using PEBAX 1675 as polymer phase. Zeolite $4 \mathrm{~A}$ was embedded up to $30 \mathrm{wt}$ \% in the polymeric matrix, showing agglomeration at higher loading. A 3-fold enhancement of the $\mathrm{CO}_{2}$ permeability was observed with increase in inorganic loading, but the selective feature showed an optimum between 5 and 10 wt. \%, which is possibly due to the interfacial voids formation. Zhao et al. [148] fabricated mixed matrix embedding up to 50 wt.\% SAPO-34 zeolite (pore diameter $3.8 \AA$ ) in PEBAX 1657 . The $\mathrm{CO}_{2}$ permeability increased proportionally to the inorganic content, achieving three-fold enhancement when compared to the pristine polymer. The consistency with the Maxwell model prediction also suggested the achievement of a proper polymer-filler interface. However, the $\mathrm{CO}_{2}$-selective feature of the hybrids were negligibly affected (Table 7). Interestingly, even though SAPO-34 inorganic membranes own impressive $\mathrm{CO}_{2} / \mathrm{H}_{2}$ selectivity [149], the performance of the pristine PEBAX 1675 were negligibly affected for the entire loading range investigated. Rezakazemi et al. [150] investigated the influence of 4A zeolite on the transport properties of polydimethylsiloxane (PDMS). The hybrid membranes showed a proper polymer-fillers interface up to $50 \mathrm{wt}$ \% loading. Interestingly, a significant $\mathrm{H}_{2}$-sieving effect was observed for the fabricated membranes: $\mathrm{H}_{2}$ permeability increased along with the inorganic content, whereas both $\mathrm{CO}_{2}$ and $\mathrm{CH}_{4}$ transport was hindered. The pristine PDMS was found to be $\mathrm{CO}_{2}$-selective for $\mathrm{H}_{2}$ separation, but at 20 wt.\% 4A loading, the hybrid material showed $\mathrm{H}_{2}$ - selective feature, suggesting that the membrane shifted from being solubility-driven to a condition where the diffusion coefficient dominates the gas transport. 
Recently, Atalay-Oral et al. [151] proposed a comparative study about the effect of different zeolites on the transport properties of polyvinylacetate (PVAc). They compared four different zeolites: 4A (pore size $4.2 \AA$ ), Ferrierite (pore size $4.2 \AA$ ), $5 \mathrm{~A}$ (pore size $5.2 \AA$ ), and Silicalite- 1 (pore size $5.5 \AA$ ). For all of the different fillers, the $\mathrm{CO}_{2}$-selective features of the mixed matrix membranes were increased. Ferrierite showed the better improvement in terms of performance: the selective feature (both $\mathrm{CO}_{2} / \mathrm{CH}_{4}$ and $\mathrm{CO}_{2} / \mathrm{N}_{2}$ ) increased proportionally to the inorganic content (Table 7), whereas the permeability increased at $20 \mathrm{wt} . \%$ loading, but negligible differences were observed at higher inorganic content. The authors suggest the strong interactions between Ferrierite cations and $\mathrm{CO}_{2}$ molecules to be the main reason the superior performance of the Ferrierite-based hybrid membranes. Another study compared the performance of Zeolite $\mathrm{A}(\mathrm{Si} / \mathrm{Al}=1)$ and zeolite ITQ-29 $(\mathrm{Si} / \mathrm{Al}=\infty)$ when embedded in PTMSP [152]. Surprisingly, when single gas tests were performed on a hybrid membrane containing 20 wt.\% Zeolite A loading, a 35\% drop in $\mathrm{CO}_{2}$ permeability was observed being combined with a 70-fold enhancement of the $\mathrm{CO}_{2} / \mathrm{N}_{2}$ selectivity (Table 7), surpassing the Robeson's upper bound. The extraordinary performance was attributed to the molecular sieving ability of the nanoparticles and to the achievement of a proper interface morphology. A much lower improvement was observed in the case of ITQ-29 zeolite, which is mainly due to the poor polymer-zeolite interactions and consequently interfacial voids formation. These results highlighted that choosing the proper $\mathrm{Si} / \mathrm{Al}$ ratio is extremely important in the design of hybrid membranes, as it directly affects the organic/inorganic interfacial morphology. Nevertheless, the same authors reported that under mixed gas conditions, the separation factor of the Zeolite A/PTMSP membranes appeared to be lower (5) when compared to the ideal selectivity (63) [153]. The authors concluded that the influence of the diffusivity selectivity dominates the transport, rather than the preferential sorption capacity in the mixed matrix.

As previously reported for MOFs and POFs, surface functionalization of zeolites is reported as a successful approach to improve the polymer-particles compatibility, and, thus, the membrane performance. The presence of unselective interfacial voids at the interface between zeolite 4A and PSF determined a significant drop of the $\mathrm{CO}_{2} / \mathrm{CH}_{4}$ separation efficiency (Table 7), without enhancing the $\mathrm{CO}_{2}$ permeability to a significant extent [154]. However, the functionalization of the zeolites particles with $\mathrm{MgCl}_{2}$ and $\mathrm{NH}_{4} \mathrm{OH}$ resulted in increased selectivity up to $30 \mathrm{wt} . \%$ loading, with a limited effect on the $\mathrm{CO}_{2}$ permeability. Similarly, zeolite $5 \mathrm{~A}$ have also been modified with Mg-based moieties to improve the adhesion with the polymer chain in Matrimid-based membranes [155]. Surface treatment of zeolite with $\mathrm{Mg}(\mathrm{OH})_{2}$ improved both $\mathrm{CO}_{2}$ permeability (10.2 to 22.4 Barrer) and $\mathrm{CO}_{2} / \mathrm{CH}_{4}$ selectivity (33.6 to 36.4). As shown in Figure 9, the modification of the nanoparticles allowed for significantly improving the interface morphology between the nanoparticles and the polymer phase, preventing the formation of interfacial voids. Effect of surface modification was investigated also for zeolite $\mathrm{NaY}$. Mixed matrix membrane were fabricated embedding the pristine and modified nanoparticles (loading range: $0-25 \mathrm{wt} . \%$ ) in cellulose acetate [156]. Surface modification of zeolite with NH functional groups was performed in order to improve the $\mathrm{CO}_{2}$ separation performances. However, in this case, the functionalization showed minor improvement when compared to the pristine nanoparticles (Table 7). 

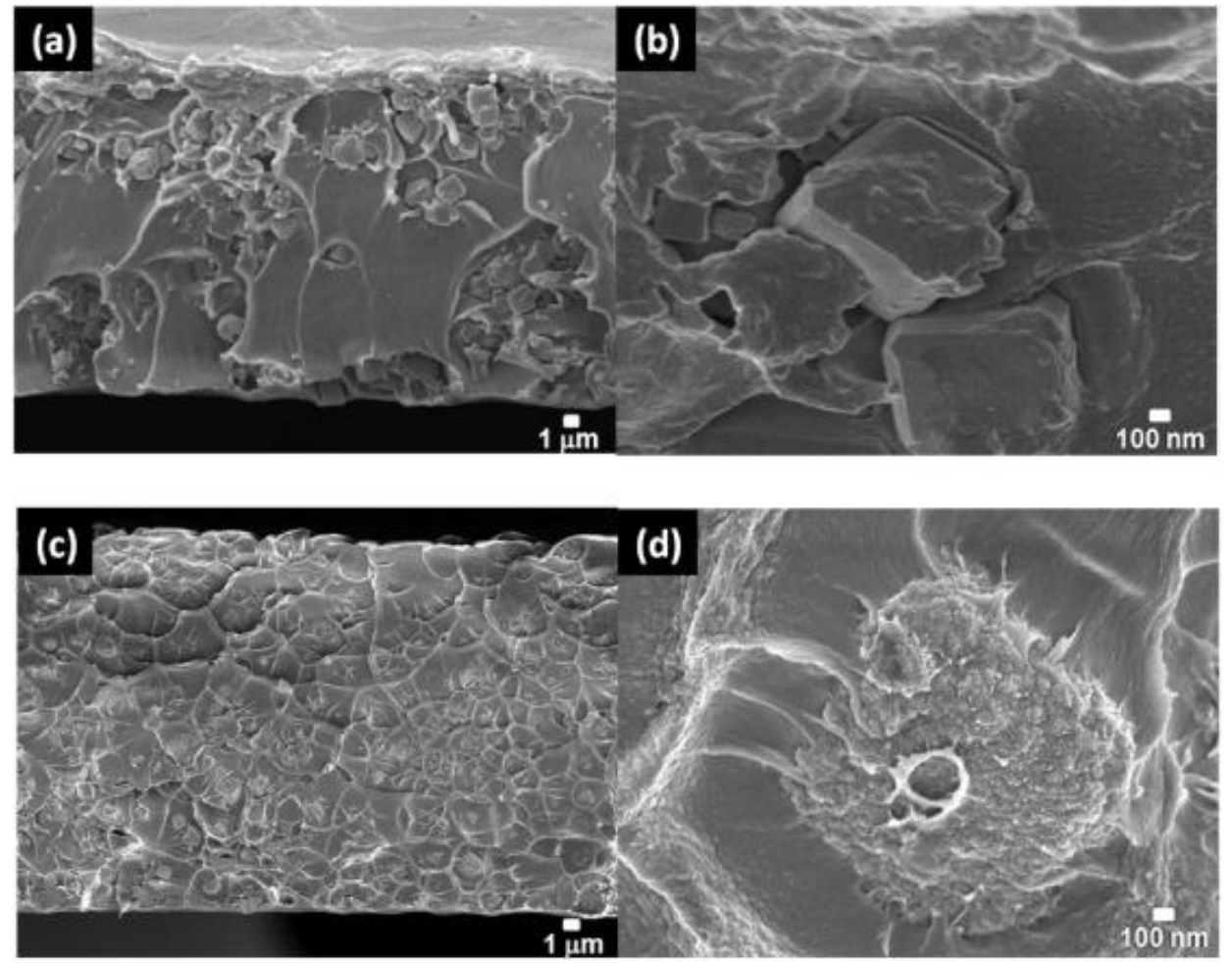

Figure 9. Cross section FESEM images of mixed-matrix membranes: $(\mathbf{a}, \mathbf{b})$ Matrimid with embedded pristine zeolite 5A; and, (c,d) Matrimid with embedded surface modified zeolite 5A [155], with copyright permission from (c) 2016 Elsevier.

Table 7. Gas separation performance of zeolites-based mixed matrix membranes (operating conditions ranging within $1-5$ bar, $20-35{ }^{\circ} \mathrm{C}$, unless differently specified).

\begin{tabular}{|c|c|c|c|c|c|c|c|}
\hline Filler & Polymer & $\begin{array}{l}\text { Loading } \\
\text { (wt.\%) }\end{array}$ & $\begin{array}{c}P_{\mathrm{CO} 2} \\
\text { (Barrer) }\end{array}$ & $\alpha_{\mathrm{CO} 2 / \mathrm{N} 2}$ & $\alpha_{\mathrm{CO} 2 / \mathrm{CH} 4}$ & $\alpha_{\mathrm{CO} 2 / \mathrm{H} 2}$ & Ref. \\
\hline \multirow{4}{*}{ ZSM-5 } & PEBAX 1675 & 0 & 120 & & 20.3 & & [143] \\
\hline & & 5 & 230 & & 21 & & \\
\hline & & 10 & 191 & & 32.5 & & \\
\hline & & 15 & 170 & & 33.9 & & \\
\hline \multirow{5}{*}{ ZSM-5 } & Matrimid 5218 & 0 & $5.1^{\mathrm{a}}$ & & 14.8 & & [144] \\
\hline & & 6 & $6.6^{\mathrm{a}}$ & & 15.6 & & \\
\hline & & 15 & $11.1^{\mathrm{a}}$ & & 7.2 & & \\
\hline & & 24 & $14.5^{\mathrm{a}}$ & & 4.8 & & \\
\hline & & 30 & $21^{\mathrm{a}}$ & & 3.6 & & \\
\hline \multirow{3}{*}{$13 X$} & PEBAX 1675 & 0 & 81.4 & 41 & & & [145] \\
\hline & & 10 & 104 & 39 & & & \\
\hline & & 15 & 114 & 47 & & & \\
\hline \multirow{5}{*}{$4 \mathrm{~A}$} & PEBAX 1675 & 0 & 55.8 & 39.9 & 18.0 & & [147] \\
\hline & & 5 & 71.4 & 51.0 & 32.5 & & \\
\hline & & 10 & 97 & 53.9 & 26.2 & & \\
\hline & & 20 & 113.7 & 39.2 & 17.5 & & \\
\hline & & 30 & 155.8 & 13.0 & 7.9 & & \\
\hline
\end{tabular}


Table 7. Cont

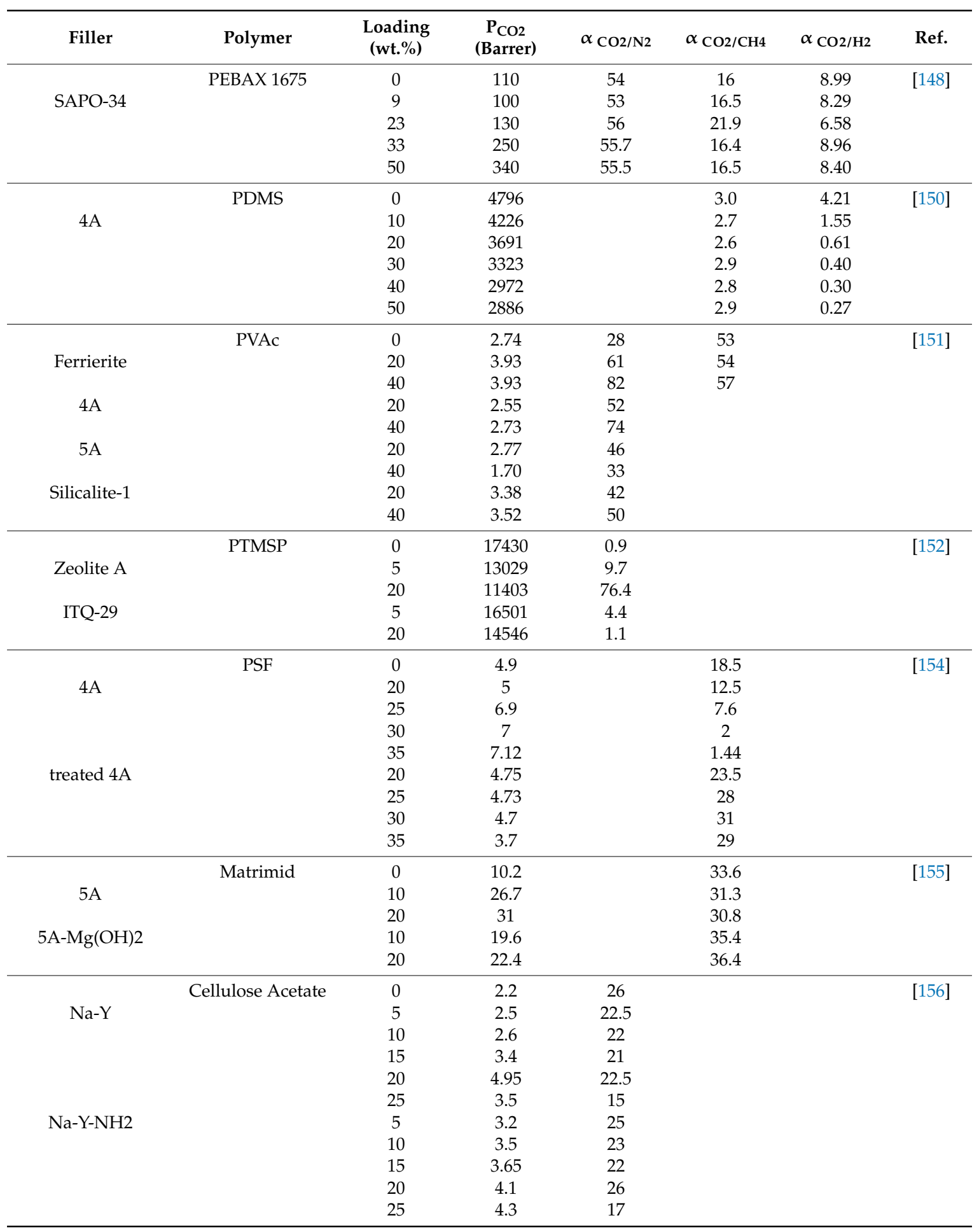

a Permeance (GPU); membrane thickness 3-5 $\mu \mathrm{m}$.

According to the data reviewed, the fabrication of hybrid membranes containing zeolites can be promising for $\mathrm{CO}_{2}$ capture applications. Loading up to $50 \mathrm{wt} . \%$ have been investigated, and rubbery materials (e.g., PEBAX or PDMS) showed good compatibility with the pristine nanoparticles, independently from their nature. Similar to MOFs, increasing the loading of pristine zeolites within polymeric phases enhances the $\mathrm{CO}_{2}$ permeability of the hybrid membranes. However, this effect is mainly observed for low permeable polymers, since when high free volume polymers are used 
the hybrid membranes showed lower permeability when compared to the polymeric precursor. The effect on the selective features depends on the organic-inorganic interface, but a sieving effect for $\mathrm{CO}_{2}$ is rarely observed. As observed for MOFs, surface modification is a suitable approach to improve the polymer-particles interface, but typically, the better compatibility mainly improves the selective features, and $\mathrm{CO}_{2}$ permeability appears to be negligibly affected by the presence of the inorganic phase.

\section{Porous Nanosheets}

Two-dimensional nanoporous nanomaterials have been of great interest owing to their layered structure, which can significantly improve the sieving effect of nanoporous materials to gas transport. Inorganic membranes that are made of 2D metal organic frameworks have been reported in literature, showing promising separation performance $[157,158]$. 2D structures have also been reported for zeolites [159], and inorganic membranes have been fabricated [160,161], even though their potential for gas separation remains unexplored. The high aspect ratio of two-dimensional nanoporous particles makes them extremely attractive for the fabrication of mixed matrix membranes. Layered fillers perpendicular to the concentration gradient of the gas species in the membranes can give rise to outstanding separation performance because of a significant increase in tortuosity, hence in diffusive pathways, of the penetrants that cannot permeate through the nanoporous structure (Figure 10). A comparison in the water/ethanol separation performance of ZIF-8 and its 2D derivate (ZIF-L) showed a simultaneous improvement of both permeability and selectivity at even lower MOF loading [162]. Next generation of hybrid membranes containing porous nanosheets that are incorporated in polymer matrix will provide a solution in order to enhance the separation performance of membranes for $\mathrm{CO}_{2}$ separation.

Porous layered and delaminated materials, with an intermediate structure between clay-like morphology and porous frameworks, represent an interesting class of porous 2D nanofillers. These materials can be exfoliated from bulk crystals, giving rise to high aspect ratio structures containing a porous architecture that can be of interest for gas separation applications. Layered aluminophospates (AlPO), layered silicates (AMH-3), layered titanosilicates JDF-L1, and layered COFs (NUS-2/3) are some examples that have been used for the fabrication of mixed matrix membranes. Nevertheless, very few studies have been dedicated to $\mathrm{CO}_{2}$ separation, since selective sieving of $\mathrm{H}_{2}$ from bigger molecules like $\mathrm{CH}_{4}$ have been investigated to a bigger extent.

A pioneering work was developed by Kim et al. [163], where nanoporous layered silicate AMH-3 (pore size $3.4 \AA$ ) was first exfoliated and subsequently embedded in cellulose acetate, achieving a loading up to $6 \mathrm{wt} . \%$. The $\mathrm{CO}_{2}$ permeability increased along with the inorganic loading, and this enhancement was attributed to the competing effects of transport through the nanopores, the interlayer spaces, and through a lower-density cellulose acetate phase. Negligible influence was observed on the selective features. Kang et al. [164] reported novel synthesis of NUS-2 and NUS-3 layered materials that are based on COFs with excellent water and acid stability. Both of the COFs exhibit hexagonal channels with diameters of $0.8 \mathrm{~nm}$ and $1.8 \mathrm{~nm}$ for NUS-2 and NUS-3, respectively. The flower-like nanofillers contain leafs of 1-2 $\mu \mathrm{m}$ length and 50-100 $\mathrm{nm}$ width. The synthesized nanofillers were dispersed in two different polymer matrices Ultem (PEI) and polybenzimidazole (PBI) and separation performances for $\mathrm{H}_{2} / \mathrm{CO}_{2}$ and $\mathrm{CO}_{2} / \mathrm{CH}_{4}$ were studied. For $\mathrm{CO}_{2} / \mathrm{CH}_{4}$ separation with Ultem, both of the nanofillers increased $\mathrm{CO}_{2}$ permeability and selectivity at 10 and $20 \mathrm{wt} . \%$ loading moving the pristine polymers closer to the upper bound. However, when the filler content was increased to $30 \mathrm{wt} . \%$, the selective features of the membrane dropped, possibly due to void formation at the polymer/filler interface. On the other hand, for $\mathrm{H}_{2}$ separation from $\mathrm{CO}_{2}$, the PBI sample containing $20 \mathrm{wt}$.\% NUS-2 surpassed the upper bound thanks to an impressive enhancement of the $\mathrm{H}_{2} / \mathrm{CO}_{2}$ selectivity. Alternatively, NUS-3 increased the permeability while maintaining or decreasing the selectivity. The highest $\mathrm{H}_{2}$ permeability was obtained at $30 \mathrm{wt} . \%$ loading, which is 17 times the permeability of pristine PBI, which is followed by a $50 \%$ reduction in selectivity. 
a

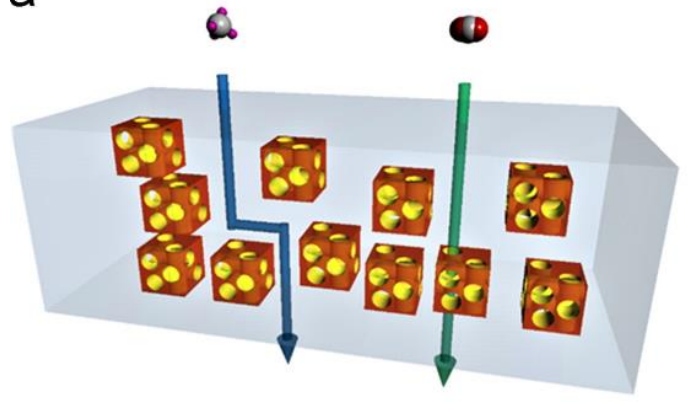

b

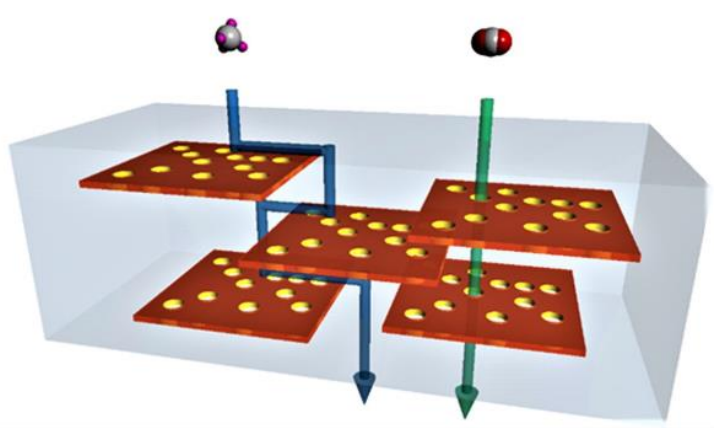

Figure 10. Schematic representation of the effect of isotropic particles (a) and nanoporous sheets (b) on the transport through mixed matrix membranes. Reprinted from [163], with copyright permission from (C) 2013 Elsevier.

Rodenas et al. [165], in 2014, synthesized and compared CuBDC MOFs with three different morphologies: isotropic nanocrystals (nc-CuBDC), bulk-type crystals (b-CuBDC), and nanosheets (ns-CuBDC). The different nanoparticles were embedded within a polyimide-based (Matrimid 5218) polymeric matrix. It was shown that the CuBDC offered large surface area, which was about five-fold higher than the one that was obtained for the $b-C u B D C$. Mixed gas permeation tests showed that the addition of both nc-CuBDC and b-CuBDC ( $8 \mathrm{wt}$.\% loading) determined a drop in the $\mathrm{CO}_{2} / \mathrm{CH}_{4}$ selectivity when compared to the pristine polymer. However, when a similar loading of ns-CuBDC was embedded in the polymeric matrix, a 30\% enhancement in the separation factor was observed. This effect was even more evident when the feed pressure was increased from 3 to 7.5 bar, where the selectivity improvement reached a $80 \%$ higher value as compared to the pristine polymer. At 3 bar feed pressure, the $\mathrm{CO}_{2}$ permeability gradually increased from 5.78 to 9.91 Barrer (at $3.7 \mathrm{wt} . \%$ loading) and then decreased to 4.09 Barrer (at $8.3 \mathrm{wt} . \%$, Table 8). At a similar loading of bulk and nanocrystals, a minor reduction in $\mathrm{CO}_{2}$ permeability was observed. Interestingly, the embedment of ns-CuBDC was also reported to limit the effect of $\mathrm{CO}_{2}$-induced plasticization characteristic of polyimides at high partial pressure of $\mathrm{CO}_{2}$. The authors attributed this effect to the depletion of MOF-free permeation pathways, sustaining the selective features of the membrane under high $\mathrm{CO}_{2}$ concentration within the hybrid matrix. A similar work has also been recently reported by Shete et al. [166], who embedded Cu-based MOF nanosheets (lateral size $2.5 \mu \mathrm{m}$, thickness $25 \mathrm{~nm}$ ) in Matrimid 5218. Results that were obtained by the two studies are quite similar, with a decrease in $\mathrm{CO}_{2}$ permeability at increasing the nanosheets loading with improved selectivity (Table 8), strengthening the consistency of the influence of nanosheets on the transport properties of polyimides. The main difference is related to the influence of the feed pressure: in the latter case, the mixed matrix membranes selectivity decreased with increasing the operating pressure, whereas an opposite trend was observed in the other study.

The $\mathrm{CO}_{2} / \mathrm{CH}_{4}$ gas separation performance of ultrathin layer that was obtained by dispersing 2D MOFs in PIM-1 was investigated by Cheng et al. [167]. CuBDC nanosheets with a thickness of 15 to $40 \mathrm{~nm}$ and $\sim 100$ aspect ratio were successfully embedded into PIM-1 up to $5 \mathrm{wt} . \%$ loading. Thin films (200 to $2200 \mathrm{~nm}$ ) were then coated on a porous $\mathrm{Al}_{2} \mathrm{O}_{3}$ support via spin-coating technique. At $10 \%$ loading, the enhancement in $\mathrm{CO}_{2}$ selectivity from 4.4 to 16 ( $\sim 300 \%$ increase) was observed. Nevertheless, the selectivity improvement with an increase in MOF loading was at significant expense of the $\mathrm{CO}_{2}$ permeance, which dropped from 1750 to 500 GPU with a 2 wt.\% loading. Interestingly, no significant differences in permeance have been observed between 2, 5, 10, and $15 \mathrm{wt} . \%$ loading, suggesting that the transport is dominated by the embedded phase already in the low loadings (Table 8 ). The gas selectivity enhancement was attributed to the tortuosity and the pathway created by centrifugal force, which helped to align nanosheets horizontally. At higher loading up to $15 \mathrm{wt} . \%$, the selectivity reduction was observed mainly due to the presence of nonselective voids and agglomeration. 
Yang et al. [168] recently reported the influence of CuBDC nanosheets on the performance of high free volume polymers, such as PIM-1 and 6FDA-DAM. Nanosheets with a lateral dimension of 1-8 $\mu \mathrm{m}$ and a thickness of $40 \mathrm{~nm}$ were synthesized and embedded in the polymer phase via sonication. As observed previously for PIM-1, the incorporation of nanosheets resulted in a decrease of $\mathrm{CO}_{2}$ permeability at the low loadings for both PIM-1 and 6FDA-DAM (Table 8). Notably, in the case of PIM-1 small differences were observed between the two different filler loadings, whereas in the case of 6FDA-DAM, the permeability decrease was more evident between the 2 and $4 \mathrm{wt} . \%$ loading. In both cases, the presence of the porous nanosheets led to a significant increase $(20-40 \%)$ in the selective feature of the hybrid membranes.

In another study, Kang et al. [169] prepared MMMs with a newly synthesized 2D MOF $\left(10 \times 100 \mathrm{~nm}^{2}\right), \quad\left[\mathrm{Cu}_{2}(\mathrm{ndc})_{2}(\right.$ dabco $\left.)\right] \mathrm{n}, \quad($ ndc $=1,4$-naphthalene dicarboxylate, dabco $=1,4-$ diazabicyclo[2.2.2]octane), and incorporated into PBI (polybenzimidazole) matrix for pre-combustion $\mathrm{CO}_{2}$ separation. MOF loading from 10 to $20 \mathrm{wt}$ \% provided highly selective MMMs, with about $100 \%$ increment in $\mathrm{H}_{2} / \mathrm{CO}_{2}$ ideal selectivity. The authors attributed the high selective features to fast $\mathrm{H}_{2}$ permeation through the MOF, whereas $\mathrm{CO}_{2}$ follows slower diffusive pathways in view of the larger kinetic diameter. Higher MOF loadings (> $20 \mathrm{wt} . \%$ ) resulted in a selectivity drop in selectivity, which is possibly due to void formation. Comparison of different morphologies showed that MOF nanosheets offered better selectivity and permeability of the hybrid membranes because of the shape, orientation, and interfacial adhesion inside the matrix. As in the previous case, similar loadings of bulk or nanocrystals (20 wt.\%) showed lower selectivity values compared to the nanosheet morphology.

Table 8. Gas separation performance of mixed matrix membranes containing MOFs nanosheets (operating conditions ranging within 1-5 bar, $20-35{ }^{\circ} \mathrm{C}$, mixed gas conditions unless differently specified).

\begin{tabular}{|c|c|c|c|c|c|c|c|}
\hline Filler & Polymer & $\begin{array}{c}\text { Loading } \\
\text { (wt.\%) }\end{array}$ & $\begin{array}{c}\mathrm{P}_{\mathrm{CO} 2} \\
\text { (Barrer) }\end{array}$ & $\alpha_{\mathrm{CO} 2 / \mathrm{N} 2}$ & $\alpha_{\mathrm{CO} 2 / \mathrm{CH} 4}$ & $\alpha_{\mathrm{H} 2 / \mathrm{CO} 2}$ & Ref. \\
\hline \multirow{4}{*}{ AMH-3 } & Cellulose Acetate & 0 & 7.55 & & 29.61 & & [163] \\
\hline & & 2 & 9.65 & & 29.24 & & \\
\hline & & 4 & 10.36 & & 30.03 & & \\
\hline & & 6 & 11.59 & & 29.71 & & \\
\hline \multirow{3}{*}{ NUS-2 } & Ultem & $0^{\mathrm{a}}$ & 2.22 & & 20.2 & 2.88 & [164] \\
\hline & & $10^{\mathrm{a}}$ & 3.75 & & 25 & 3.39 & \\
\hline & & $20^{\mathrm{a}}$ & 4.92 & & 22.4 & 4.61 & \\
\hline \multirow{4}{*}{ NUS-3 } & & $30^{\mathrm{a}}$ & 8.70 & & 12.7 & 1.89 & \\
\hline & & $10^{\mathrm{a}}$ & 5.89 & & 22.7 & 2.46 & \\
\hline & & $20^{\mathrm{a}}$ & 15 & & 28.3 & 2.23 & \\
\hline & & $30^{a}$ & 8.11 & & 10.7 & 2.45 & \\
\hline \multirow{5}{*}{$n s-C u B D C$ b } & Matrimid 5218 & 0 & 5.78 & & 59.8 & & [165] \\
\hline & & 1.7 & 5.38 & & 61.6 & & \\
\hline & & 3.7 & 9.91 & & 59.5 & & \\
\hline & & 4.3 & 4.74 & & 63.5 & & \\
\hline & & 8.2 & 4.09 & & 78.7 & & \\
\hline $\mathrm{b}-\mathrm{CuBDC}{ }^{\mathrm{b}}$ & & 7.9 & 5.21 & & 45 & & \\
\hline$n c-C u B D C{ }^{b}$ & & 8.3 & 5.03 & & 49.4 & & \\
\hline \multirow{5}{*}{ CuBDC } & Matrimid 5218 & 0 & $7.2^{c}$ & 23.7 & & & [166] \\
\hline & & 4 & $6.4^{\mathrm{c}}$ & 42.0 & & & \\
\hline & & 8 & $4.0^{\mathrm{c}}$ & 48.1 & & & \\
\hline & & 0 & 15.2 & & 25.3 & & \\
\hline & & 12 & 6.6 & & 40.3 & & \\
\hline
\end{tabular}


Table 8. Cont.

\begin{tabular}{|c|c|c|c|c|c|c|c|}
\hline Filler & Polymer & $\begin{array}{c}\text { Loading } \\
\text { (wt. \%) }\end{array}$ & $\begin{array}{c}P_{\mathrm{CO} 2} \\
\text { (Barrer) }\end{array}$ & $\alpha_{\mathrm{CO} 2 / \mathrm{N} 2}$ & $\alpha_{\mathrm{CO} 2 / \mathrm{CH} 4}$ & $\alpha_{\mathrm{H} 2 / \mathrm{CO} 2}$ & Ref. \\
\hline \multirow{8}{*}{ CuBDC-ns } & PIM-1 & 0 & $1750^{\mathrm{d}}$ & & 4.4 & & [167] \\
\hline & & 2 & $500^{d}$ & & 10.2 & & \\
\hline & & 5 & $490^{d}$ & & 12.9 & & \\
\hline & & 10 & $400^{\mathrm{d}}$ & & 16.0 & & \\
\hline & & 15 & $490^{d}$ & & 11.7 & & \\
\hline & & 0 & $161^{\mathrm{d}}$ & & 12.2 & & \\
\hline & & 10 & $196^{\mathrm{d}}$ & & 10.8 & & \\
\hline & & 10 & $407^{\mathrm{d}}$ & & 15.5 & & \\
\hline \multirow{3}{*}{ CuBDC-ns } & PIM-1 & 0 & 3100 & & 17 & & [168] \\
\hline & & 2 & 2030 & & 24 & & \\
\hline & & 4 & 2300 & & 22 & & \\
\hline \multirow{3}{*}{ CuBDC-ns } & 6FDA-DAM & 0 & 590 & & 30 & & \\
\hline & & 2 & 570 & & 37 & & \\
\hline & & 4 & 430 & & 43 & & \\
\hline \multirow{5}{*}{$\mathrm{ns}-\mathrm{Cu}_{2}(\mathrm{ndc})_{2}(\mathrm{dabco})^{\mathrm{b}}$} & PBI & 0 & 3.62 & & & 9.3 & [169] \\
\hline & & 10 & 4.86 & & & 18.7 & \\
\hline & & 20 & 6.15 & & & 22.8 & \\
\hline & & 30 & 11.9 & & & 12.3 & \\
\hline & & 50 & 66.4 & & & 4.8 & \\
\hline $\mathrm{bc}-\mathrm{Cu}_{2}(\mathrm{ndc})_{2}(\mathrm{dabco})^{\mathrm{b}}$ & & 20 & 5.18 & & & 12.6 & \\
\hline$n c-\mathrm{Cu}_{2}(\mathrm{ndc})_{2}(\mathrm{dabco})^{\mathrm{b}}$ & & 20 & 5.29 & & & 17.6 & \\
\hline
\end{tabular}

Despite the early stage of the research, the analysis of the performance achieved while using 2D nanoporous materials for the fabrication of mixed matrix membranes clearly showed a promising potential within $\mathrm{CO}_{2}$ capture. Systematically, the 2D shape was demonstrated to be able to achieve better performance when compared to the isotropic particles, independently from their size. Interestingly, compared to isotropic nanoparticles, the effect of nanosheets is already visible in the low loading range, similar to what has been observed for graphene [22]. The use of 2D porous nanoparticles can be of particular interest for the enhancement of the selective feature of high free volume polymers, where a partial loss in $\mathrm{CO}_{2}$ permeability can be tolerated if being counterbalanced by a significant enhancement of the separation factor. A notable increase of studies that are dedicated to this topic is expected in the near future.

\section{Conclusions and Perspective}

The recent advances in the synthesis and improvements of 2D and 3D porous nanophases has driven a continuous research within the development of mixed matrix membranes for gas separation purposes. In particular, the possibility of tuning the pore diameter to a gas-sieving level and the $\mathrm{CO}_{2}$-philicity of the pore cavity has the potential to facilitate the simultaneous enhancement of the solubility and diffusivity coefficient of carbon dioxide. Therefore, $\mathrm{CO}_{2}$ permeability and selectivity can be expected to benefit from these features, leading to a shift in the separation performance towards the upper right corner of the Robeson plot.

Notable attention has been given to MOF nanoparticles and MOFs nanosheets. The pore opening size falling within the gas kinetic diameters and the presence of unsaturated open metal sites makes them of particular interest for $\mathrm{CO}_{2}$ separation. Analysis of adding ZIF nanoparticles into highly or moderately permeable polymeric membrane materials reveals a clear tendency to improve the $\mathrm{CO}_{2}$ permeability when the nanofiller loading is increased to 30-40 wt.\%. The incorporation of ZIFs has been frequently reported to be associated to the disruption the polymer chain packing, leading to an increase of the MMMs free volume. However, selectivity enhancement was seldom reported despite the expected sieving effect and the observed suitable interface morphology. The ZIFs flexible framework is 
expected to be among the main reasons for this phenomenon. Also, in the case of other analyzed MOFs (UiO-66, MILs and various metallic-based MOFs), the $\mathrm{CO}_{2}$ permeability enhancement was frequently observed, with the enhancement being proportional to the MOF content. However, the increase in selective feature was typically reported only at low particles loading (especially for UiO-66) and mild operative conditions, suggesting that the sieving ability of the pore opening is not extremely effective for gas separation purpose. Structural flexibility and poor interface interactions were frequently mentioned as the possible causes. Therefore, the achievement of a more rigid structure of the MOFs cage and more effect functionalization are desirable to improve the efficiency of the embedded phase. Interestingly, particles with smaller size have shown to be more effective compared to inorganic phases with bigger size. In addition, particles with reduced size can facilitate the fabrication of thin $(<1 \mu \mathrm{m})$ selective layers.

Porous nanosheets showed a promising potential for the fabrication of mixed matrix membranes for $\mathrm{CO}_{2}$ separation. When compared to 3D porous materials, the impact of $2 \mathrm{D}$ nonoporous materials is demonstrated even at low loading range ( $<10 \mathrm{wt} . \%)$. The use of $2 \mathrm{D}$ shape was systematically demonstrated to obtain better performance compared to isotropic particles. Higher selectivity can be achieved using MOF nanosheets, even when they are incorporated in high free volume polymers, but the variation typically takes place to the expense of the gas transport through the selective layer. The intrinsic nature of these 2D nanoparticles has the potential to be a successful strategy to efficiently fabricate mixed matrix membranes with superior separation performance in the form of thin composite membranes. Therefore, future work has to focus on the reduction of the thickness of these 2D porous layers, allowing for achieving membrane thickness in the order of 100-200 nm.

Porous organic frameworks (POFs) have also been recently investigated for $\mathrm{CO}_{2}$ separation. Their fully-organic nature facilitates their dispersion in polymer phases, but their more rigid structure confers interesting feature to the hybrid membranes. Experimental results gave evidence of an unprecedented capacity of stopping physical aging in high free volume polymers. Even though $\mathrm{CO}_{2}$ permeability is frequently enhanced using PAFs, negligible influence on selectivity of the hybrids was observed. Nevertheless, their promising performance has been disclosed only for thick self-standing membranes, and more investigation on their efficiency for thin films are needed to fully understand their potential.

Zeolites, as one of the most common fillers, attracted great interest in MMMs fabrication and have been investigated for last two decades. When compared to MOFs, the absence of organic ligand in the lattice, the control of zeolite/polymer interface is more difficult than MOF/polymer interface. Therefore, many efforts have been spent to ensure the achievement of proper interface morphology to reduce the negative effects that are associated to interfacial voids. Loading of up to $50 \mathrm{wt} . \%$ has been reported, and rubbery polymers (e.g., PDMS) showed good compatibility and adhesion with pristine nanoparticles. Increase in zeolite content led to higher permeability and effect of pristine zeolites on $\mathrm{CO}_{2}$ permeability was more pronounced for low permeable polymers when compared to high free volume polymers. Surface modification of zeolites have shown better compatibility and improved selectivity with negligible effect in $\mathrm{CO}_{2}$ permeability.

The following focuses may be of appreciable impact in the future development of MMMs with superior transport properties:

- to reduce primary particle size of existing MOFs and expedite their incorporation in thin composite polymeric membranes;

- to increase the $\mathrm{CO}_{2}$ affinity and the polymer/particle interactions by novel surface functionalization procedures on the nanoparticle or by post-functionalization after membrane preparation, aiming at improving the $\mathrm{CO}_{2}$ separation performance and simplifying their dispersion in the polymeric phases;

- to tune the structure and morphology of POFs with the aim of enhancing the selectivity of hybrid matrix when used in high free volume polymers; 
- to design and fabricate novel 2D MOF frameworks with improved sieving ability that do not sacrifice the gas transport through the selective layer; and,

- to systematically investigate the potential of hybrid membranes in $\mathrm{H}_{2}$ separation, exploiting the exceptional $\mathrm{H}_{2}$ sieving ability of some MOFs.

Funding: "This research and the APC were funded by the European Union's Horizon 2020 Research and Innovation program, grant number 727734".

Conflicts of Interest: The authors declare no conflict of interest.

\section{References}

1. Pera-Titus, M. Porous Inorganic Membranes for CO2 Capture: Present and Prospects. Chem. Rev. 2014, 114, 1413-1492. [CrossRef] [PubMed]

2. Rackley, S.A. Chapter 4-Carbon Capture from Power Generation. In Carbon Capture and Storage; Rackley, S.A., Ed.; Butterworth-Heinemann: Oxford, UK, 2010; pp. 65-93, ISBN 978-1-85617-636-1.

3. Rackley, S.A. Chapter 5-Carbon Capture from Industrial Processes. In Carbon Capture and Storage; Rackley, S.A., Ed.; Butterworth-Heinemann: Oxford, UK, 2010; pp. 95-102, ISBN 978-1-85617-636-1.

4. Boot-Handford, M.E.; Abanades, J.C.; Anthony, E.J.; Blunt, M.J.; Brandani, S.; Mac Dowell, N.; Fernandez, J.R.; Ferrari, M.C.; Gross, R.; Hallett, J.P.; et al. Carbon capture and storage update. Energy Environ. Sci. 2014, 7, 130-189. [CrossRef]

5. Dalane, K.; Dai, Z.; Mogseth, G.; Hillestad, M.; Deng, L. Potential applications of membrane separation for subsea natural gas processing: A review. J. Nat. Gas Sci. Eng. 2017, 39, 101-117. [CrossRef]

6. Ahmadi, M.; Tas, E.; Kilic, A.; Kumbaraci, V.; Talinli, N.; Ahunbay, M.G.; Tantekin-Ersolmaz, S.B. Highly $\mathrm{CO}_{2}$ Selective Microporous Metal-Imidazolate Framework (MMIF) Based Mixed Matrix Membranes. ACS Appl. Mater. Interfaces 2017, 9, 35936-35946. [CrossRef] [PubMed]

7. Yu, J.; Xie, L.H.; Li, J.R.; Ma, Y.; Seminario, J.M.; Balbuena, P.B. $\mathrm{CO}_{2}$ Capture and Separations Using MOFs: Computational and Experimental Studies. Chem. Rev. 2017, 117, 9674-9754. [CrossRef] [PubMed]

8. Koros, W.J.; Zhang, C. Materials for next-generation molecularly selective synthetic membranes. Nat. Mater. 2017, 16, 289-297. [CrossRef] [PubMed]

9. Dai, Z.; Ansaloni, L.; Deng, L. Recent advances in multi-layer composite polymeric membranes for $\mathrm{CO}_{2}$ separation: A review. Green Energy Environ. 2012, 1, 102-128. [CrossRef]

10. Ansaloni, L.; Deng, L. Advances in polymer-inorganic hybrids as membrane materials. In Recent Developments in Polymer Macro, Micro and Nano Blends: Preparation and Characterisation; Woodhead Publishing: Sawston, UK; Cambridge, UK, 2016; pp. 163-206. ISBN 9780081004272.

11. Robeson, L.M. Correlation of separation factor versus permeability for polymeric membranes. J. Memb. Sci. 1991, 62, 165-185. [CrossRef]

12. Robeson, L.M. The upper bound revisited. J. Membr. Sci. 2008, 320, 390-400. [CrossRef]

13. Freeman, B.D. Basis of Permeability/Selectivity Tradeoff Relations in Polymeric Gas Separation Membranes. Macromolecules 1999, 32, 375-380. [CrossRef]

14. Robeson, L.M.; Smith, Z.P.; Freeman, B.D.; Paul, D.R. Contributions of diffusion and solubility selectivity to the upper bound analysis for glassy gas separation membranes. J. Membr. Sci. 2014, 453, 71-83. [CrossRef]

15. Park, H.B.; Jung, C.H.; Lee, Y.M.; Hill, A.J.; Pas, S.J.; Mudie, S.T.; Van Wagner, E.; Freeman, B.D.; Cookson, D.J. Polymers with cavities tuned for fast selective transport of small molecules and ions. Science 2007, 318, 254-258. [CrossRef] [PubMed]

16. Low, Z.-X.; Budd, P.M.; McKeown, N.B.; Patterson, D.A. Gas Permeation Properties, Physical Aging, and Its Mitigation in High Free Volume Glassy Polymers. Chem. Rev. 2018. [CrossRef] [PubMed]

17. Rafiq, S.; Deng, L.; Hägg, M.-B. Role of Facilitated Transport Membranes and Composite Membranes for Efficient $\mathrm{CO}_{2}$ Capture-A Review. ChemBioEng Rev. 2016, 3, 68-85. [CrossRef]

18. Caro, J. Hierarchy in inorganic membranes. Chem. Soc. Rev. 2016, 45, 3468-3478. [CrossRef] [PubMed]

19. Adams, R.; Carson, C.; Ward, J.; Tannenbaum, R.; Koros, W. Metal organic framework mixed matrix membranes for gas separations. Microporous Mesoporous Mater. 2010, 131, 13-20. [CrossRef] 
20. Galizia, M.; Chi, W.S.; Smith, Z.P.; Merkel, T.C.; Baker, R.W.; Freeman, B.D. 50th Anniversary Perspective: Polymers and Mixed Matrix Membranes for Gas and Vapor Separation: A Review and Prospective Opportunities. Macromolecules 2017, 50, 7809-7843. [CrossRef]

21. Dong, G.; Li, H.; Chen, V. Challenges and opportunities for mixed-matrix membranes for gas separation. J. Mater. Chem. A 2013, 1, 4610-4630. [CrossRef]

22. Janakiram, S.; Ahmadi, M.; Dai, Z.; Ansaloni, L.; Deng, L. Performance of nanocomposite membranes containing 0D to 2D nanofillers for $\mathrm{CO}_{2}$ separation: A review. Membranes 2018, 8, 24. [CrossRef] [PubMed]

23. Rezakazemi, M.; Ebadi Amooghin, A.; Montazer-Rahmati, M.M.; Ismail, A.F.; Matsuura, T. State-of-the-art membrane based $\mathrm{CO}_{2}$ separation using mixed matrix membranes (MMMs): An overview on current status and future directions. Prog. Polym. Sci. 2014, 39, 817-861. [CrossRef]

24. Seoane, B.; Coronas, J.; Gascon, I.; Benavides, M.E.; Karvan, O.; Caro, J.; Kapteijn, F.; Gascon, J. Metal-organic framework based mixed matrix membranes: A solution for highly efficient $\mathrm{CO}_{2}$ capture? Chem. Soc. Rev. 2015, 44, 2421-2454. [CrossRef] [PubMed]

25. Jusoh, N.; Fong Yeong, Y.; Leng Chew, T.; Keong Lau, K.; Mohd Shariff, A. Separation \& Purification Reviews Current Development and Challenges of Mixed Matrix Membranes for $\mathrm{CO}_{2} / \mathrm{CH}_{4}$ Separation Current Development and Challenges of Mixed Matrix Membranes for $\mathrm{CO}_{2} / \mathrm{CH}_{4}$ Separation. Sep. Purif. Rev. 2016, 45, 321-344. [CrossRef]

26. Vinoba, M.; Bhagiyalakshmi, M.; Alqaheem, Y.; Alomair, A.A.; Pérez, A.; Rana, M.S. Recent progress of fillers in mixed matrix membranes for $\mathrm{CO}_{2}$ separation: A review. Sep. Purif. Technol. 2017, 188, 431-450. [CrossRef]

27. Wang, M.; Wang, Z.; Zhao, S.; Wang, J.; Wang, S. Recent advances on mixed matrix membranes for CO2 separation. Chinese J. Chem. Eng. 2017, 25, 1581-1597. [CrossRef]

28. Zhou, H.-C.; Long, J.R.; Yaghi, O.M. Introduction to Metal-Organic Frameworks. Chem. Rev. 2012, 112, 673-674. [CrossRef] [PubMed]

29. Farrusseng, D.; Aguado, S.; Pinel, C. Metal-Organic Frameworks: Opportunities for Catalysis. Angew. Chemie Int. Ed. 2009, 48, 7502-7513. [CrossRef] [PubMed]

30. Chen, B.; Yang, Z.; Zhu, Y.; Xia, Y. Zeolitic imidazolate framework materials: recent progress in synthesis and applications. J. Mater. Chem. A 2014, 2, 16811-16831. [CrossRef]

31. James, S.L. Metal-organic frameworks. Chem. Soc. Rev. 2003, 32, 276-288. [CrossRef] [PubMed]

32. Stock, N.; Biswas, S. Synthesis of metal-organic frameworks (MOFs): routes to various MOF topologies, morphologies, and composites. Chem. Rev. 2011, 112, 933-969. [CrossRef] [PubMed]

33. Hyun, S.; Hwa Lee, J.; Yeong Jung, G.; Kyeong Kim, Y.; Kyung Kim, T.; Jeoung, S.; Kyu Kwak, S.; Moon, D.; Ri Moon, H. Exploration of Gate-Opening and Breathing Phenomena in a Tailored Flexible Metal—Organic Framework. Inorg. Chem 2016, 55, 1920-1925. [CrossRef] [PubMed]

34. Schneemann, A.; Bon, V.; Schwedler, I.; Senkovska, I.; Kaskel, S.; Fischer, R.A. Flexible metal-organic frameworks. Chem. Soc. Rev. 2014, 43, 6062-6096. [CrossRef] [PubMed]

35. Castellanos, S.; Kapteijn, F.; Gascon, J. Photoswitchable metal organic frameworks: turn on the lights and close the windows. CrystEngComm 2016, 18, 4006-4012. [CrossRef]

36. Alhamami, M.; Doan, H.; Cheng, C.-H. A Review on Breathing Behaviors of Metal-Organic-Frameworks (MOFs) for Gas Adsorption. Materials (Basel) 2014, 7, 3198-3250. [CrossRef] [PubMed]

37. Fairen-Jimenez, D.; Moggach, S.A.; Wharmby, M.T.; Wright, P.A.; Parsons, S.; Duren, T. Opening the gate: framework flexibility in ZIF-8 explored by experiments and simulations. J. Am. Chem. Soc. 2011, 133, 8900-8902. [CrossRef] [PubMed]

38. Kolokolov, D.I.; Maryasov, A.G.; Ollivier, J.; Freude, D.; Haase, J.; Stepanov, A.G.; Jobic, H. Uncovering the Rotation and Translational Mobility of Benzene Confined in UiO-66 (Zr) Metal-Organic Framework by the ${ }^{2}$ H NMR-QENS Experimental Toolbox. J. Phys. Chem. C 2017, 121, 2844-2857. [CrossRef]

39. Damron, J.T.; Ma, J.; Kurz, R.; Saalwächter, K.; Matzger, A.J.; Ramamoorthy, A. The Influence of Chemical Modification on Linker Rotational Dynamics in Metal-Organic Frameworks. Angew. Chem. Int. Ed. 2018, 57, 8678-8681. [CrossRef] [PubMed]

40. Yoo, G.Y.; Lee, W.R.; Jo, H.; Park, J.; Song, J.H.; Lim, K.S.; Moon, D.; Jung, H.; Lim, J.; Han, S.S.; Jung, Y.; Hong, C.S. Adsorption of Carbon Dioxide on Unsaturated Metal Sites in $\mathrm{M}_{2}$ (dobpdc) Frameworks with Exceptional Structural Stability and Relation between Lewis Acidity and Adsorption Enthalpy. Chem. - A Eur. J. 2016, 22, 7444-7451. [CrossRef] [PubMed] 
41. Poloni, R.; Lee, K.; Berger, R.F.; Smit, B.; Neaton, J.B. Understanding Trends in $\mathrm{CO}_{2}$ Adsorption in Metal-Organic Frameworks with Open-Metal Sites. J. Phys. Chem. Lett. 2014, 5, 861-865. [CrossRef] [PubMed]

42. Thornton, A.W.; Dubbeldam, D.; Liu, M.S.; Ladewig, B.P.; Hill, A.J.; Hill, M.R. Feasibility of zeolitic imidazolate framework membranes for clean energy applications. Energy Environ. Sci. 2012, 5, 7637-7646. [CrossRef]

43. Bhattacharjee, S.; Jang, M.-S.; Kwon, H.-J.; Ahn, W.-S. Zeolitic imidazolate frameworks: Synthesis, functionalization, and catalytic/adsorption applications. Catal. Surv. Asia 2014, 18, 101-127. [CrossRef]

44. Park, K.S.; Ni, Z.; Côté, A.P.; Choi, J.Y.; Huang, R.; Uribe-Romo, F.J.; Chae, H.K.; O’Keeffe, M.; Yaghi, O.M. Exceptional chemical and thermal stability of zeolitic imidazolate frameworks. Proc. Natl. Acad. Sci. USA 2006, 103, 10186-10191. [CrossRef] [PubMed]

45. Banerjee, R.; Phan, A.; Wang, B.; Knobler, C.; Furukawa, H.; O’keeffe, M.; Yaghi, O.M. High-throughput synthesis of zeolitic imidazolate frameworks and application to $\mathrm{CO}_{2}$ capture. Science 2008, 319, 939-943. [CrossRef] [PubMed]

46. Fairen-Jimenez, D.; Galvelis, R.; Torrisi, A.; Gellan, A.D.; Wharmby, M.T.; Wright, P.A.; Mellot-Draznieks, C.; Düren, T. Flexibility and swing effect on the adsorption of energy-related gases on ZIF-8: combined experimental and simulation study. Dalt. Trans. 2012, 41, 10752-10762. [CrossRef] [PubMed]

47. Coudert, F.-X. Molecular Mechanism of Swing Effect in Zeolitic Imidazolate Framework ZIF-8: Continuous Deformation upon Adsorption. ChemPhysChem 2017, 18, 2732-2738. [CrossRef] [PubMed]

48. Ordoñez, M.J.C.; Balkus, K.J., Jr.; Ferraris, J.P.; Musselman, I.H. Molecular sieving realized with ZIF-8/Matrimid@mixed-matrix membranes. J. Memb. Sci. 2010, 361, 28-37. [CrossRef]

49. Basu, S.; Cano-Odena, A.; Vankelecom, I.F.J. MOF-containing mixed-matrix membranes for $\mathrm{CO}_{2} / \mathrm{CH}_{4}$ and $\mathrm{CO}_{2} / \mathrm{N}_{2}$ binary gas mixture separations. Sep. Purif. Technol. 2011, 81, 31-40. [CrossRef]

50. Song, Q.; Nataraj, S.K.; Roussenova, M.V; Tan, J.C.; Hughes, D.J.; Li, W.; Bourgoin, P.; Alam, M.A.; Cheetham, A.K.; Al-Muhtaseb, S.A.; et al. Zeolitic imidazolate framework (ZIF-8) based polymer nanocomposite membranes for gas separation. Energy Environ. Sci. 2012, 5, 8359-8369. [CrossRef]

51. Thompson, J.A.; Chapman, K.W.; Koros, W.J.; Jones, C.W.; Nair, S. Sonication-induced Ostwald ripening of ZIF-8 nanoparticles and formation of ZIF-8/polymer composite membranes. Microporous Mesoporous Mater. 2012, 158, 292-299. [CrossRef]

52. Thompson, J.A.; Vaughn, J.T.; Brunelli, N.A.; Koros, W.J.; Jones, C.W.; Nair, S. Mixed-linker zeolitic imidazolate framework mixed-matrix membranes for aggressive $\mathrm{CO}_{2}$ separation from natural gas. Microporous Mesoporous Mater. 2014, 192, 43-51. [CrossRef]

53. Casado-Coterillo, C.; Fernandez-Barquin, A.; Zornoza, B.; Tellez, C.; Coronas, J.; Irabien, A. Synthesis and characterisation of MOF/ionic liquid/chitosan mixed matrix membranes for $\mathrm{CO}_{2} / \mathrm{N}_{2}$ separation. RSC Adv. 2015, 5, 102350-102361. [CrossRef]

54. Carter, D.; Tezel, F.H.; Kruczek, B.; Kalipcilar, H. Investigation and comparison of mixed matrix membranes composed of polyimide matrimid with ZIF-8, silicalite, and SAPO-34. J. Memb. Sci. 2017, 544, 35-46. [CrossRef]

55. Guo, A.; Ban, Y.; Yang, K.; Yang, W. Metal-organic framework-based mixed matrix membranes: Synergetic effect of adsorption and diffusion for $\mathrm{CO}_{2} / \mathrm{CH}_{4}$ separation. J. Memb. Sci. 2018, 562, 76-84. [CrossRef]

56. Jusoh, N.; Yeong, Y.F.; Lau, K.K.; Shariff, A.M. Transport properties of mixed matrix membranes encompassing zeolitic imidazolate framework 8 (ZIF-8) nanofiller and 6FDA-durene polymer: Optimization of process variables for the separation of $\mathrm{CO}_{2}$ from $\mathrm{CH}_{4}$. J. Clean. Prod. 2017, 149, 80-95. [CrossRef]

57. Wijenayake, S.N.; Panapitiya, N.P.; Versteeg, S.H.; Nguyen, C.N.; Goel, S.; Balkus, K.J.; Musselman, I.H.; Ferraris, J.P. Surface cross-linking of ZIF-8/polyimide mixed matrix membranes (MMMs) for gas separation. Ind. Eng. Chem. Res. 2013, 52, 6991-7001. [CrossRef]

58. Zhang, Z.; Xian, S.; Xia, Q.; Wang, H.; Li, Z.; Li, J. Enhancement of $\mathrm{CO}_{2}$ adsorption and $\mathrm{CO}_{2} / \mathrm{N}_{2}$ selectivity on ZIF-8 via postsynthetic modification. AIChE J. 2013, 59, 2195-2206. [CrossRef]

59. Askari, M.; Chung, T.-S. Natural gas purification and olefin/paraffin separation using thermal cross-linkable co-polyimide/ZIF-8 mixed matrix membranes. J. Memb. Sci. 2013, 444, 173-183. [CrossRef]

60. Nafisi, V.; Hägg, M.-B. Gas separation properties of ZIF-8/6FDA-durene diamine mixed matrix membrane. Sep. Purif. Technol. 2014, 128, 31-38. [CrossRef] 
61. Nafisi, V.; Hägg, M.B. Development of dual layer of ZIF-8/PEBAX-2533 mixed matrix membrane for $\mathrm{CO}_{2}$ capture. J. Memb. Sci. 2014, 459, 244-255. [CrossRef]

62. Sánchez-Laínez, J.; Zornoza, B.; Téllez, C.; Coronas, J. Asymmetric polybenzimidazole membranes with thin selective skin layer containing ZIF-8 for $\mathrm{H}_{2} / \mathrm{CO}_{2}$ separation at pre-combustion capture conditions. J. Memb. Sci. 2018, 563, 427-434. [CrossRef]

63. Dai, Y.; Johnson, J.R.; Karvan, O.; Sholl, D.S.; Koros, W.J. Ultem ${ }^{\circledR} / Z I F-8$ mixed matrix hollow fiber membranes for $\mathrm{CO}_{2} / \mathrm{N}_{2}$ separations. J. Memb. Sci. 2012, 401-402, 76-82. [CrossRef]

64. Mubashir, M.; Fong, Y.Y.; Leng, C.T.; Keong, L.K. Issues and Current Trends of Hollow-Fiber Mixed-Matrix Membranes for $\mathrm{CO}_{2}$ Separation from $\mathrm{N}_{2}$ and $\mathrm{CH}_{4}$. Chem. Eng. Technol. 2018, 41, 235-252. [CrossRef]

65. Zhu, J.; Qin, L.; Uliana, A.; Hou, J.; Wang, J.; Zhang, Y.; Li, X.; Yuan, S.; Li, J.; Tian, M.; et al. Elevated Performance of Thin Film Nanocomposite Membranes Enabled by Modified Hydrophilic MOFs for Nanofiltration. ACS Appl. Mater. Interfaces 2017, 9, 1975-1986. [CrossRef] [PubMed]

66. Sorribas, S.; Gorgojo, P.; Téllez, C.; Coronas, J.; Livingston, A.G. High Flux Thin Film Nanocomposite Membranes Based on Metal-Organic Frameworks for Organic Solvent Nanofiltration. J. Am. Chem. Soc. 2013, 135, 15201-15208. [CrossRef] [PubMed]

67. Xiao, F.; Wang, B.; Hu, X.; Nair, S.; Chen, Y. Thin film nanocomposite membrane containing zeolitic imidazolate framework-8 via interfacial polymerization for highly permeable nanofiltration. J. Taiwan Inst. Chem. Eng. 2018, 83, 159-167. [CrossRef]

68. Echaide-Górriz, C.; Navarro, M.; Téllez, C.; Coronas, J. Simultaneous use of MOFs MIL-101(Cr) and ZIF-11 in thin film nanocomposite membranes for organic solvent nanofiltration. Dalt. Trans. 2017, 46, 6244-6252. [CrossRef] [PubMed]

69. Sánchez-Laínez, J.; Paseta, L.; Navarro, M.; Zornoza, B.; Téllez, C.; Coronas, J. Ultrapermeable Thin Film ZIF-8/Polyamide Membrane for $\mathrm{H}_{2} / \mathrm{CO}_{2}$ Separation at High Temperature without Using Sweep Gas. Adv. Mater. Interfaces 2018, 1800647. [CrossRef]

70. Li, Y.; Liang, F.; Bux, H.; Yang, W.; Caro, J. Zeolitic imidazolate framework ZIF-7 based molecular sieve membrane for hydrogen separation. J. Memb. Sci. 2010, 354, 48-54. [CrossRef]

71. Arami-Niya, A.; Birkett, G.; Zhu, Z.; Rufford, T.E. Gate opening effect of zeolitic imidazolate framework ZIF-7 for adsorption of $\mathrm{CH}_{4}$ and $\mathrm{CO}_{2}$ from $\mathrm{N}_{2}$. J. Mater. Chem. A 2017, 5, 21389-21399. [CrossRef]

72. Li, T.; Pan, Y.; Peinemann, K.-V.; Lai, Z. Carbon dioxide selective mixed matrix composite membrane containing ZIF-7 nano-fillers. J. Memb. Sci. 2013, 425, 235-242. [CrossRef]

73. Al-maythalony, B.A.; Alloush, A.M.; Faizan, M.; Dafallah, H.; Elgzoly, M.A.A.; Seliman, A.A.A.; Al-ahmed, A.; Yamani, Z.H.; Habib, M.A.M.; Cordova, K.E.; et al. Tuning the Interplay between Selectivity and Permeability of ZIF-7 Mixed Matrix Membranes. ACS Appl. Mater. Interfaces 2017, 9, 33401-33407. [CrossRef] [PubMed]

74. Morris, W.; Doonan, C.J.; Furukawa, H.; Banerjee, R.; Yaghi, O.M. Crystals as molecules: postsynthesis covalent functionalization of zeolitic imidazolate frameworks. J. Am. Chem. Soc. 2008, 130, 12626-12627. [CrossRef] [PubMed]

75. Phan, A.; Doonan, C.J.; Uribe-Romo, F.J.; Knobler, C.B.; O’keeffe, M.; Yaghi, O.M. Synthesis, Structure, and Carbon Dioxide Capture Properties of Zeolitic Imidazolate Frameworks. Acc. Chem. Res. 2010, 58. [CrossRef] [PubMed]

76. Japip, S.; Xiao, Y.; Chung, T.-S. Particle-Size Effects on Gas Transport Properties of 6FDA-Durene/ZIF-71 Mixed Matrix Membranes. Ind. Eng. Chem. Res. 2016, 55, 9507-9517. [CrossRef]

77. Ehsani, A.; Pakizeh, M. Synthesis, characterization and gas permeation study of ZIF-11/Pebax ${ }^{\circledR} 2533$ mixed matrix membranes. J. Taiwan Inst. Chem. Eng. 2016, 66, 414-423. [CrossRef]

78. Boroglu, M.S.; Yumru, A.B. Gas separation performance of 6FDA-DAM-ZIF-11 mixed-matrix membranes for $\mathrm{H}_{2} / \mathrm{CH}_{4}$ and $\mathrm{CO}_{2} / \mathrm{CH}_{4}$ separation. Sep. Purif. Technol. 2017, 173, 269-279. [CrossRef]

79. Hao, L.; Liao, K.-S.; Chung, T.-S. Photo-oxidative PIM-1 based mixed matrix membranes with superior gas separation performance. J. Mater. Chem. A 2015, 3, 17273-17281. [CrossRef]

80. Bae, T.; Lee, J.S.; Qiu, W.; Koros, W.J.; Jones, C.W.; Nair, S. A High-Performance Gas-Separation Membrane Containing Submicrometer-Sized Metal-Organic Framework Crystals. Angew. Chemie Int. Ed. 2010, 49, 9863-9866. [CrossRef] [PubMed]

81. Zhang, Q.; Luo, S.; Weidman, J.R.; Guo, R. Preparation and gas separation performance of mixed-matrix membranes based on triptycene-containing polyimide and zeolite imidazole framework (ZIF-90). Polymer (Guildf) 2017, 131, 209-216. [CrossRef] 
82. DeStefano, M.R.; Islamoglu, T.; Garibay, S.J.; Hupp, J.T.; Farha, O.K. Room-Temperature Synthesis of UiO-66 and Thermal Modulation of Densities of Defect Sites. Chem. Mater. 2017, 29, 1357-1361. [CrossRef]

83. Cavka, J.H.; Jakobsen, S.; Olsbye, U.; Guillou, N.; Lamberti, C.; Bordiga, S.; Lillerud, K.P. A new zirconium inorganic building brick forming metal organic frameworks with exceptional stability. J. Am. Chem. Soc. 2008, 130, 13850-13851. [CrossRef] [PubMed]

84. Friebe, S.; Geppert, B.; Steinbach, F.; Caro, J. Metal-Organic Framework UiO-66 Layer: A Highly Oriented Membrane with Good Selectivity and Hydrogen Permeance. ACS Appl. Mater. Interfaces 2017, 9, 12878-12885. [CrossRef] [PubMed]

85. Kolokolov, D.I.; Stepanov, A.G.; Guillerm, V.; Serre, C.; Frick, B.; Jobic, H. Probing the Dynamics of the Porous Zr Terephthalate UiO-66 Framework Using 2H NMR and Neutron Scattering. J. Phys. Chem. C 2012, 116, 12131-12136. [CrossRef]

86. Shen, J.; Liu, G.; Huang, K.; Li, Q.; Guan, K.; Li, Y.; Jin, W. UiO-66-polyether block amide mixed matrix membranes for $\mathrm{CO}_{2}$ separation. J. Memb. Sci. 2016, 513, 155-165. [CrossRef]

87. Anjum, M.W.; Vermoortele, F.; Khan, A.L.; Bueken, B.; De Vos, D.E.; Vankelecom, I.F.J. Modulated UiO-66-based mixed-matrix membranes for $\mathrm{CO}_{2}$ separation. ACS Appl. Mater. Interfaces 2015, 7, 25193-25201. [CrossRef] [PubMed]

88. Venna, S.R.; Lartey, M.; Li, T.; Spore, A.; Kumar, S.; Nulwala, H.B.; Luebke, D.R.; Rosi, N.L.; Albenze, E. Fabrication of MMMs with improved gas separation properties using externally-functionalized MOF particles. J. Mater. Chem. A 2015, 3, 5014-5022. [CrossRef]

89. Khdhayyer, M.R.; Esposito, E.; Fuoco, A.; Monteleone, M.; Giorno, L.; Jansen, J.C.; Attfield, M.P.; Budd, P.M. Mixed matrix membranes based on UiO-66 MOFs in the polymer of intrinsic microporosity PIM-1. Sep. Purif. Technol. 2017, 173, 304-313. [CrossRef]

90. Ghalei, B.; Sakurai, K.; Kinoshita, Y.; Wakimoto, K.; Isfahani, A.P.; Song, Q.; Doitomi, K.; Furukawa, S.; Hirao, H.; Kusuda, H.; et al. Enhanced selectivity in mixed matrix membranes for $\mathrm{CO}_{2}$ capture through efficient dispersion of amine-functionalized MOF nanoparticles. Nat. Energy 2017, 2, 17086. [CrossRef]

91. Zamidi Ahmad, M.; Navarro, M.; Lhotka, M.; Zornoza, B.; Téllez, C.; Fila, V.; Coronas, J. Enhancement of $\mathrm{CO}_{2} / \mathrm{CH}_{4}$ separation performances of $6 \mathrm{FDA}$-based co-polyimides mixed matrix membranes embedded with UiO-66 nanoparticles. Sep. Purif. Technol. 2018, 192, 465-474. [CrossRef]

92. Ahmad, M.Z.; Navarro, M.; Lhotka, M.; Zornoza, B.; Téllez, C.; de Vos, W.M.; Benes, N.E.; Konnertz, N.M.; Visser, T.; Semino, R.; et al. Enhanced gas separation performance of 6FDA-DAM based mixed matrix membranes by incorporating MOF UiO-66 and its derivatives. J. Memb. Sci. 2018, 558, 64-77. [CrossRef]

93. Yazaydın, A.O.; Benin, A.I.; Faheem, S.A.; Jakubczak, P.; Low, J.J.; Willis, R.R.; Snurr, R.Q. Enhanced $\mathrm{CO}_{2}$ adsorption in metal-organic frameworks via occupation of open-metal sites by coordinated water molecules. Chem. Mater. 2009, 21, 1425-1430. [CrossRef]

94. Du, M.; Li, L.; Li, M.; Si, R. Adsorption mechanism on metal organic frameworks of Cu-BTC, Fe-BTC and ZIF-8 for $\mathrm{CO}_{2}$ capture investigated by X-ray absorption fine structure. RSC Adv. 2016, 6, 62705-62716. [CrossRef]

95. Ge, L.; Zhou, W.; Rudolph, V.; Zhu, Z. Mixed matrix membranes incorporated with size-reduced Cu-BTC for improved gas separation. J. Mater. Chem. A 2013, 1, 6350-6358. [CrossRef]

96. Abedini, R.; Mosayebi, A.; Mokhtari, M. Improved $\mathrm{CO}_{2}$ separation of azide cross-linked PMP mixed matrix membrane embedded by nano-CuBTC metal organic framework. Process Saf. Environ. Prot. 2018, 114, 229-239. [CrossRef]

97. Tayebeh, K.; Mohammadreza, O.; Serge, K.; Denis, R. Amine-functionalized CuBTC/poly(ether-b-amide-6) (Pebax ${ }^{\circledR} \mathrm{MH}$ 1657) mixed matrix membranes for $\mathrm{CO}_{2} / \mathrm{CH}_{4}$ separation. Can. J. Chem. Eng. 2017, 95, 2024-2033. [CrossRef]

98. Perez, E.V; Balkus, K.J.; Ferraris, J.P.; Musselman, I.H. Metal-organic polyhedra 18 mixed-matrix membranes for gas separation. J. Memb. Sci. 2014, 463, 82-93. [CrossRef]

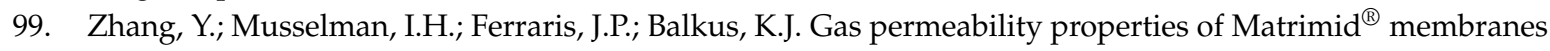
containing the metal-organic framework Cu-BPY-HFS. J. Memb. Sci. 2008, 313, 170-181. [CrossRef]

100. Sandrine, B.; Philip, L.L.; Christian, S.; Franck, M.; Thierry, L.; Gérard, F. Different Adsorption Behaviors of Methane and Carbon Dioxide in the Isotypic Nanoporous Metal Terephthalates MIL-53 and MIL-47. J. Am. Chem. Soc. 2005, 127, 13519-13521. [CrossRef] 
101. Hu, Y.H.; Zhang, L. Hydrogen Storage in Metal-Organic Frameworks. Adv. Mater. 2010, 22, E117-E130. [CrossRef] [PubMed]

102. Adhikari, A.K.; Lin, K.-S.; Tu, M.-T. Hydrogen storage capacity enhancement of MIL-53(Cr) by Pd loaded activated carbon doping. J. Taiwan Inst. Chem. Eng. 2016, 63, 463-472. [CrossRef]

103. Lin, K.-S.; Adhikari, A.K.; Tu, M.-T.; Wang, C.-H.; Chiang, C.-L. Preparation, characterization, and hydrogen storage capacity of MIL-53 metal-organic frameworks. J. Nanosci. Nanotechnol. 2013, 13, 2549-2556. [CrossRef] [PubMed]

104. Mulder, F.M.; Assfour, B.; Huot, J.; Dingemans, T.J.; Wagemaker, M.; Ramirez-Cuesta, A.J. Hydrogen in the Metal-Organic Framework Cr MIL-53. J. Phys. Chem. C 2010, 114, 10648-10655. [CrossRef]

105. Hamon, L.; Llewellyn, P.L.; Devic, T.; Ghoufi, A.; Clet, G.; Guillerm, V.; Pirngruber, G.D.; Maurin, G.; Serre, C.; Driver, G.; et al. Co-adsorption and Separation of $\mathrm{CO}_{2}-\mathrm{CH}_{4}$ Mixtures in the Highly Flexible MIL-53(Cr) MOF. J. Am. Chem. Soc. 2009, 131, 17490-17499. [CrossRef] [PubMed]

106. Llewellyn, P.L.; Bourrelly, S.; Serre, C.; Filinchuk, Y.; Férey, G. How Hydration Drastically Improves Adsorption Selectivity for $\mathrm{CO}_{2}$ over $\mathrm{CH}_{4}$ in the Flexible Chromium Terephthalate MIL-53. Angew. Chemie Int. Ed. 2006, 45, 7751-7754. [CrossRef] [PubMed]

107. Hamon, L.; Serre, C.; Devic, T.; Loiseau, T.; Millange, F.; Férey, G.; Weireld, G. De Comparative Study of Hydrogen Sulfide Adsorption in the MIL-53(Al, Cr, Fe), MIL-47(V), MIL-100(Cr), and MIL-101(Cr) Metal-Organic Frameworks at Room Temperature. J. Am. Chem. Soc. 2009, 131, 8775-8777. [CrossRef] [PubMed]

108. Dorosti, F.; Omidkhah, M.; Abedini, R. Fabrication and characterization of Matrimid/MIL-53 mixed matrix membrane for $\mathrm{CO}_{2} / \mathrm{CH}_{4}$ separation. Chem. Eng. Res. Des. 2014, 92, 2439-2448. [CrossRef]

109. Hsieh, J.O.; Balkus, K.J.; Ferraris, J.P.; Musselman, I.H. MIL-53 frameworks in mixed-matrix membranes. Microporous Mesoporous Mater. 2014, 196, 165-174. [CrossRef]

110. Abedini, R.; Omidkhah, M.; Dorosti, F. Highly permeable poly(4-methyl-1-pentyne)/ $\mathrm{NH}_{2}-\mathrm{MIL} 53$ (Al) mixed matrix membrane for $\mathrm{CO}_{2} / \mathrm{CH}_{4}$ separation. RSC Adv. 2014, 4, 36522-36537. [CrossRef]

111. Feijani, E.A.; Mahdavi, H.; Tavasoli, A. Poly(vinylidene fluoride) based mixed matrix membranes comprising metal organic frameworks for gas separation applications. Chem. Eng. Res. Des. 2015, 96, 87-102. [CrossRef]

112. Ahmadi Feijani, E.; Tavasoli, A.; Mahdavi, H. Improving Gas Separation Performance of Poly(vinylidene fluoride) Based Mixed Matrix Membranes Containing Metal-Organic Frameworks by Chemical Modification. Ind. Eng. Chem. Res. 2015, 54, 12124-12134. [CrossRef]

113. Tien-Binh, N.; Vinh-Thang, H.; Chen, X.Y.; Rodrigue, D.; Kaliaguine, S. Polymer functionalization to enhance interface quality of mixed matrix membranes for high $\mathrm{CO}_{2} / \mathrm{CH}_{4}$ gas separation. J. Mater. Chem. A 2015, 3, 15202-15213. [CrossRef]

114. Zhu, H.; Jie, X.; Wang, L.; Liu, D.; Cao, Y. Polydimethylsiloxane/postmodified MIL-53 composite layer coated on asymmetric hollow fiber membrane for improving gas separation performance. J. Appl. Polym. Sci. 2017, 134. [CrossRef]

115. Hong, D.-Y.; Hwang, Y.K.; Serre, C.; Férey, G.; Chang, J.-S. Porous Chromium Terephthalate MIL-101 with Coordinatively Unsaturated Sites: Surface Functionalization, Encapsulation, Sorption and Catalysis. Adv. Funct. Mater. 2009, 19, 1537-1552. [CrossRef]

116. Naseri, M.; Mousavi, S.F.; Mohammadi, T.; Bakhtiari, O. Synthesis and gas transport performance of MIL-101/Matrimid mixed matrix membranes. J. Ind. Eng. Chem. 2015, 29, 249-256. [CrossRef]

117. Rajati, H.; Navarchian, A.H.; Tangestaninejad, S. Preparation and characterization of mixed matrix membranes based on Matrimid/PVDF blend and MIL-101(Cr) as filler for $\mathrm{CO}_{2} / \mathrm{CH}_{4}$ separation. Chem. Eng. Sci. 2018, 185, 92-104. [CrossRef]

118. Zhang, W.; Liu, D.; Guo, X.; Huang, H.; Zhong, C. Fabrication of mixed-matrix membranes with MOF-derived porous carbon for $\mathrm{CO}_{2}$ separation. AIChE J. 2018. [CrossRef]

119. Tanh Jeazet, H.B.; Sorribas, S.; Román-Marín, J.M.; Zornoza, B.; Téllez, C.; Coronas, J.; Janiak, C. Increased Selectivity in $\mathrm{CO}_{2} / \mathrm{CH}_{4}$ Separation with Mixed-Matrix Membranes of Polysulfone and Mixed-MOFs MIL-101(Cr) and ZIF-8. Eur. J. Inorg. Chem. 2016, 2016, 4363-4367. [CrossRef]

120. Xie, K.; Fu, Q.; Webley, P.A.; Qiao, G.G. MOF Scaffold for a High-Performance Mixed-Matrix Membrane. Angew. Chemie Int. Ed. 2018. [CrossRef]

121. Shahid, S.; Nijmeijer, K. High pressure gas separation performance of mixed-matrix polymer membranes containing mesoporous Fe(BTC). J. Memb. Sci. 2014, 459, 33-44. [CrossRef] 
122. Rita, A.; Ribeiro, R.P.P.L.; Mota, J.P.B.; Alves, V.D.; Esteves, I.A.A.C. Separation and Purification Technology $\mathrm{CO}_{2} / \mathrm{N}_{2}$ gas separation using $\mathrm{Fe}(\mathrm{BTC})$-based mixed matrix membranes: A view on the adsorptive and filler properties of metal-organic frameworks. Sep. Purif. Technol. 2018, 202, 174-184. [CrossRef]

123. Dorosti, F.; Alizadehdakhel, A. Fabrication and investigation of PEBAX/Fe-BTC, a high permeable and $\mathrm{CO}_{2}$ selective mixed matrix membrane. Chem. Eng. Res. Des. 2017, 136, 119-128. [CrossRef]

124. Cadiau, A.; Adil, K.; Bhatt, P.M.; Belmabkhout, Y.; Eddaoudi, M. A metal-organic framework-based splitter for separating propylene from propane. Science 2016, 353, 137-140. [CrossRef] [PubMed]

125. Chen, K.; Xu, K.; Xiang, L.; Dong, X.; Han, Y.; Wang, C.; Sun, L.; Pan, Y. Enhanced $\mathrm{CO}_{2} / \mathrm{CH}_{4}$ separation performance of mixed-matrix membranes through dispersion of sorption-selective MOF nanocrystals. J. Membr. Sci. 2018, 563, 360-370. [CrossRef]

126. Bae, T.-H.; Long, J.R. $\mathrm{CO}_{2} / \mathrm{N}_{2}$ separations with mixed-matrix membranes containing $\mathrm{Mg}_{2}$ (dobdc) nanocrystals. Energy Environ. Sci. 2013, 6, 3565-3569. [CrossRef]

127. Smith, Z.P.; Bachman, J.E.; Li, T.; Gludovatz, B.; Kusuma, V.A.; Xu, T.; Hopkinson, D.P.; Ritchie, R.O.; Long, J.R. Increasing $\mathrm{M}_{2}$ (dobdc) Loading in Selective Mixed-Matrix Membranes: A Rubber Toughening Approach. Chem. Mater. 2018, 30, 1484-1495. [CrossRef]

128. Konstas, K.; Taylor, J.W.; Thornton, A.W.; Doherty, C.M.; Lim, W.X.; Bastow, T.J.; Kennedy, D.F.; Wood, C.D.; Cox, B.J.; Hill, J.M. Lithiated porous aromatic frameworks with exceptional gas storage capacity. Angew. Chemie Int. Ed. 2012, 51, 6639-6642. [CrossRef] [PubMed]

129. Dechnik, J.; Gascon, J.; Doonan, C.; Janiak, C.; Sumby, C.J. Mixed-matrix membranes. Angew. Chemie Int. Ed. 2017, 56, 9292-9310. [CrossRef] [PubMed]

130. Thomas, J.M.H.; Trewin, A. Amorphous PAF-1: Guiding the rational design of ultraporous materials. J. Phys. Chem. C 2014, 118, 19712-19722. [CrossRef]

131. Ben, T.; Ren, H.; Ma, S.; Cao, D.; Lan, J.; Jing, X.; Wang, W.; Xu, J.; Deng, F.; Simmons, J.M. Targeted synthesis of a porous aromatic framework with high stability and exceptionally high surface area. Angew. Chem. 2009, 121, 9621-9624. [CrossRef]

132. Li, Y.; Roy, S.; Ben, T.; Xu, S.; Qiu, S. Micropore engineering of carbonized porous aromatic framework (PAF-1) for supercapacitors application. Phys. Chem. Chem. Phys. 2014, 16, 12909-12917. [CrossRef] [PubMed]

133. Fu, J.; Wu, J.; Custelcean, R.; Jiang, D. Nitrogen-doped porous aromatic frameworks for enhanced $\mathrm{CO}_{2}$ adsorption. J. Colloid Interface Sci. 2015, 438, 191-195. [CrossRef] [PubMed]

134. Ben, T.; Qiu, S. Porous aromatic frameworks: Synthesis structure and functions. CrystEngComm 2013, 15, 17-26. [CrossRef]

135. Lau, C.H.; Nguyen, P.T.; Hill, M.R.; Thornton, A.W.; Konstas, K.; Doherty, C.M.; Mulder, R.J.; Bourgeois, L.; Liu, A.C.Y.; Sprouster, D.J. Ending aging in super glassy polymer membranes. Angew. Chem. Int. Ed. 2014, 53, 5322-5326. [CrossRef] [PubMed]

136. Volkov, A.V; Bakhtin, D.S.; Kulikov, L.A.; Terenina, M.V.; Golubev, G.S.; Bondarenko, G.N.; Legkov, S.A.; Shandryuk, G.A.; Volkov, V.V; Khotimskiy, V.S. Stabilization of gas transport properties of PTMSP with porous aromatic framework: Effect of annealing. J. Memb. Sci. 2016, 517, 80-90. [CrossRef]

137. Lau, C.H.; Konstas, K.; Doherty, C.M.; Kanehashi, S.; Ozcelik, B.; Kentish, S.E.; Hill, A.J.; Hill, M.R. Tailoring Physical Aging in Super Glassy Polymers with Functionalized Porous Aromatic Frameworks for $\mathrm{CO}_{2}$ Capture Tailoring Physical Aging in Super Glassy Polymers with Functionalized Porous Aromatic Frameworks for $\mathrm{CO}_{2}$ Capture. Chem. Mater. 2015, 27, 4756-4762. [CrossRef]

138. Mitra, T.; Bhavsar, R.S.; Adams, D.J.; Budd, P.M.; Cooper, A.I. PIM-1 mixed matrix membranes for gas separations using cost-effective hypercrosslinked nanoparticle fillers. Chem. Commun. 2016, 52, 5581-5584. [CrossRef] [PubMed]

139. Yaumi, A.L.; Bakar, M.Z.A.; Hameed, B.H. Recent advances in functionalized composite solid materials for carbon dioxide capture. Energy 2017, 124, 461-480. [CrossRef]

140. Matsukata, M.; Sawamura, K.; Sekine, Y.; Kikuchi, E. Chapter 8-Review on Prospects for Energy Saving in Distillation Process with Microporous Membranes. In Inorganic Polymeric and Composite Membranes; Oyama, S.T., Stagg-Williams, S., Eds.; Elsevier: New York, NY, USA, 2011; Volume 14, pp. 175-193, ISBN 0927-5193.

141. Rangnekar, N.; Mittal, N.; Elyassi, B.; Caro, J.; Tsapatsis, M. Zeolite membranes-A review and comparison with MOFs. Chem. Soc. Rev. 2015, 44, 7128-7154. [CrossRef] [PubMed] 
142. Bastani, D.; Esmaeili, N.; Asadollahi, M. Polymeric mixed matrix membranes containing zeolites as a filler for gas separation applications: A review. J. Ind. Eng. Chem. 2013, 19, 375-393. [CrossRef]

143. Hosseinzadeh Beiragh, H.; Omidkhah, M.; Abedini, R.; Khosravi, T.; Pakseresht, S. Synthesis and characterization of poly (ether-block-amide) mixed matrix membranes incorporated by nanoporous ZSM-5 particles for $\mathrm{CO}_{2} / \mathrm{CH}_{4}$ separation. Asia-Pac. J. Chem. Eng. 2016, 11, 522-532. [CrossRef]

144. Dorosti, F.; Omidkhah, M.; Abedini, R. Enhanced $\mathrm{CO}_{2} / \mathrm{CH}_{4}$ separation properties of asymmetric mixed matrix membrane by incorporating nano-porous ZSM-5 and MIL-53 particles into Matrimid ${ }^{\circledR} 5218$. J. Nat. Gas Sci. Eng. 2015, 25, 88-102. [CrossRef]

145. Bryan, N.; Lasseuguette, E.; Van Dalen, M.; Permogorov, N.; Amieiro, A.; Brandani, S.; Ferrari, M.C. Development of mixed matrix mebranes containing zeolites for post-combustion carbon capture. Energy Procedia 2014, 63, 160-166. [CrossRef]

146. Bezerra, D.P.; da Silva, F.W.M.; de Moura, P.A.S.; Sousa, A.G.S.; Vieira, R.S.; Rodriguez-Castellon, E.; Azevedo, D.C.S. $\mathrm{CO}_{2}$ adsorption in amine-grafted zeolite 13X. Appl. Surf. Sci. 2014, 314, 314-321. [CrossRef]

147. Surya Murali, R.; Ismail, A.F.; Rahman, M.A.; Sridhar, S. Mixed matrix membranes of Pebax-1657 loaded with 4A zeolite for gaseous separations. Sep. Purif. Technol. 2014, 129, 1-8. [CrossRef]

148. Zhao, D.; Ren, J.; Li, H.; Hua, K.; Deng, M. Poly(amide-6-b-ethylene oxide)/SAPO-34 mixed matrix membrane for $\mathrm{CO}_{2}$ separation. J. Energy Chem. 2014, 23, 227-234. [CrossRef]

149. Hong, M.; Li, S.; Falconer, J.L.; Noble, R.D. Hydrogen purification using a SAPO-34 membrane. J. Memb. Sci. 2008, 307, 277-283. [CrossRef]

150. Rezakazemi, M.; Shahidi, K.; Mohammadi, T. Hydrogen separation and purification using crosslinkable PDMS/zeolite A nanoparticles mixed matrix membranes. Int. J. Hydrog. Energy 2012, 37, 14576-14589. [CrossRef]

151. Atalay-Oral, Ç.; Tokay, B.; Erdem-enatalar, A.; Tantekin-ŞErsolmaz, B. Ferrierite-poly(vinyl acetate) mixed matrix membranes for gas separation: A comparative study. Microporous Mesoporous Mater. 2018, 259, 17-25. [CrossRef]

152. Fernández-Barquín, A.; Casado-Coterillo, C.; Palomino, M.; Valencia, S.; Irabien, A. LTA/Poly(1trimethylsilyl-1-propyne) Mixed-Matrix Membranes for High-Temperature $\mathrm{CO}_{2} / \mathrm{N}_{2}$ Separation. Chem. Eng. Technol. 2015, 38, 658-666. [CrossRef]

153. Fernández-Barquín, A.; Casado-Coterillo, C.; Palomino, M.; Valencia, S.; Irabien, A. Permselectivity improvement in membranes for $\mathrm{CO}_{2} / \mathrm{N}_{2}$ separation. Sep. Purif. Technol. 2016, 157, 102-111. [CrossRef]

154. Gong, H.; Lee, S.S.; Bae, T.-H. Mixed-matrix membranes containing inorganically surface-modified 5A zeolite for enhanced $\mathrm{CO}_{2} / \mathrm{CH}_{4}$ separation. Microporous Mesoporous Mater. 2017, 237, 82-89. [CrossRef]

155. Pakizeh, M.; Hokmabadi, S. Experimental study of the effect of zeolite 4 A treated with magnesium hydroxide on the characteristics and gas-permeation properties of polysulfone-based mixed-matrix membranes. J. Appl. Polym. Sci. 2017, 134. [CrossRef]

156. Sanaeepur, H.; Nasernejad, B. Advances Aminosilane-functionalization of a nanoporous Y-type zeolite for application in a cellulose acetate based mixed matrix membrane for $\mathrm{CO}_{2}$ separation. RSC Adv. 2014, 4, 63966-63976. [CrossRef]

157. Peng, Y.; Li, Y.; Ban, Y.; Jin, H.; Jiao, W.; Liu, X.; Yang, W. Metal-organic framework nanosheets as building blocks for molecular sieving membranes. Science 2014, 346, 1356-1359. [CrossRef] [PubMed]

158. Zhong, Z.; Yao, J.; Chen, R.; Low, Z.; He, M.; Liu, J.Z.; Wang, H. Oriented two-dimensional zeolitic imidazolate framework-L membranes and their gas permeation properties. J. Mater. Chem. A 2015, 3, 15715-15722. [CrossRef]

159. Roth, W.J.; Nachtigall, P.; Morris, R.E.; Čejka, J. Two-Dimensional Zeolites: Current Status and Perspectives. Chem. Rev. 2014, 114, 4807-4837. [CrossRef] [PubMed]

160. Jeon, M.Y.; Kim, D.; Kumar, P.; Lee, P.S.; Rangnekar, N.; Bai, P.; Shete, M.; Elyassi, B.; Lee, H.S.; Narasimharao, K.; et al. Ultra-selective high-flux membranes from directly synthesized zeolite nanosheets. Nature 2017, 543, 690. [CrossRef] [PubMed]

161. Varoon, K.; Zhang, X.; Elyassi, B.; Brewer, D.D.; Gettel, M.; Kumar, S.; Lee, J.A.; Maheshwari, S.; Mittal, A.; Sung, C.-Y.; et al. Dispersible Exfoliated Zeolite Nanosheets and Their Application as a Selective Membrane. Science 2011, 334, 72-75. [CrossRef] [PubMed] 
162. Liu, G.; Jiang, Z.; Cao, K.; Nair, S.; Cheng, X.; Zhao, J.; Gomaa, H.; Wu, H.; Pan, F. Pervaporation performance comparison of hybrid membranes filled with two-dimensional ZIF-L nanosheets and zero-dimensional ZIF-8 nanoparticles. J. Memb. Sci. 2017, 523, 185-196. [CrossRef]

163. Kim, W.; Lee, J.S.; Bucknall, D.G.; Koros, W.J.; Nair, S. Nanoporous layered silicate AMH-3/cellulose acetate nanocomposite membranes for gas separations. J. Memb. Sci. 2013, 441, 129-136. [CrossRef]

164. Kang, Z.; Peng, Y.; Qian, Y.; Yuan, D.; Addicoat, M.A.; Heine, T.; Hu, Z.; Tee, L.; Guo, Z.; Zhao, D. Mixed Matrix Membranes (MMMs) Comprising Exfoliated 2D Covalent Organic Frameworks (COFs) for Efficient $\mathrm{CO}_{2}$ Separation. Chem. Mater. 2016, 28, 1277-1285. [CrossRef]

165. Rodenas, T.; Luz, I.; Prieto, G.; Seoane, B.; Miro, H.; Corma, A.; Kapteijn, F.; Llabrés i Xamena, F.X.; Gascon, J. Metal-organic framework nanosheets in polymer composite materials for gas separation. Nat. Mater. 2014, 14, 48. [CrossRef] [PubMed]

166. Shete, M.; Kumar, P.; Bachman, J.E.; Ma, X.; Smith, Z.P.; Xu, W.; Mkhoyan, K.A.; Long, J.R.; Tsapatsis, M. On the direct synthesis of $\mathrm{Cu}(\mathrm{BDC}) \mathrm{MOF}$ nanosheets and their performance in mixed matrix membranes. J. Memb. Sci. 2018, 549, 312-320. [CrossRef]

167. Cheng, Y.; Wang, X.; Jia, C.; Wang, Y.; Zhai, L.; Wang, Q.; Zhao, D. Ultrathin mixed matrix membranes containing two-dimensional metal-organic framework nanosheets for efficient $\mathrm{CO}_{2} / \mathrm{CH}_{4}$ separation. J. Memb. Sci. 2017, 539, 213-223. [CrossRef]

168. Yang, Y.; Goh, K.; Wang, R.; Bae, T.-H. High-performance nanocomposite membranes realized by efficient molecular sieving with CuBDC nanosheets. Chem. Commun. 2017, 53, 4254-4257. [CrossRef] [PubMed]

169. Kang, Z.; Peng, Y.; Hu, Z.; Qian, Y.; Chi, C.; Yeo, L.Y.; Tee, L.; Zhao, D. Mixed matrix membranes composed of two-dimensional metal-organic framework nanosheets for pre-combustion $\mathrm{CO}_{2}$ capture: A relationship study of filler morphology versus membrane performance. J. Mater. Chem. A 2015, 3, 20801-20810. [CrossRef]

(C) 2018 by the authors. Licensee MDPI, Basel, Switzerland. This article is an open access article distributed under the terms and conditions of the Creative Commons Attribution (CC BY) license (http:/ / creativecommons.org/licenses/by/4.0/). 